U.S. DEPARTMENT OF COMMERCE National Technical Information Service

PB-257 233

\title{
Determination of Soil Liquefaction Characteristics by Large-Scale Laboratory Tests
}

Shannon and Wilson, Inc /Agbabian Associates

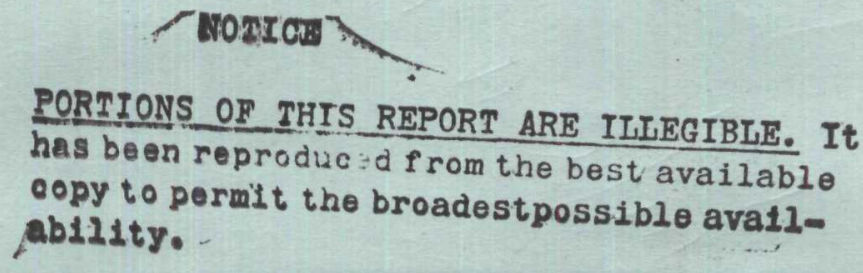

Prepared for

Nuclear Regulatory Commission, Washington, D C Office of Nuclear Regulatory Research

May 75

\section{MASTER




\section{DISCLAIMER}

This report was prepared as an account of work sponsored by an agency of the United States Government. Neither the United States Government nor any agency Thereof, nor any of their employees, makes any warranty, express or implied, or assumes any legal liability or responsibility for the accuracy, completeness, or usefulness of any information, apparatus, product, or process disclosed, or represents that its use would not infringe privately owned rights. Reference herein to any specific commercial product, process, or service by trade name, trademark, manufacturer, or otherwise does not necessarily constitute or imply its endorsement, recommendation, or favoring by the United States Government or any agency thereof. The views and opinions of authors expressed herein do not necessarily state or reflect those of the United States Government or any agency thereof. 


\section{DISCLAIMER}

Portions of this document may be illegible in electronic image products. Images are produced from the best available original document. 


\section{DWTRRIIAATION UF SOIL LIQUEFAC HIC: CH SAOTFRISTICS BY LARGE-SCALE IABORATORY TESTS}

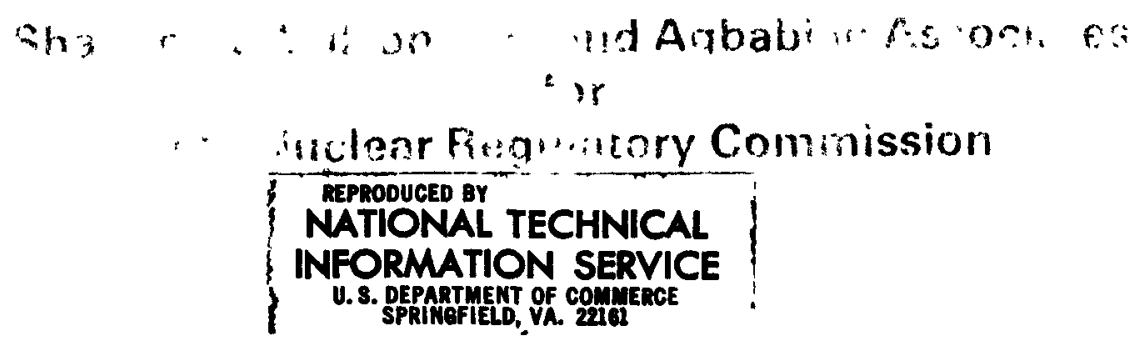



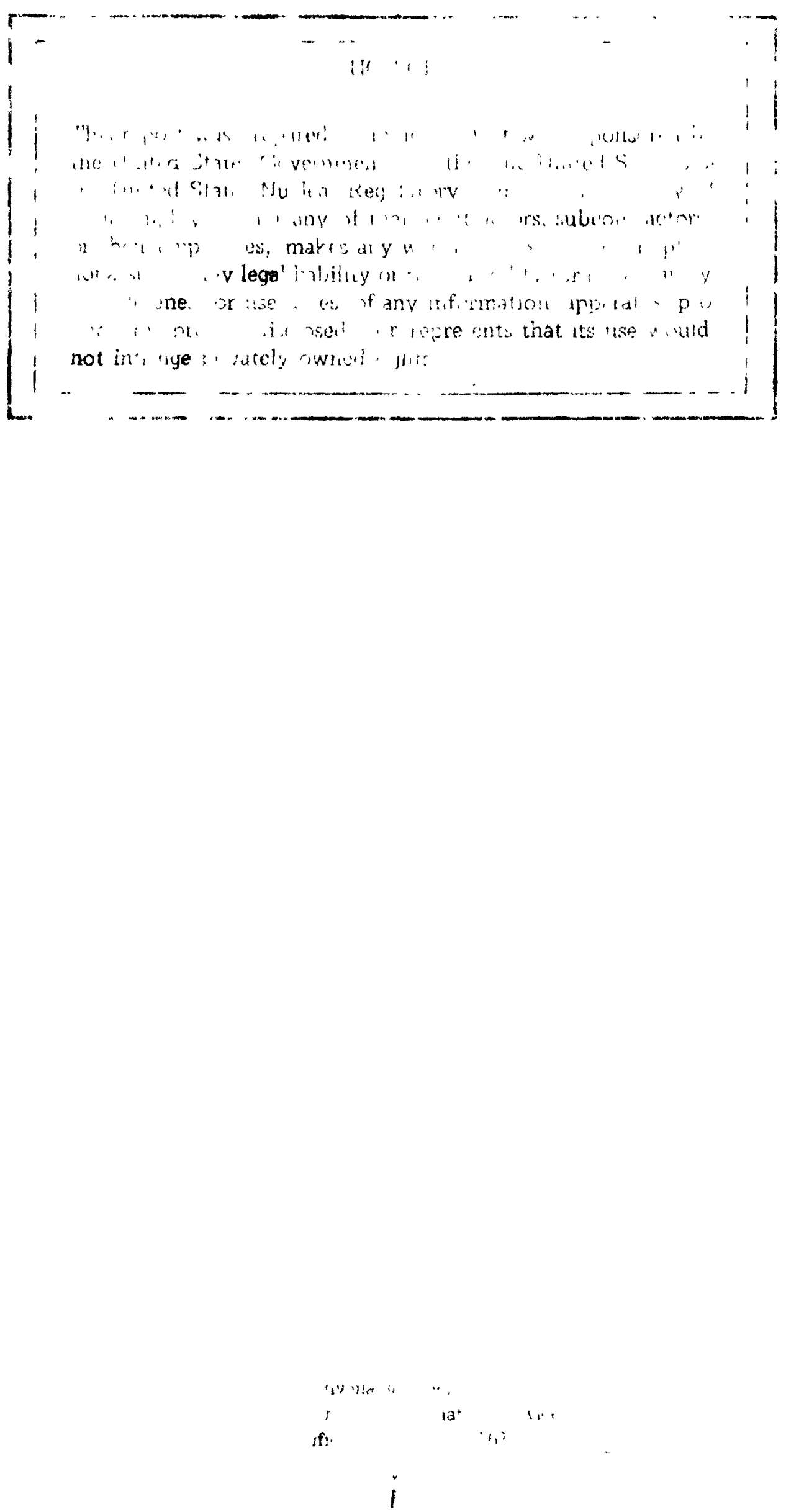


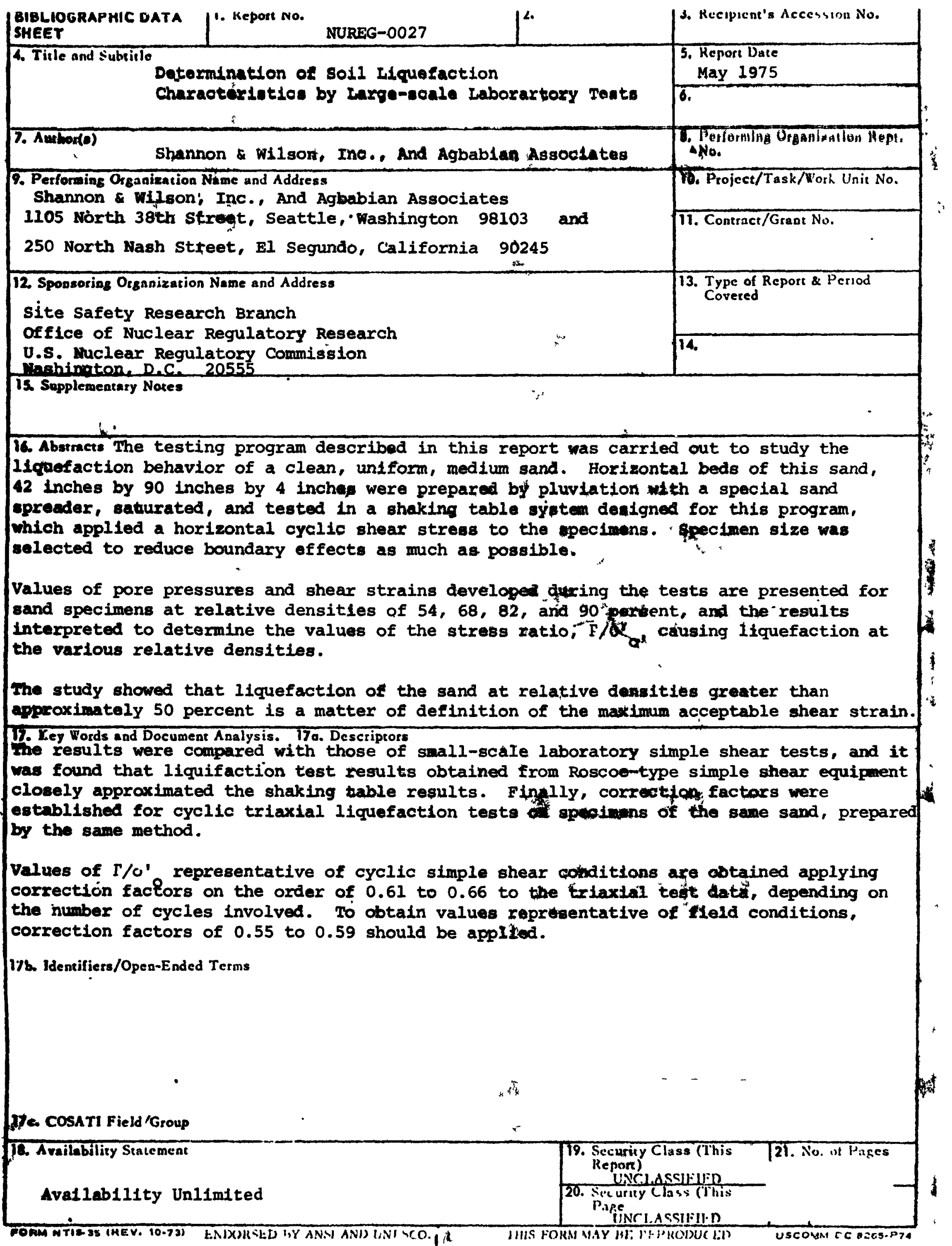




\section{DETERMINATION OF SOIL LIQUEFACTION CHARACTERISTICS BY LARGE-SCALE LABORATORY TESTS}

Manuscript Completed: May 1975

Date Published: September 1976

Shannon \& Wilson, Inc. and Agbabian Associates

Seattle, Washington, 98103

El Segundo, California 90245

Prepared for the U.S. Nuclear Regulatory Commission Under Contract No. AT(04-3)-954 


\section{$\underline{\text { ABSTRACT }}$}

The testing program described in this report was carried out to study the liquefaction behavior of a clean, uniform, medium sand. Horizontal beds of this sand, 42 inches by 90 inches by 4 inches were prepared by pluviation with a special sand spreader, saturated, and tested in a shaking table system designed for this program, which applied a horizontal cyclic shear stress to the specimens. Specimen size was selected to reduce boundary effects as much as possible.

Values of pore pressures and shear strains developed during the tests are presented for sand specimens at relative densities of 54 , 68,82 , and 90 percent, and the results interpreted to determine the values of the stress ratio, $T / \sigma^{\prime}{ }^{\prime}$ ' causing liquefaction at the various relative densities.

The study showed that liquefaction of the sand at relative densities greater than approximately 50 percent is a matter of definition of the maximum accoptable shear strain. The results were compared with those of small-scale laboratory simple shear tests, and it was found that liquefaction test results obtained from Roscoe-type simple shear equipment closely approximated the shaking table results. Finally, correction factors were established for 'yelic: triaxial liquetaltion tests on specimens of the same sand, preparea by the same method.

Values of $1 / 1{ }^{\prime}$ opresentative of cyclic simple shear conditions are obtained applying correction factors on the order of 0.61 to 0.66 to the triaxial test data, depending on the number of cycles involved. To obtain values representative of field conditions, correction factors of 0.55 to 0.59 should be applied. 
1:II:WORI)

Ihis report presents the results of large scale laboratory shaking 1.dble tests on saturated sands condusted by the University of calıfornia

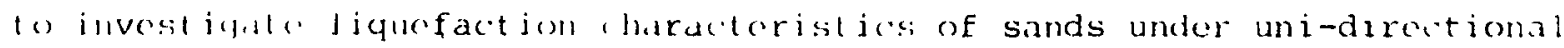
sthaking and essontially boundary-fres conditions. This is the second repret

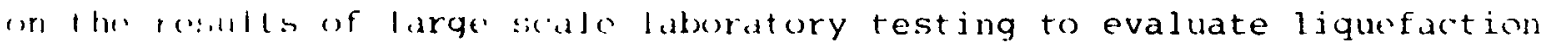

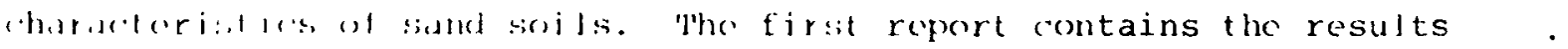

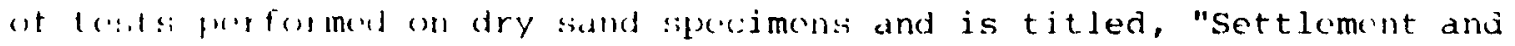

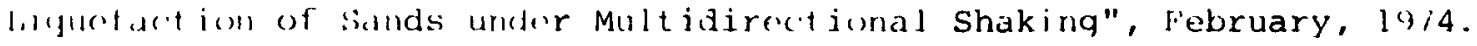

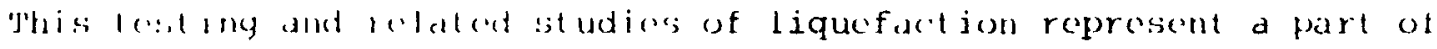
continuing rescarch efforts to evaluate free field soil behavior under carthquake loading conditions, and are important steps in the overall project for improving methods of evaluation and prediction of soil behavior at potentia] nuclear power plant sites when subjected to vibratory ground mot ions.

'This work was conduled and the roport prepared by the University ot Colitormia, korkoley, California, undor subcontract to the joint vemlur, of Shmmon of Wilsm, Im:., (SW) and Agbabian Associates (AA)

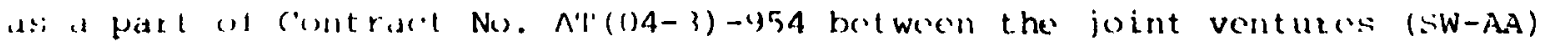
and the Initod states Nuclear Regulatory Commission.

The principal investigators and authors of this report for the University of california are Pedro De Alba, Clarence K. Chan, and Dr. H. Bolton Seed. Important contributions to the investigation were also made by R. Pykc, K. Mori, T. Fujioka, C. Tsai, T. Pickrell, B. Debeling and M. Brock, members of the rescarch staff of the Soil Mechanics Laboratory and the Earthquake Engineering Research Center of the University of California, Berkeley. For the joint venture, Dr. I. Arango served as project monitor for the entire investigation and Dr. R. Miller was project manager for the jolnt venture. Mr. S. D. Wilson provided a critical review of the report. 


\begin{tabular}{|c|c|c|}
\hline \multicolumn{3}{|c|}{ Abstract } \\
\hline \multicolumn{3}{|c|}{ Foreword } \\
\hline List & of Figures & $i x$ \\
\hline List & of Tables & $x i 1 i$ \\
\hline List & of Symbols - Roman Letters, Greek Letters & xi: \\
\hline \multicolumn{2}{|c|}{ I. INTRODUCTION } & 1 \\
\hline & Previous Shaking Table Studies & 3 \\
\hline & Variables and Definitions & 5 \\
\hline & Field Liquefaction Data & 13 \\
\hline \multirow[t]{3}{*}{ II. } & SHAKING TABLE DESIGN AND INSTRUMENTATION & 15 \\
\hline & Des1gn & 15 \\
\hline & Instrumentation & 29 \\
\hline \multirow[t]{8}{*}{ III. } & TESTING PROCEDURES AND BASIC RESULTS & 33 \\
\hline & Material & 33 \\
\hline & Specimen Preparation & 33 \\
\hline & Saturation & 46 \\
\hline & Relative Densities & 48 \\
\hline & Initial Effective Pressure & 48 \\
\hline & Cyclic Shear Stress & 49 \\
\hline & Results & 50 \\
\hline
\end{tabular}


IV. STRESS RATIO CORRECTION FOR COMPLIANCE EFFECTS

V. DISCUSSION

Pore Pressure Development During Shaking

Comparisons with Results of Previous Shaking Table Tests

Comparisons with Results from Laboratory Apparatus

Shear Strains After Initial Liquefaction

VI. COMPARISON WITH CYCLIC TRIAXIAL TESTS

VII. SUMMARY AND CONCLUSIONS

Appendix I Compliance Measurements

Appendix II Dynamic Pore Pressure Records

Appendix III Effective Pressure and $B$ Value Measurements

Append1x IV Instrument Characteristics 


\section{LIST OF RIGURES}

F18.

No.

1.1 Stress Conditions on Modelled Soll Element

1.2 Laboratory Simple Shear Test Results

1.3 Relationship Between $\left(\tau_{\mathrm{hv}}\right)$ av $/ \sigma_{0}^{\prime}$ and Relative Density for Known Cases of Liquefaction and Non-Liquefaction

2.1 Shaking Table Ready for Testing

2.2 Section of Ballast System and Vacuum Plate

2.3 Section through Shaking Table Clamping System

2.4 Cross-section of Shaking Table System

2.5 Distribution of Instruments

2.6 Model Footing Experiment

3.1 Monterey No. 0 Sand, Batch 3

3.2 Soils Susceptible to Liquefaction

3.3 Section of Spreader Box

3.4 Sand Deposition Using Spreader

3.5 Vertical Density Variation

3.6 Triming the Specimen

3.7 Finished Specimen Covered with Membrane

3.8 Placing the Ballast on the Specimen

3.9 Specimen with Ballast and Filler Materlal

in Place

3.10 Chamber in Position for Specimen Saturation

3.11 Typical Test Records

3.12 Dynamic Pore Pressure Development, Relative Density $=54 \%$
Page

No. 
Fig.

No.

3.13 Dynamic Pore Pressure Development, Relative Density $=68 \%$

3.14 Dynamic Pore Pressure Development, Relative Density $=82$ and $90 \%$

3.15 Specimen Behavior after Liquefaction

3.16 Specimen Behavior after Liquefaction

3.17 Shear Strain Development, Relative Density = $54 \%$

3.18 Shear Strain Development, Relative Density = $54 \%$

3.19 Shear Strain Development, Relative Density = $68 \%$

3.20 Shear Strain Development, Relative Density = $68 \%$

3.21 Shear Strain Development, Relative Density = $82 \%$

3.22 Shear Strain Development, Relative Density $=$ $82 \%$

3.23 Shear Strain Development, Relative Density = $90 \%$

3.24 Section of Footing Settlement Record

3.25 Upper Footing Settlement

3.26 Footing Settlement (Results Corrected to $q=25$ psi)

$3.27 \tau / 0_{o}^{\prime}$ vs. $\mathrm{N}_{c}$ for Initial Liquefaction

4.1 Basic Input Data for Liquefaction Model

4.2 Volumetric Strain vs. Specimen Height

4.3 Total Volumetric Strain and System Compliance

4.4 Material Rebound vs. Initial Effective Stress

4.5 Calculated vs. Measured $\tau / \sigma_{0}^{\prime}-N_{c}$ Curves
Page

No. 
4.6 Correction Factors from Martin's Model

4.7 Stress Ratios for Alternate Correction Method

4.8 Effect of Denstty and Number of Cycles on $\varepsilon_{v}$ 90

4.9 Correction Factors - Comparison

4.10 Corrected $\tau / \sigma_{0}^{\prime}$ vs. $N_{c}$ for Initial Liquefaction

5.1 Normalized Data - Dynamic Pore Pressures

5.2 Normalized Data - Dynamic Pore Pressures

5.3 Normalized Data - Dynamic Pore Pressures

5.4 Normalized Dynamic Pore Pressure Curves

5.5 Comparison of Shaking Table Test Results for $D_{r}=50 \%$

101

5.6 Comparison of Shaking Table and Simple Shear Liquefaction Test Results for $D_{F}=50 \%$

5.7 Relationship between $\tau / \sigma_{0}^{\prime}$ and Number of Cycles Causing Different Levels of Strain

5.8 Limiting Shear Strains - 5 Stress Cycles

5.9 Limfting Shear Strains - 10 Stress Cycles

5.10 Limiting Shear Strains - 30 Stress Cycles

5.11 Average Rate of Footing Settlement

5.12 Comparison of Field Data with Shaking Table Results for Inttial Liquefaction at $\mathrm{N}_{c}=10$, 15, 20 Cycles

5.13 Comparison of Field Data with Shaking Table Results for $\pm \gamma=5$ Percent at $N_{c}=10,15$, 20 Cycles

6.1 Triaxial Liquefaction Test Results from Mulilis (1975)

6.2 Comparison of Shaking Table and Triaxial Test Results 
F1g.

No.

Tttle

6.3 Comparison of Shaking Table and Triaxial Test Results

122

6.4 Correction Factors for Triaxlal Test Results

123

A-1.1 Back Pressure Application

128

A-1.2 Total Volumetric Rebound of 4" High Specimen for $\sigma_{0}^{\prime}=4.5 \mathrm{psi}, \mathrm{D}_{r}=54 \%$

A-1.3 Total Volumetric Rebound of 4" High Specimen for $\sigma_{0}^{1}=8 \mathrm{psi}$

A-1.4 Total Volumetric Rebound of 4" High Specimen for $\sigma_{0}^{\prime}=13$ psi

A-1.5 Total Volumetric Rebound for 1/8" High Specimen

133

A-2.1 Dynamic Pore Pressure Development

A-2.2 Dynamic Pore Pressure Development

137

A-2.3 Dynamic Pore Pressure Development 138

A-2.4 Dynamic Pore Pressure Development 139

A-2.5 Dynamic Pore Pressure Development 140

A-2.6 Dynamic Pore Pressure Development 141

A-3.1 B-Measurement Device 143

A-3.2 Effective Pressure Calculation 144

A-3.3 Suspended Specimen Chamber, Showing Pressure Regulators and Measuring Device 


\section{LIST OF TABLES}

Table

Page

No.

No.

I.1 Previous Shaking Table Work

6

III.1

Sand Characteristics

35

IV.1 Correction Values - Method 2

92

A. 3.1

Measured B Values

146 
The following are used repeatedly in the text. Symbols used only once are defined where they occur.

\section{Greek Letters}

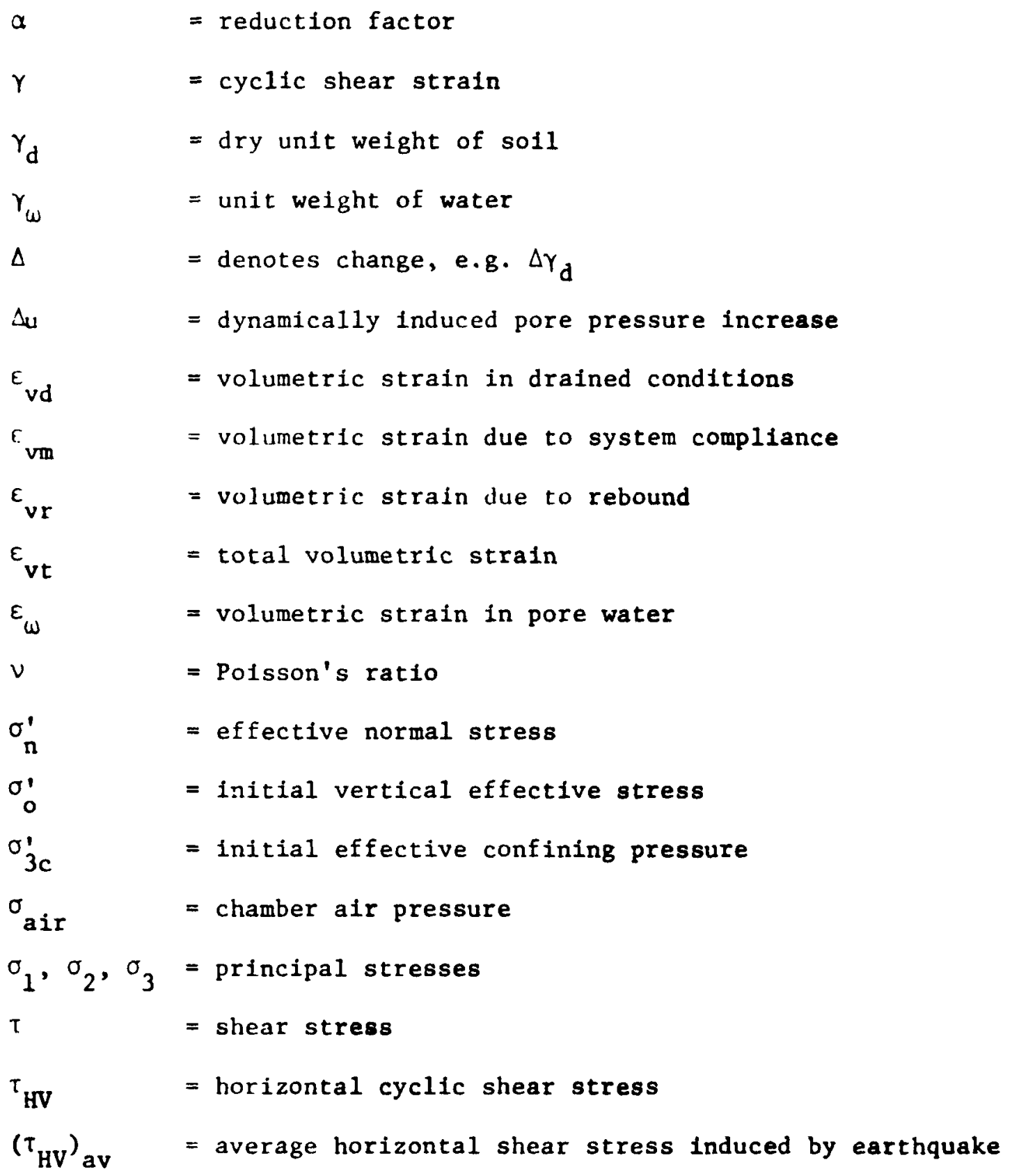




$\begin{array}{ll}\tau_{\mathrm{m}} & =\text { maximum shear strase } \\ \omega_{\mathrm{ba11}} & =\text { unft weight of ballast }\end{array}$

\section{Roman Letters}
A
= acceleration
B
= Skempton's pore pressure coefficient
C
= correction factor for compliance effects
$\mathrm{C}_{\mathbf{r}}$
= correction factor for triaxial liquefaction test results
$\mathbf{D}_{\mathbf{r}}$
= relative density
G
= shear modulus of elasticity
8
= acceleration of gravity
$\mathbf{K}_{\omega}$
= bulk modulus of water
Ko
= coefficient of earth pressure at rest
$\mathbf{k}_{\mathbf{r}}$
= rebound modulus
$\mathbf{k}_{\mathbf{m}}$
= gradient of volume change due to membrane penetra- tion
m
- mas8
$\mathrm{N}_{\mathbf{c}}$
- number of stress cycles
$\mathrm{N}_{\mathrm{cl}}$
- number of stress cycles to liquefaction
$\mathbf{n}$
= porosity
$\mathbf{q}$
= pressure applied to model footing
U
= pore pressure
$\mathrm{u}_{\mathrm{b}}$
= back pressure 


\section{INTRODUCTION}

Liquefaction is a general term which has been used to describe various forms of unstable behavior of saturated sands during earthquakes. Slope fallures, Including flow slides, settlement and tilting of foundations due to 'quicksand' conditions in bearing strata, collapse of quay walls, embankment spreading, and the uplift of buried storage tanks and swimming pools above the ground surface have all been attributed to liquefaction in 1 ts several forms.

At least three distinct phenomena are characterized as liquefaction. All imply a loss of shearing strength due to pore pressure increase, with the consequent appearance of strains which may be intolerable to civil engineering structures:

1. Pore pressure increase produced under monotonically increasing load, under undrained conditions; this problem was first studied by Casagrande (1936) who related it to the concept of critical void ratio applied to the static undrained strength of send.

2. Pore pressure increase produced by cycllc loading under undrained conditions; the basic studies of Seed and Lee (1966) showed that cyclic stresses far below the static undrained strength could produce pore pressure bulldup and excessive strains as the pore pressure increase became equal to the initial effective pressure. 
3. Luss of shearlng strength of a soll layer caused by upward flow of water from an underlying deposit in which mechanism (2) has produced excess pore pressures; the resulting 'quick' condition causes some of the most obvious damage due to liquefaction.

This study will concentrate on mechanism (2), the behavior of saturated sands subjected to cyclic loading under undrained conditions. The first quantitative studies of this behavior were published by Seed and lee (1966), who used the triaxial apparatus to study liquefaction of a uniform medium sand under cyclic loading conditions. Many studies have been published since on various aspects of the liquefaction problem using the triaxial apparatus, and more recently the simple shear and ring shear apparatus. Much valuable information on the relationships between the basic variables involved in the liquefaction problem has been obtained. However, in each of the small-scale tests, the particular specimen configuration, the boundary conditions and the loading conditions all combine to affect the test results in a characteristic way for each device. Although these effects can be qualitatively separated and described ${ }^{2}$, many engineers have felt that there is no completely satisfactory method for correcting the experimental results in such a way as to obtain the 'true'

1e.g. Lee and Seed (1967), Lee and Fitton (1968), Peacock and Seed (1968), Finn et al. (1971a), Ishihara and Li (1972), Yoshimi and Oh-Oka (1973).

${ }^{2}$ e.g. Seed and Peacock (1970), Finn (1972). 
field behavior of the soll. In view of the 1imtations of smallscale tests, it has been suggested that improved results might be obtained by tests on large specimens, with which the behavior of a natural soil mass could be more closely approximated, and where a 'free fleld' zone, removed from the effects of boundaries, might be created. This report describes such a study, utilizing specimens $7^{\prime} 6^{\prime \prime}$ by $3^{\prime} 6^{\prime \prime}$ in plan, and four in. thick, in which cyclic stresses were induced by means of a shaking table.

\section{Previous Shaking Table Studies}

The concept of placing a large container of saturated soll on a shaking table and subjecting it to impact loading or cyclic loading is not new; some of the first liquefaction studles were carried out in this way. Maslov (1957) reported the use of a 4.9 feet-high box contalning 27 tons of saturated sand, vibrated horizontally to obtain the critical acceleration at which liquefaction would occur; he noted the Inapplicability of the critical vold ratio concept in the case of cyclic loading, and the increase in the critical acceleration value with increasing overburden, as well as the importance of density; however; his tests were apparently carried out with a free upper soll surface, thus representing at most the upper 4.9 feet of a sand deposit. Furthermore, the proportions of the sand container were such that no true free field conditions could be said to exist in the sand, especially since the spectmen was in contact with the rigid

\footnotetext{
'Shannon and Wilson Inc. and Agbabian-Jacobsen Assocs. (1971, 1972).
} 
chamber walls and could not deform freely under stress. Varlous other studies have been carried out since using diverse sizes and shapes of containers'. These studies expanded the work of Maslov; however, although some improvements were made in exper1mental techniques, all these experiments share one or more drawbacks with this early study, as will be discussed in the following paragraphs :

A basic defect of most of these studies is the shape of the container. Studies by Arango and Seed (1974) and Kovacs, Seed and Chan (1971), on clay banks indicate the need for length to height ratios of the order of $10: 1$ to obtain free field cond1tions in the specimen. It is reasonable to assume that similar proportions should apply to sand spectmens. A related objection is that the sand has been placed in direct contact with the rigid walls of the specimen chamber, thus limiting the shear deformation of the specimen under applied stress in a way which would not occur in nature. The results are thus heavily influenced by the boundary conditions.

Further, in much of this work, the upper surface of the specimen has been left free to drain. Tests in this condition will reflect the behavior of superficial deposits only; it was not possible to study the behavior of saturated sands at depths where drainage cannot occur. This is an important drawback, since

1e.g. Florin and Ivanov (1961), Nunnally (1966), Tanimoto (1967), Yoshimi (1967), Finn et al, (1970, 1971b), Whitman (1970), O-Hara (1972), Ortigosa (1972). 
liquefaction of burled layers has been responsible for most of the disastrous liquefaction fallures during earthquakes.

Finally, the generation of cyclic stresses sufficlently

large to produce liquefaction has also been a problem; much of the work done to date has been carried out with sands at relative densitles of less than 50 percent, for which liquefaction could readily be induced. This left unanswered the important question of soil behavior at higher densities.

Table I.l summarizes the sallent features of shaking table studies carried out since 1957; it will be seen that all share one or more of the characteristics described above. It was considered that these difficulties could be overcome with a properly designed testing system, which would simulate the behavior of a thin layer of saturated sand at a cercain depth beneath a horizontal ground surface. The layer would be subjected to initial effective normal atresses $\sigma_{0}^{\prime}$ and $K_{0} \sigma_{0}^{\prime} F I g .1 .1$, where $K_{0}$ is the coefficient of earth pressure at rest. During an earthquake, this layer would be subjected to variable cyclic loading, produced basically by the upward propagation of horizontal shear waves from bedrock, Fig. 1.1b. The testing system would simulate a simplifled earthquake loading, that is, constant-amplitude cyclic motion in one horfzontal direction. The development of such a testing system and the results obtained are described in the following pages.

\section{Variables and Definitions}

At this point, it is considered conventent to review briefly 
TABLE I. 1

PREVIOUS SHAKING TABLE WORK

\begin{tabular}{|c|c|c|c|c|c|c|c|}
\hline Author & Date & $\begin{array}{l}\text { Lxix H } \\
\text { Approx. } \\
\text { Specimen } \\
\text { Dimensions } \\
\text { (in) }\end{array}$ & $\begin{array}{c}\text { Length } \\
\text { to } \\
\text { Height } \\
\text { Ratio }\end{array}$ & $\begin{array}{l}\text { Specimens } \\
\text { Limited by } \\
\text { Rigid Walls }\end{array}$ & Overburden & $\begin{array}{c}\text { Max. } \\
\text { Overburden } \\
\text { Pressure }\end{array}$ & $\begin{array}{l}\quad \text { Max. } \\
\text { Relative } \\
\text { Density } \\
\text { Reported }\end{array}$ \\
\hline Maslov & 1957 & $\begin{array}{r}120 \times 120 \times 59 \\
\text { (estimated) }\end{array}$ & $2: 1$ & Yes & free surface & soil weight & -- \\
\hline Nunna11y & 1966 & $6 \times 6 \times 40$ & $0.15: 1$ & Yes & load blocks & & "1oose" \\
\hline Tanimoto & 1967 & $31 \times 31 \times 51$ & $0.62: 1$ & Yes & free surface & soil weight & "loose" \\
\hline Yoshimi & 1967 & $20 \times 10 \times 11$ & $1.88: 1$ & Yes & $\begin{array}{l}\text { air press. } \\
\text { over membrane }\end{array}$ & $0.85 \mathrm{ps} 1$ & $52 \%$ \\
\hline Whitman & 1970 & $53 \times 35 \times 15$ & $3.7: 1$ & Yes & free surface & soil weight & -- \\
\hline Finn et al. & 1970 & $96 \times 18 \times 6$ & $16: 1$ & Yes & $\begin{array}{l}\text { air press. } \\
\text { over membrane }\end{array}$ & $0.5 \mathrm{psi}$ & $37 \%$ \\
\hline Finn et al. & 1971 & $72 \times 18 \times 7$ & $10.3: 1$ & Yes & $\begin{array}{c}\text { a1r press. } \\
\text { over membrane }\end{array}$ & 5 psi & $30 \%$ \\
\hline O-Hara & 1972 & $40 \times 23 \times 12$ & $3.4: 1$ & Yes & $\begin{array}{l}\text { air press. } \\
\text { over membrane }\end{array}$ & $4.3 \mathrm{psi}$ & $58 \%$ \\
\hline Ortigosa & 1972 & $47 \times 23 \times 20$ & $2.3: 1$ & Yes & free surface & sol1 welght & $70 \%$ \\
\hline
\end{tabular}




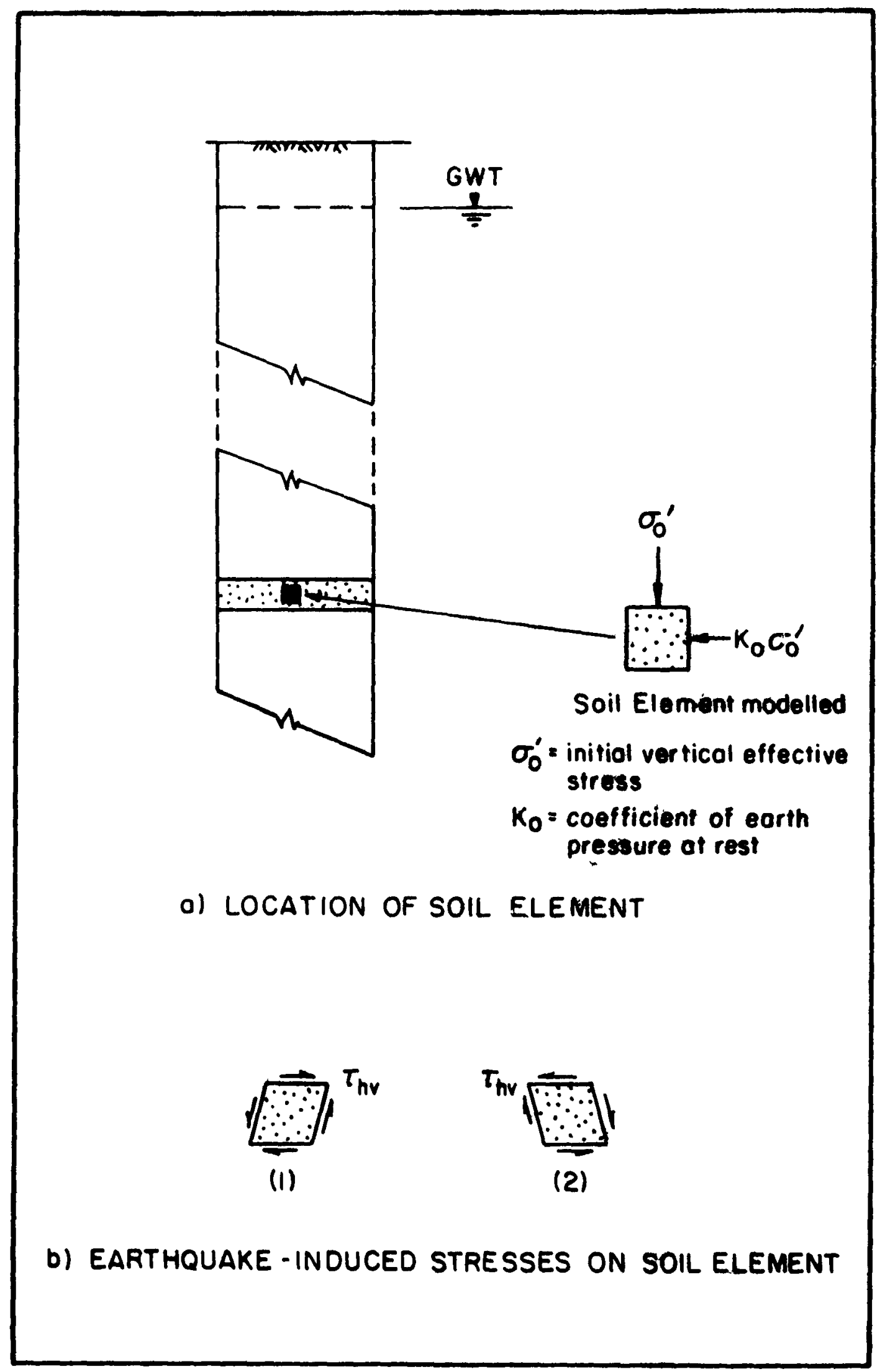

Fig. I.1 STRESS CONDITIONS ON MODELLED SOIL ELEMENT 
the variables that control the liquefaction process under discussion as well as the definition of liquefaction that will be adopted.

In this study, liquefaction will be defined in terms of excessive deformation, as proposed by Seed and Lee (1966). Accordingly, complete liquefaction will refer to the condition in which the soil develops intolerable deformations from the engineering point of view, that is, when its resistance to deformation over a wide strain range is negligible (e.g. cyclic shear strain $\gamma= \pm 20 \%$ ). Partial liquefaction will describe a condition in which the soil presents no resistance to deformation over a strain range that is not considered excessive, and initial liquefaction will be said to occur when signs of partlal liquefaction first appear or when residual pore water pressures become equal to the applied confining pressure.

As regards the earthquake and soil characteristics controlling the liquefaction process, experimental work has shown that there are four principal variables involved:

1. Relative density

2. Initial effective confining pressure

3. Peak earthquake acceleration and number of significant earthquake stress cycles

4. Soil characteristics: gradation, grain size, etc.

Their influence on liquefaction may be summarized as follows:

1. Relative Density, $\mathrm{Dr}$. Resistance to initial liquefaction increases with relative density; laboratory evidence shows that 
this Increase is approximately linear up to about $\mathrm{Dr}=80$ percent, after which the resistance increases more rapldiy, as shown in Fig. 1.2. It was considered of major interest to investigate in the shaking table tests the liquefaction behavior of soils for relative densities above 50 percent, for which little or no largescale test data were avallable.

2. Initial effective confining pressure. It has been well established in the laboratory that resistance to liquefaction at a given density increases with increasing confining pressure, as shown for example in Fig. 1.2.a. The importance of overburden pressures in increasing liquefaction resistance was pointed out in an early study by Florin and Ivanov in 1961, and confirmed in the field during the Nigata earthquake of June 16, 1964, where sand deposits under nine feet of fill remained stable, while similar surrounding deposits liquefled (Seed and Idr188, 1967). Results from Nigata Indicate that no liquefaction occurred for initial vertical effective stresses greater than about 29 psi, that 1s, for depths exceeding 50 or 60 feet, although exceptionalIy long or violent earthquakes could produce liquefaction at greater depths.

The most easily determined parameter representing the confining pressure in the fleld is the initial effective vertical stress, $\sigma_{0}^{\prime}$, which may be readily obtained for known 6011 densities; in reporting field results, $\sigma_{0}^{\prime}$ may be comblned with the average shear stress produced by the earthquake to obtain a new parameter $\frac{\tau}{\sigma_{0}^{T}}$, which, determined for a given number of 

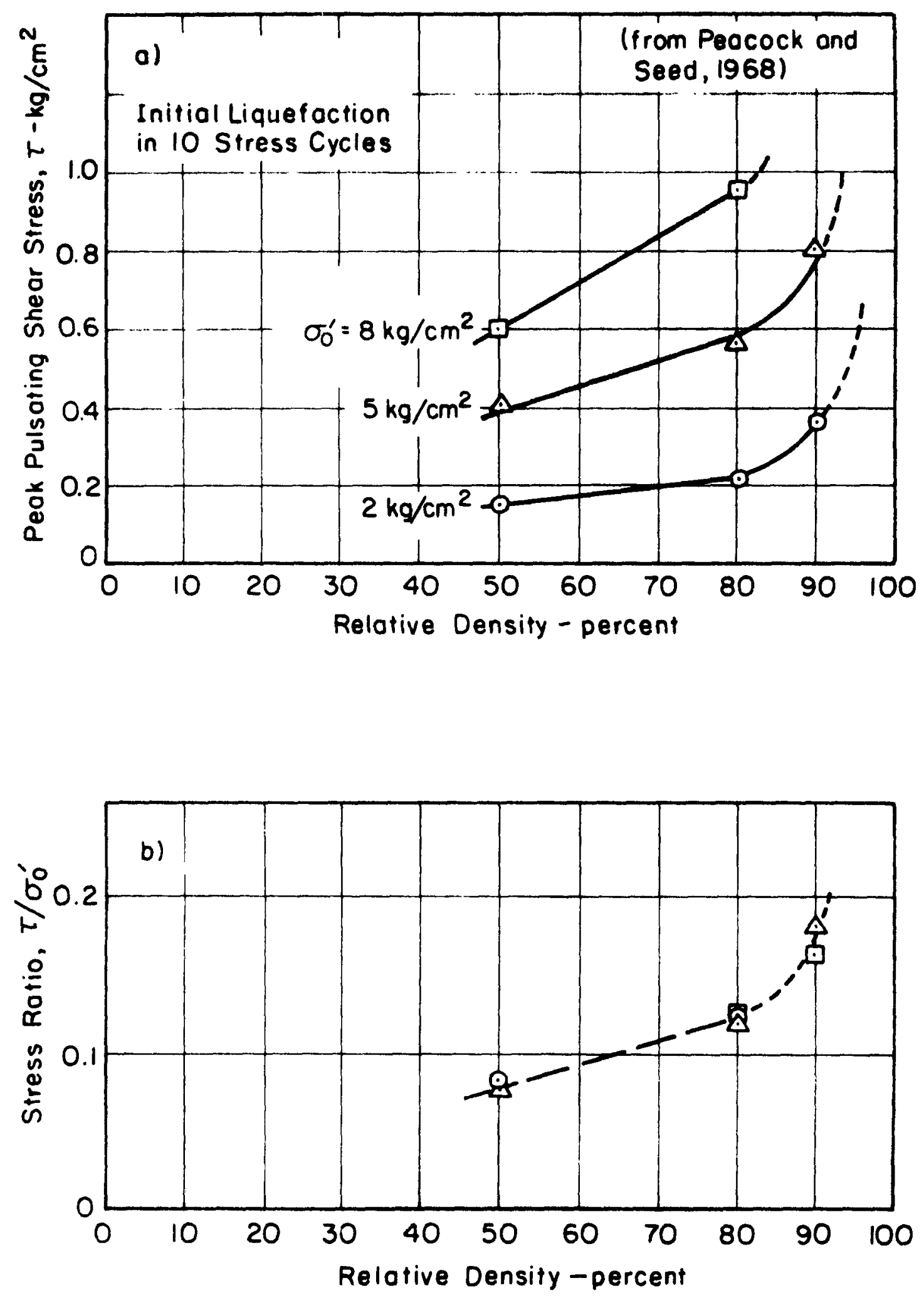

Fig. 1.2 LABORATORY SIMPLE SHEAR TEST RESULTS 
cycles, implicitly includes both the princlpal earthquake characteristics of peak acceleration and number of signiflcant stress cycles, and the effect of overburden pressure in reducing 11quefaction potential. Thus a single plot of $\frac{\tau}{\sigma_{0}^{1}}$ v8 $\mathrm{Dr}$ will show the effects of all the principal 11quefaction variables for a given soll, Fig. 1.3. This same parameter may be used in reporting the results of laboratory tests. Fig. 1.2.b shows the plots of $\mathrm{FIg}$. 1.2.a reduced to a single curve of $\frac{\tau}{\sigma_{0}^{\prime}}$ v8 Dr.

3. Principal earthquake characteristics. As noted above, the peak acceleration, $A_{\max }$, and the duration of shaking can be represented by the average shear stress in the parameter $\frac{\tau}{\sigma_{0}^{T}}$, and the number of significant stress cycles. Seed and Idriss (1970) have suggested that the average shear stress induced by the earthquake can be approximated using the following expression:

$$
\tau_{\mathrm{av}}=0.65 \mathbf{r}_{\mathrm{d}} \times \frac{\mathrm{Yh}}{\mathrm{g}} \times \mathrm{A}_{\max }
$$

where $\gamma 18$ the unit weight of the soll, $h$ is the depth, 818 the acceleration of gravity, $A_{\max }$ is the peak earthquake acceleration and $r_{d}$ is a reduction factor proportional to depth, equal to unfty at the ground surface. This expression was used to calculate the shear stresses reported In Fig. 1.3. The number of sifnificant stress cycles can be determined by fudgment or by means of a weighting procedure for each cycle of motion as discussed by Lee and Chan (1972).

As regards frequency and duration of strong-motion earthquakes, typical values of frequency are 0.5 to $5 \mathrm{~Hz}$, with durations 


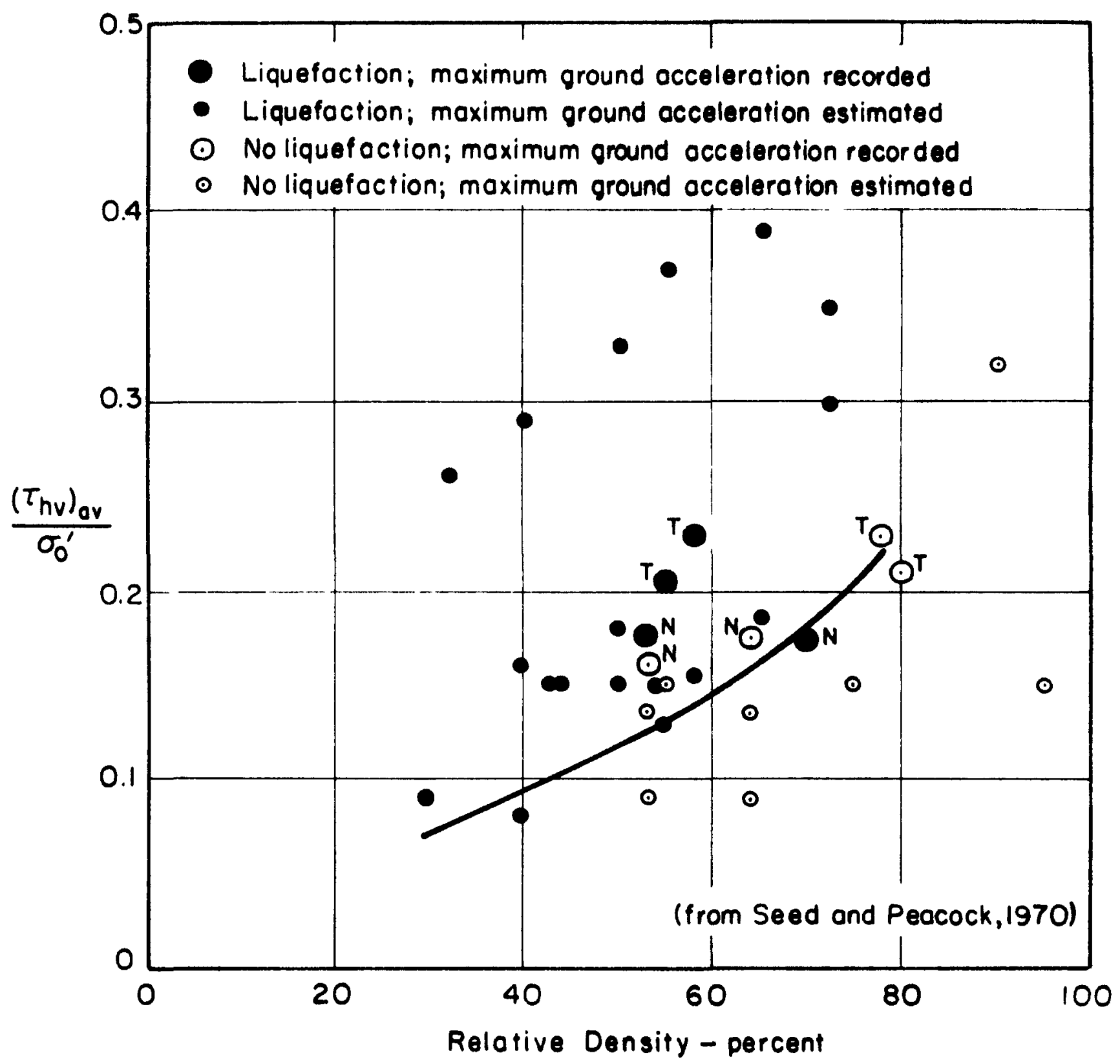

N: Points from Niigato earthquake, June 16, 1964

$T$ : Points from Tokachioki earthquake, Moy 16, 1967

Fig. 1.3 RELATIONSHIP BETWEEN $\left(\tau_{h v}\right)_{o v} / \sigma_{0}^{\prime}$ AND RELATIVE DENSITY FOR KNOWN CASES OF LIQUEFACTION AND NON - LIQUE FACTION 
of 5 to 30 seconds, thereby producing perhaps five to 30 signif1cant stress cycles.

4. Soll characteristics. Gradation, grain size, grain shape and soll structure are all significant factors influencing the liquefaction characteristics of sands. Avallable data show that fine sands exhibit the least resistance to liquefaction, but soll structure also appears to have a major influence on soll performance.

\section{Field Liquefaction Date}

Although many failures attributable to the liquefaction of horizontal sand deposits are reported in the literature ${ }^{1}$, ground surface acceleration records for the causative earthquake, at the site of the failure, are avallable only in two cases: for the Nilgata earthquake of June 16, 1964, and the Tokachoki earthquake of May 16, 1967. The best collection of fleld liquefaction data 1s to be found in Seed and Peacock (1971), where, besides the Nifgata and Tokachoki cases, many other incidents are included by applying Housner's relationship between earthquake magnitude, distance from the zone of energy release and maximum ground acceleration, to obtain approximate values of ground acceleration at sites where no ground motion records were obtained. These data are presented in Fig. 1.3, representing the behavior of 35 sites in 12 earthquakes. A lower bound representing the borderline between

'e.g. Marsal (1961), Duke and Leeds (1963), Seed (1968), Seed and Peacock (1971), Kishida (1970), Ohsak1 (1970). 
11quefaction-susceptible and non-liquefying stress and density combinations is proposed. It will be noted that this lower bound relies basically on the well-documented conditions that produced liquefaction at Nifgata. It was primarily for the purpose of obtaining more information about this lower bound, which is obviously of great importance in earthquake resistant design, that the series of experiments described in this report were conducted. 


\section{SHAKING TABLE DESIGN AND INSTRUMENTATION}

\section{Des1gn}

The shaking table describud in this chapter was designed to overcome the more obvious shortcpmings of previous devices; essentially, the result was a very large simplin hear machine, in which the shear stresses were generated by the Inertia of the specimen and its superimposed 'ballast' as the specimen base was shaken by an actuator. The specimen itself was. intended to represent a thtn deposit of saturated sand subjected to horizontal cyclic shear stress, a condition similar to that which wes considered to occur during an earthquake due to an upward propagation of shear waves from bedrock. Overburden was simulated by air prefure applied to the sand layer. The base dimenstons of the test specimen were $90 "$ by 42 " tapering to 74 " by $30^{\prime \prime}$ at the top. Its height was 4". As will be discussed in a subsequent, ection, this configuration was chosen in order to assure that chentral part of the specimen would be as nearly as possible in a 'free fleld' condition, 1.e. not influenced by the boundaries.

The specimen chamber was fesigned to whthstand the pressures necessary for confinement and turation; it rolied freely on lowfriction rollers, and was attached to the ram of an electrohydraulic actuator system which provided the necessary horizontal cyclic motion. The total weigty of pecimen and chamber was about 4200 1b. The specimen "chamber fiting table ready for testing is shown In Fig. 2.1. Six basic problems were considered in the 


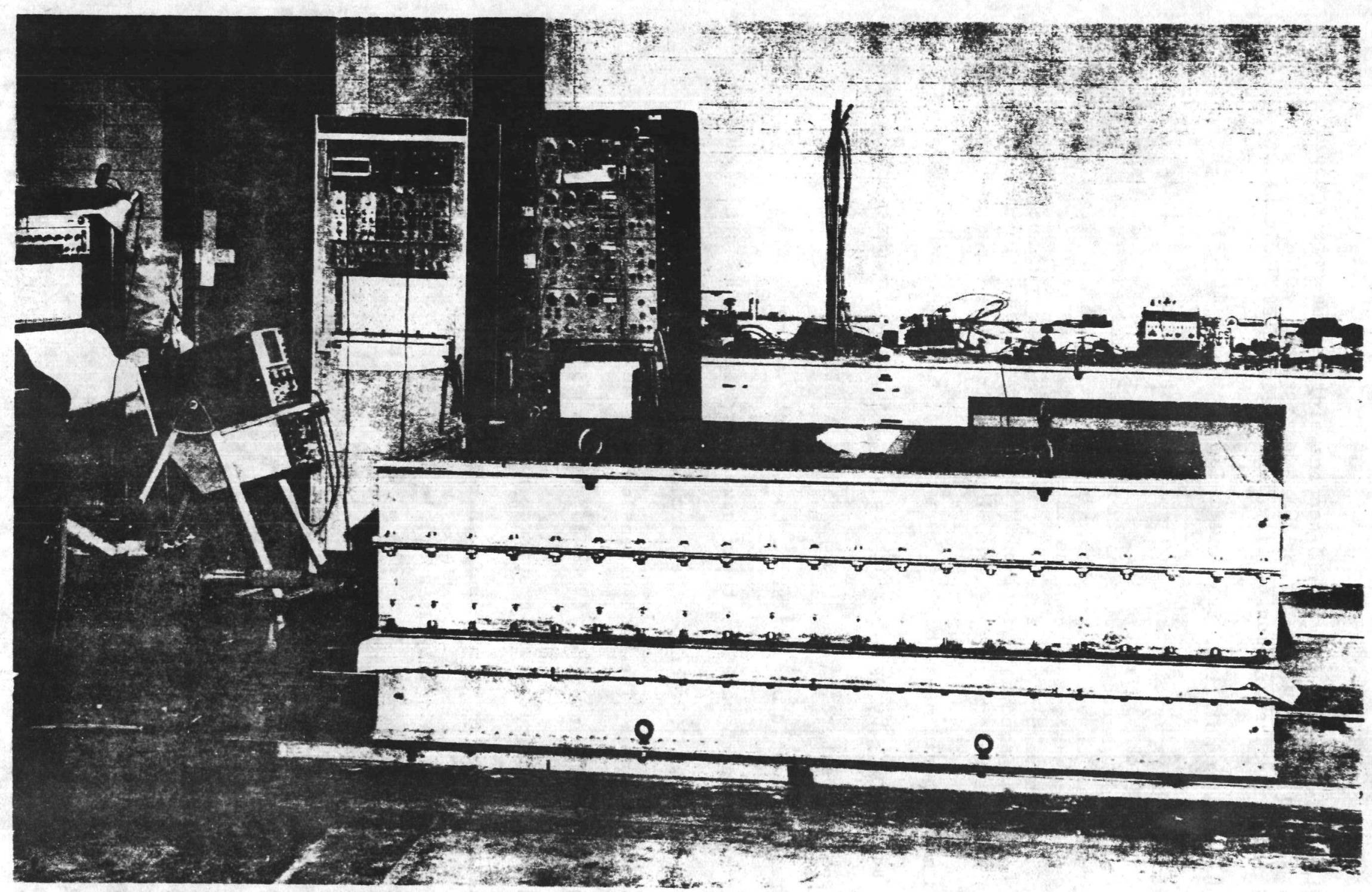

Fig. 2.1 SHAKING TABLE READY FOR TESTING 
design of the system:

1. Producing the required horizontal shear stresses.

2. Minimizing the effects of boundaries on spectmen behavior.

3. Simulation of the required overburden pressures.

4. Control of drainage.

5. Saturation.

6. Design of a rigid, light-weight specimen chamber for Internal pressures up to 50 psi.

These problems were dealt with as discussed in the following paragraphs:

1. Horizontal Shear Stresses. Since shear stresses were Induced in the specimen by inertia-forces resulting from horizontal cyclic acceleration of the base on which the specimen was built, the resulting shear stresses were proportional to the moving shear mass and the applied acceleration.

The shear stress levels required were those necessary to produce liquefaction of sand at relative densities up to about 85 percent, and within the number of stress cycles characteristic of strong-motion earthquakes, 1.e., about 30 cycles or less. The stress values producing liquefaction under these conditions were known approximately from previous work, such as that of Seed and Peacock (1971). In order to produce the necessary shear stresses with the available actuator system, a minimum shear mass was required, which could be produced in two ways: (a) by using a thici specimen (eight in. high or more) or (b) by using a thinner, 
four in. high specimen and an additional superimposed 'ballast' system. The thinner spectmen was considered preferable for two basic reasons: (1) it reduced the possibility of hydraulic gradients forming between the bottom and top of the specimen, and (2) it required smaller plan dimensions for the system to assure a free field condition at the center of the specimen. This in turn reduced the total moving mass of the system, permitting higher accelerations to be obtained with the available actuator system, within the range of earthquake frequencies.

A design based on a four in. high specimen required a ballast that would be flexible in the vertical direction, in order to adapt itself to any small irregularities of the upper surface of the test specimen, avolding stress concentrations on high spots. At the same time, it had to be rigid in the horizontal direction, so that uniform horizuntal shear stresses could be developed. The rigidflexible ballast finally adopted consisted of a rigid frame, filled with steel shot of approximately the same mean diameter as the sand'. As shown in Fig. 2.2, the shot was kept in the frame by a very thin (0.001") mylar membrane. This bottom membrane allowed the ballast to be lifted and maneuvered with a vacuum plate, shown in Figs. 2.2 and 3.8. Spacers were used to position the ballast on the specimen in such a way as to leave about 0.25 " clearance between the rigid frame and the specimen, in order to avoid stress concentrations at the ballast rim.

\footnotetext{
"The ballast weighed about $1000 \mathrm{lb}$. , and replaced approximately 6" of sand.
} 


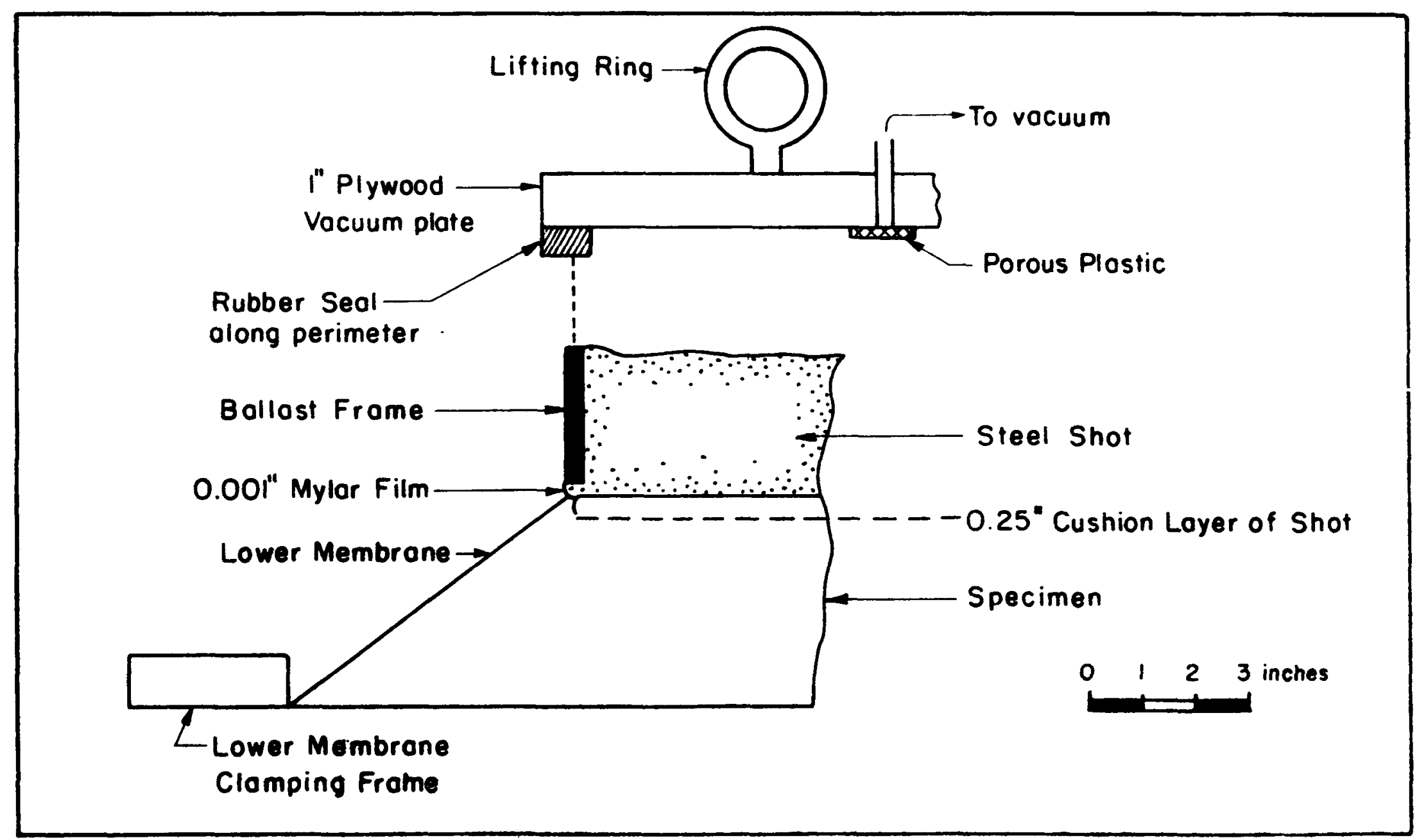

Fig. 2.2 SECTION OF BALLAST SYSTEM ANO VACUUM PLATE 
Thus, a shear force, $T=m A$, could be produced, where $m$ represents the combined mass of specimen and ballast, and $A$ the acceliration of the base of the specimen. The acceleration was provided by attaching the rail-muunted specimen chamber to an MTS electro-hydraulic actuator system. This actuator could be programed to reproduce various displacement patterns and actual earthquake records; a sinusoidal excitation was selected as most appropriate, considering that a specific earthquake record would provide information on only one special case, whereas earthquake records could always be reduced to equivalent sinusoidal motions, and more generally applicable results would be obtalned.

Finally, in chosing the frequency of motion, a compromise was sought hetween high accelerations, which required high operating Irequencies for the actuator system, and the reproduction of a frequency characteristic of strong motion earthquakes. Accordingly, an operating frequency of four $\mathrm{Hz}$ was chosen, which was in the strong motion earthquake range and for which accelerations in excess of $3 g$ could be obtained.

2. Boundary Effects. A fundamental object of the design was to obtain a free field zone within the specimen, where the influence of the boundaries would be at a minimum. With this goal in mind, the ends of the specimen were sloped inwards, as shown in Figs. 2.2 to 2.6, thus permitting it to deform freely when subjected to cyclic motion. This configuration eliminated one of the most serious drawbacks of previous shaking table work, in which the specimens were placed in direct contact with rigid container 


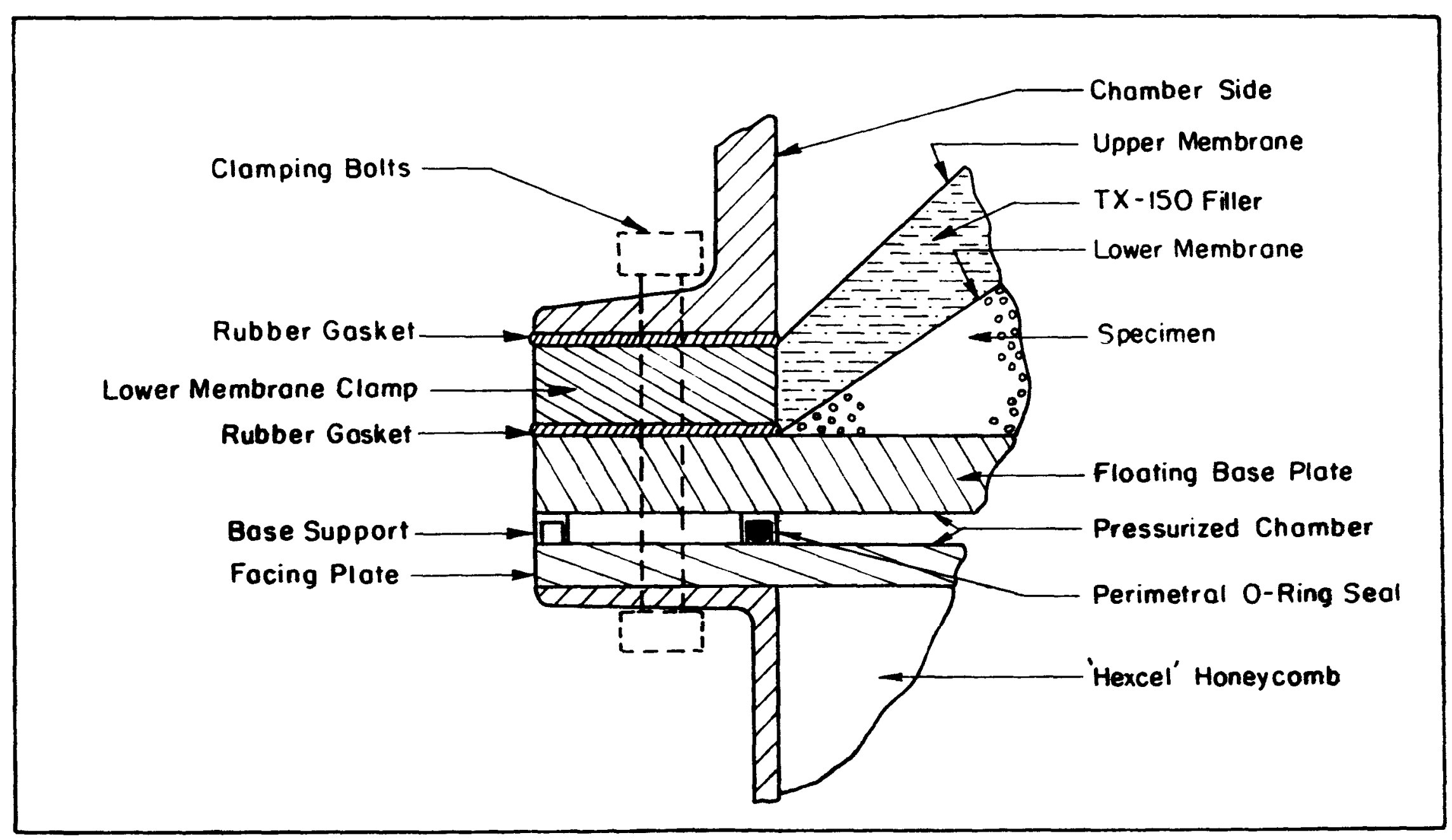

Fig. 2.3 SECTION THROUGH SHAKING TABLE CLAMPING SYSTEM 


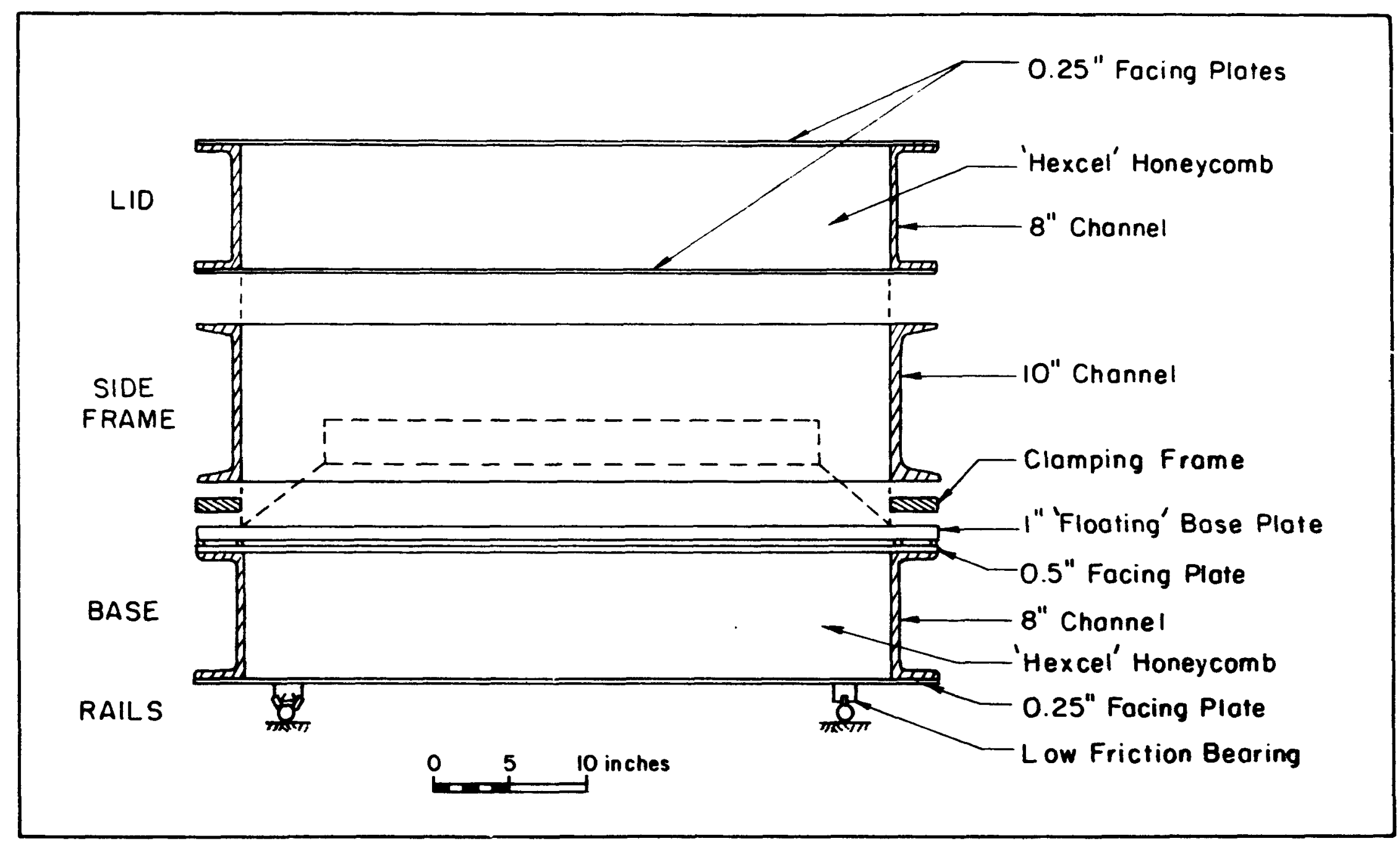

Fig. 2.4 CROSS-SECTION OF SHAKING TABLE SYSTEM 


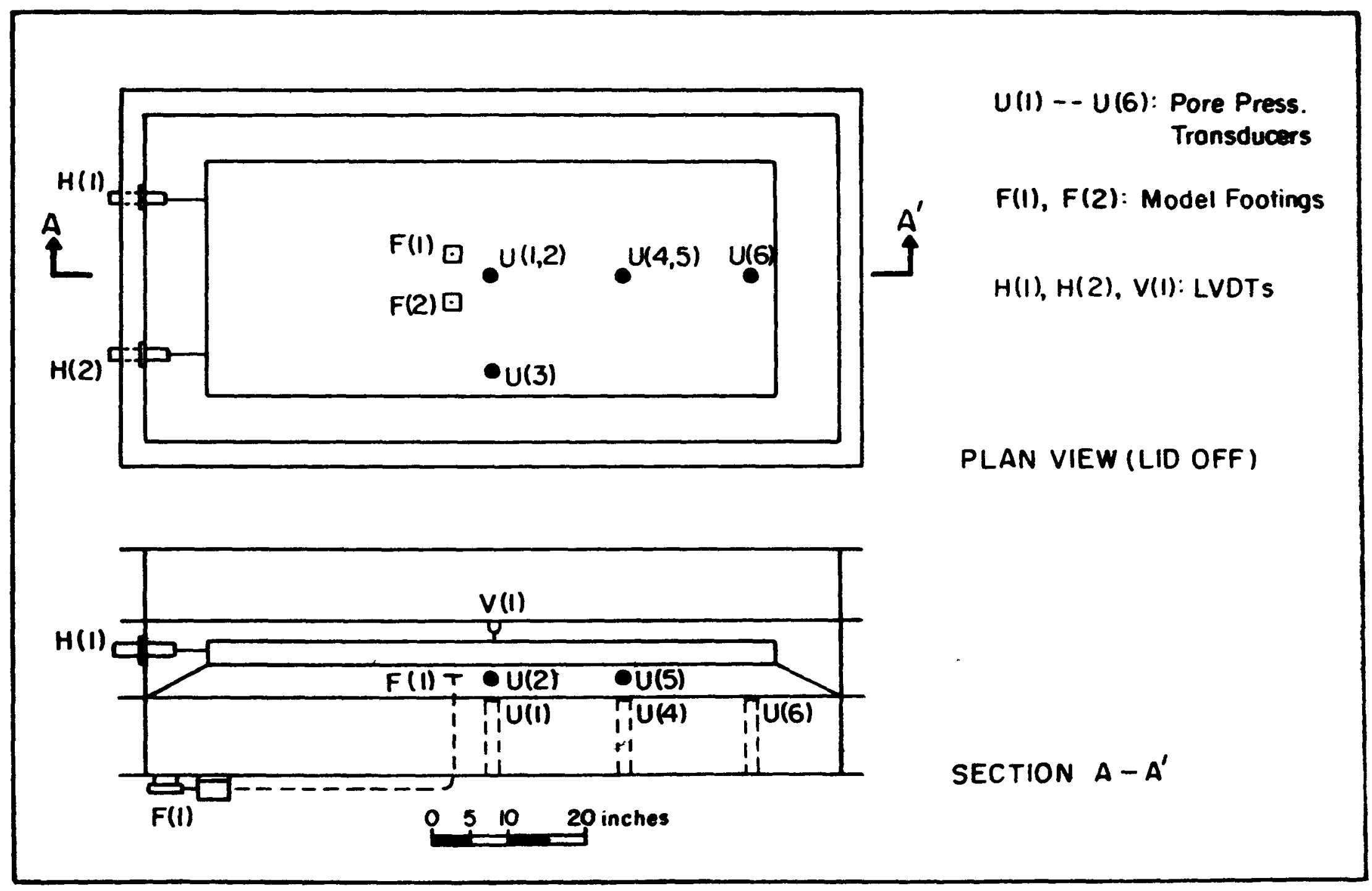

Fig. 2.5 DISTRIBUTION OF INSTRUMENTS 


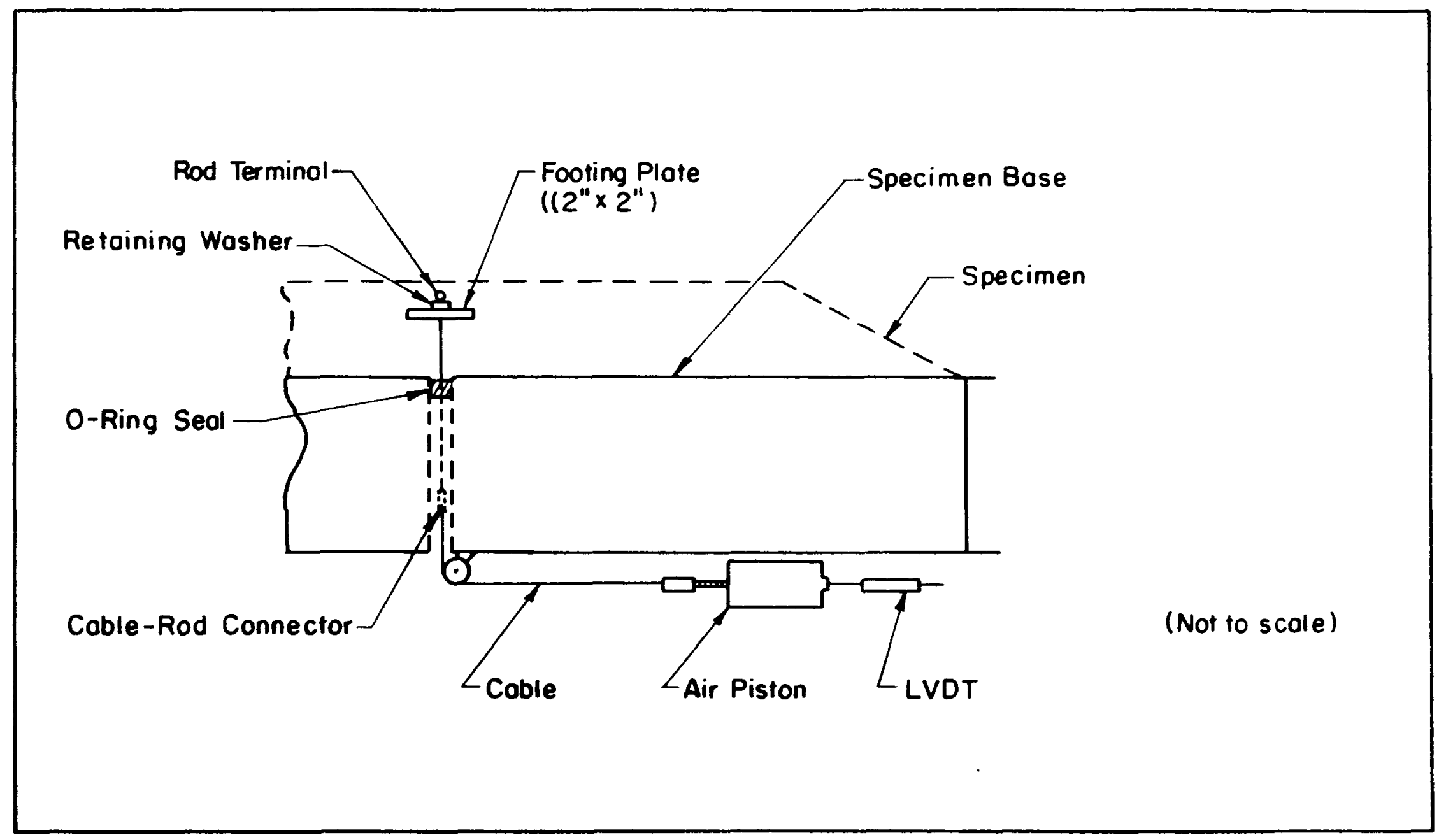

Fig. 2.6 MODEL FOOTING EXPERIMENT 
walls, thus limiting the shear strains that could be developed. In the accepted design with sloped ends, the deformation condit1ons imposed on the specimen by the horizontally rigid ballast described in section 1 were similar to those produced in simple shear.

The final plan dimensions of the specimen were then fixed considering that a free field area of approximately $5^{\prime}$ by $1^{\prime}$ In plan would be desirable to accommodate the instruments described in the following section. The influence of the end slopes could be expected to extend inwards a distance of about six times the specimen thickness from the edge of the bailast; the side slopes, which were intended to eliminate lateral friction, would probably have a negligible influence on the free field, but conservatively it was considered that their influence would extend inwards twice the slope height. Thus, for a specimen height of 4", end slopes of $2: 1$ and side slopes of $1.9: 1$, base dimensions of $92^{\prime \prime}$ by $40^{\prime \prime}$ would be required to obtain a free field of $28^{\prime \prime}$ by $12^{\prime \prime}$. Taking into account the standard sizes of materials to be used in building the table, these dimensions were rounded off to $90^{\prime \prime}$ by $42^{\prime \prime}$, giving a free fleld of $26^{\prime \prime}$ by 14 ". These dimensions also exceeded the length to height ratio of $10: 1$ proposed in Chapter I as necessary for obtaining a free field condition in the specimen.

3. Drainage and Overburden Pressure. The desired undrained conditions in the specimen were produced by covering it with an impervious rubber membrane $0.01 "$ thick which was clamped to the 
table base by $\exists$ peripheral metal frame, Figs. $2.2,2.3,2.4$ and 3.7. All water flow in or out of the specimen was then controlled through two diagonally opposed drainage valves in the base of the specimen chamber. The ballast was placed on top of the specimen, over the membrane; in this way only the sand had to be saturated, avolding the problems involved in saturating the spectmen-ballast system. However, in order to apply confining pressure to both ballast and specimen, it was necessary to cover the ballast with a second membrane, Fig. 2.3, which in turn was clamped down by the chamber sides. Then, once the lid was in position, the confining air pressure could be applied over the second membrane. To insure effective confinement of the ballast, it was connected to atmosphere by hoses leading through holes in the lower membrane clamping frame.

In an initial series of tests, this specimen-ballast system was found to perform well. However, while these tests were under way, related studies by Martin, Finn and Seed (1974) on the fundamental causes of liquefaction demonstrated the important effects of small volume changes in the test equipment on the results of liquefaction tests. As will be discussed at some length in Chapter IV, this work showed that small changes in the volume of the system, as dynamically induced pore pressure built up, would significantly retard the onset of liquefaction. Such additional volume changes could occur due to a reduction of membrane penetration as pore pressure increased, and the effect of this compliance was considered sufficiently important to justify stopping the testing program and carrying out a series of special tests in order 
to quantify it and reduce 1 as much as possible. The procedure followed in these special tests is described in Appendix I, and the results will be further discussed in Chapter IV.

It was found that an Important source of volume change was the upper membrane configuration at the contact between specimen and ballast, where the membrane was stretched to the point where it could not effectively confine a small area of the specimen at the ballast perimeter. It was therefore decided to place a filler materlal around the ballast between the membranes. This filler had to have very low shear strength and a compressibility comparable to that of water. The best materlal for this purpose was found to be a water-based highly plastic substance known commerclally as $\mathrm{TX}-150^{\prime}$, which was placed around the ballast as shown in Figs. 2.3 and 3.9. By the use of this filler, compliance was reduced by approximately 50 percent of its original value without filler, to a level that could be attributed to the inevitable membrane penetration effect alone.

4. Saturation. Saturation of the completed specimen is described in detail in Chapter III, in connection with the process of specimen preparation; it was forseen that back pressures up to 30 psi might be required in the saturation process, so that for the envisaged maximum initial effective pressures of $20 \mathrm{psi}$, the design internal pressure for the test chamber was chosen as 50 psi.

\footnotetext{
${ }^{1} 011$ Center Research Co., Lafayette, La.
} 
5. Test Chamber Design. For the specimen dimensions and chamber pressures arrived at as described in preceding paragraphs, it was then necessary to design a test chamber/shaking table system which would fulfill two basic conditions: (1) its mass had to be as low as possible, in order to produce the necessary accelerations with the available actuator system; and (2) the deflection of the base under internal pressure had to be kept very low, so that the applied shear stress would be uniform across the specimen. The design that best met the requirements of low mass and high rigidity for both base and lid was found to be an aluminum sandwich structure made up of a filler of 'Hexcel' aluminum foll honeycomb between aluminum facing plates, bonded together with structural epoxy. Side pieces were made from aluminum channels. Sections through the table are shown in Figs. 2.3 and 2.4. Des1gn deflections of the lid and base were limited to $0.07^{\prime \prime}$ and $0.03^{\prime \prime}$ respectively at 50 psi internal pressure; however, In the first test series it was found that even these low base deflections were unacceptable; premature liquefaction was observed which could be attributed to stress concentrations caused by the specimen deflectIng away from the ballast as it followed the base deflection, thus causing the ballast to ride on the edges of the specimen. The base was therefore redesigned with an additional floating base plate proposed by C. K. Chan; this base plate is shown in the sections of Figs. 2.3 and 2.4. The principle was simply to communicate the specimen chamber with another chamber under the base plate, so that internal pressures would be equal on both sides of the plate. This deslgn proved highly successful in practice; base 
deflections could be held to less than $0.001 "$. It should be noted that the upper surface of the base plate, in contact with the specimen, was covered with a layer of sand set in epoxy to provide a rough contact surface.

Finally, it should be pointed out that during pressure tests of the chamber, some signs of distress were observed at 30 ps 1 internal pressure, perhaps due to an imperfect bond between the facing plates and the cores of the composite structures; it was therefore decided that operating pressures should be limited to 25 psi, especially in view of the fact that many cycles of loading and unloading were foreseen.

\section{Instrumentation}

The most difficult problem of measurement in the shaking table tests was to establish when liquefaction, defined in terms of intolerably large shear strains, actually took place. Pore pressure measurements alone would not provide this information, as even when the dynamically induced pore pressure reached the value of the initial effective normal stress, it was possible that in the case of dense specimens, only very small strains would occur, followed by a dilation tendency that would produce an increase in effective stress and a mobilization of shearing resistance. Accordingly, together with pore pressure sensors, various devices

for measuring shear deformations in the specimen were installed:

1. Horlzontal Displacements. Two spring-loaded LVDT's of \pm 1 " stroke were Installed at one end of the chamber to measure 
the displacement of the ballast, as shown in F1g. 2.5. The usual procedure was to set one on a very sensitive scale, in order to measure cyclic displacements before liquefaction, and the other on a coarser scale to measure the larger post-1iquefaction displacements. These measurements were used to obtain average strain values for the specimen, as described in Chapter III.

2. Vertical Displacements. Two model footings were installed in each specimen to study the development of large shear deformations. These footings, which measured $2 "$ by $2 "$, were designed so that they could be loaded to bearing pressures of up to 50 psi. Fig. 2.6 shows the footing loading device; an air piston applied the required load to the footing plate by a cable and rod system led through the chamber base. The vertical displacement of the footing plate during the test was measured by recording the piston displacement with an LVDT, as shown.

Vertical displacement of the ballast was recorded with an LVDT installed in the chamber lid, F1g. 2.5, with its sliding core resting on a magnetized plate placed over the upper membrane and adhering to the ballast shot.

3. Accelerations. Besides the MTS servo-accelerometer which measured and controlled the table acceleration, two miniature accelerometers were buried inside the specimen, and another was fixed on the ballast, with the idea of obtaining horfzontal displacements by subtracting the signals of the miniature accelerometers from that of the table accelerometer, and performIng a double integration of the differential accelerations. 
Although theoretically attractive, this scheme proved impracticable, as the differential accelerations involved were of the same order as the noise in the accelerometers and recorders. Furthermore, the miniature accelerometers themselves proved to be very fragile, and had to be constantly recalibrated, so the acceleration values they provided were not always reliable.

4. Dynamic Pore Pressures. Pore pressure transducers were Installed in the base of the specimen chamber, placed as shown in Fig. 2.5. With this distribution, it was considered that a complete pattern of dynamic pore pressure distribution along the base would be obtained. In addition, two miniature pore pressure transducers were buried in the specimen, to study the vertical distribution of pore pressures during the tests. Fig. 2.5 shows the distribution of all the instruments described in the preceding paragraphs. The measurements obtained are presented in Chapter III, and instrument characteristics are 1isted in Appendix IV.

5. Saturation. In order to measure the degree of saturation of each specimen before testing it, a special device was installed for measuring Skempton's parameter $B=\frac{\Delta U}{\Delta \sigma_{3}}$. In this device, designed by $C$. K. Chan, both the chamber pressure increment, $\Delta \sigma_{3}$, and the corresponding pore pressure increment, $\Delta U$, were measured with the same transducer, thus avoiding errors due to differences in calibration of two transducers. The transducer was read with a digital voltmeter, permitting very accurate measurement of $B$. The same device was also used to set the chamber 
pressure and back pressure values, thus permitting precise

measurement of the initial effective pressure for each test. A plan of this instrument and details of B-value measurement are presented in Appendix III.

Recording the output of all the transducers described above, as well as the MrS ram displacement and the differential acceleration integrators, required a total of 18 channels. Three Sanborn strip-chart recorders, linked electrically so that all could be started simultaneously, were used for this purpose. 


\section{TESTING PROCEDURES AND BASIC RESURTS}

Th1s chapter presents the results of the shaking table program, together with a description of the sample preparation and saturation procedures and a discussion of the principal factors involved: material type, initial effective pressures, relative density values, and applied shear stresses.

\section{Material}

All tests described in this chapter were performed using Monterey number 0 sand, a commercially avallable washed and sleved beach sand. It is a uniform, medium sand composed basically of quartz and feldspar. The grain size distribution for this sand 1s shown in F1g. 3.1, and other characteristics are summarlzed in Table III.1. Its mechanical properties in static tests have been described by Lade (1972). A single batch of sand was used for all the tests. Fig. 3.2 shows that this sand is considered to be in the "most liquefiable solls" grain size range determined in the laboratory by Lee and Fitton (1968), and has a mean diameter close to that of the coarser sands that liquefied at Nilgata in the June 16, 1964, earthquake.

\section{Specimen Preparation}

All specimens were prepared by pluvial deposition, using the sand spreader system previously used by Silver and Seed (1969) and Pyke (1973); this consists essentially of a V-section sand 


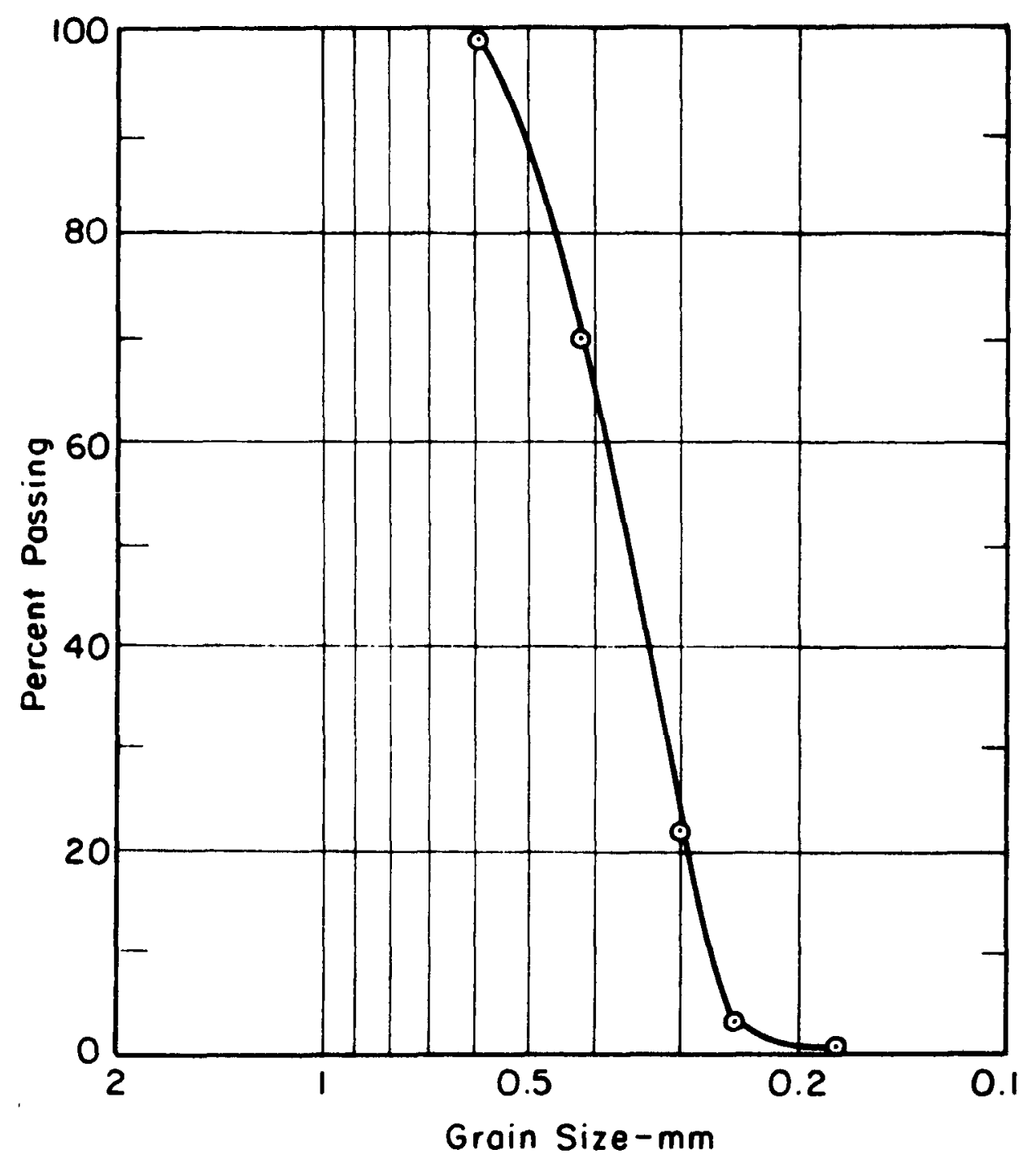

Fig. 3.I MONTEREY NO. O SAND, BATCH 3 
TABLE III.1

\section{SAND CHARACTERISTICS}

Monterey No. O Sand - Batch no. 3

$\begin{array}{lcc}\text { Mean Specific Gravity of Grains: } & 2.65 \\ \text { Maximum Density (ASTM D 2049-69): } & 105.7 \text { pcf } \\ \text { Minimum Density (Kolbuszewsk1, 1948): } & 89.3 \text { pcf } \\ \text { Maximum Void Ratio } & e_{\max }=0.564 \\ \text { Minimum Void Ratio } & e_{\min }=0.852 \\ \text { Mean Diameter } & D_{50}=0.36 \mathrm{sm} \\ & D_{60}=0.39 \mathrm{~mm} \\ & D_{10}=0.27 \mathrm{~mm} \\ \text { Coeffictent of Uniformity } & C_{u}=1.44\end{array}$




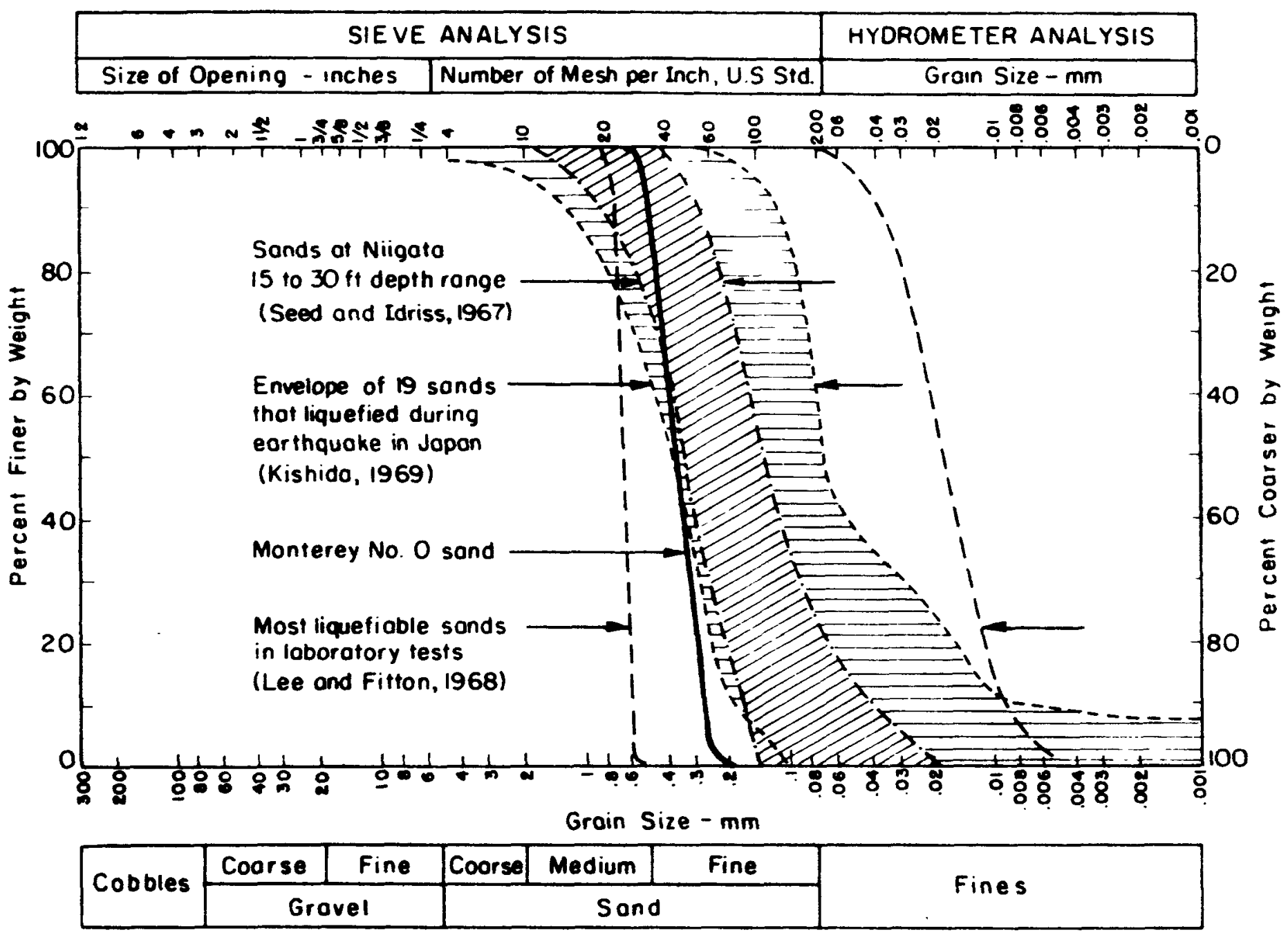

Fig. 3.2 SOILS SUSCEPTIBLE TO LIQUEFACTION 
hopper mounted on a self-propelled gantry moving at constant speed. The flow from the hopper is controlled hy a varlahlemaped roller, Fig. 3.3, which governs the intensity of the sand rain, and thus the density of the deposited layer, as established by Kolbuszewsk1 (1948).

In order to form the specimen, the base of the test chamber was first placed on stands to provide a better working height for subsequent trimming; 4" high aluminum side pieces were then bolted to the base to provide a form for deposition. The form was then filled by a series of passes of the spreader, with the roller speed set for the required density, depositing in one direction of movement only, Fig. 3.4. Walker and Whitaker (1967) have established that the deposition process using this system is relatively insensitive to the height of fall, which was malntalned constant and equal to $20^{\prime \prime}$ above the base during specimen formation.

Silver and Seed (1969) report uniform density along the length and breadth of specimens constructed using this deposition method; however, a basic question to be resolved was that of vertical uniformity of the resulting specimen. To study this question, a number of special tests were carried out with $2^{\prime \prime}$ spec1mens, the specimen forms in these tests being built up of $0.25^{\prime \prime}$ strips, so that $0.25^{\prime \prime}$ slices of the specimen could be trimed off, and their density determined from the known weight and dimensions. The results of these tests are shown in Fig. 3.5. It was concluded that vertical uniformity was satisfactory; the scatter of the points was small and within the accuracy with which it was possible to measure the density of each slice. 


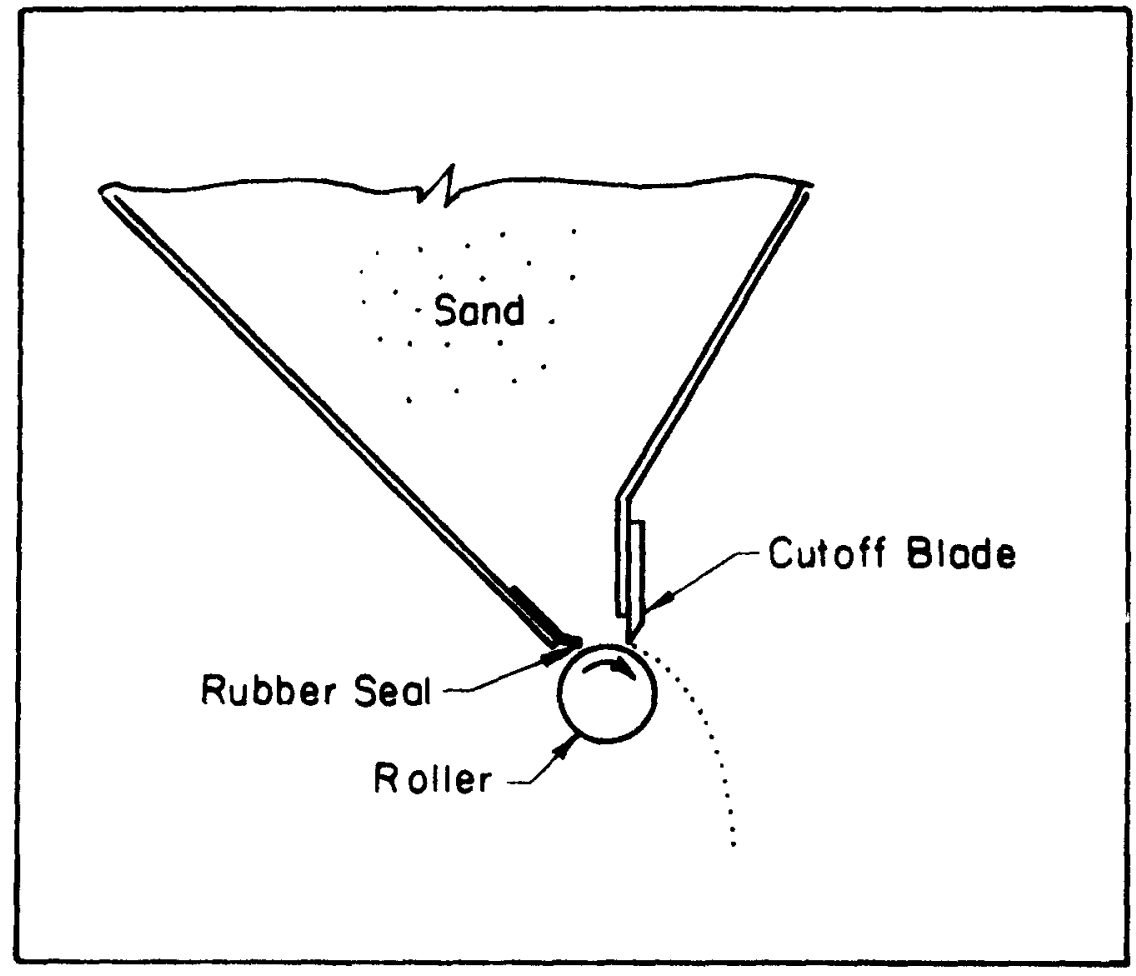

Fig. 3.3 SECTION OF SPREADER BOX 


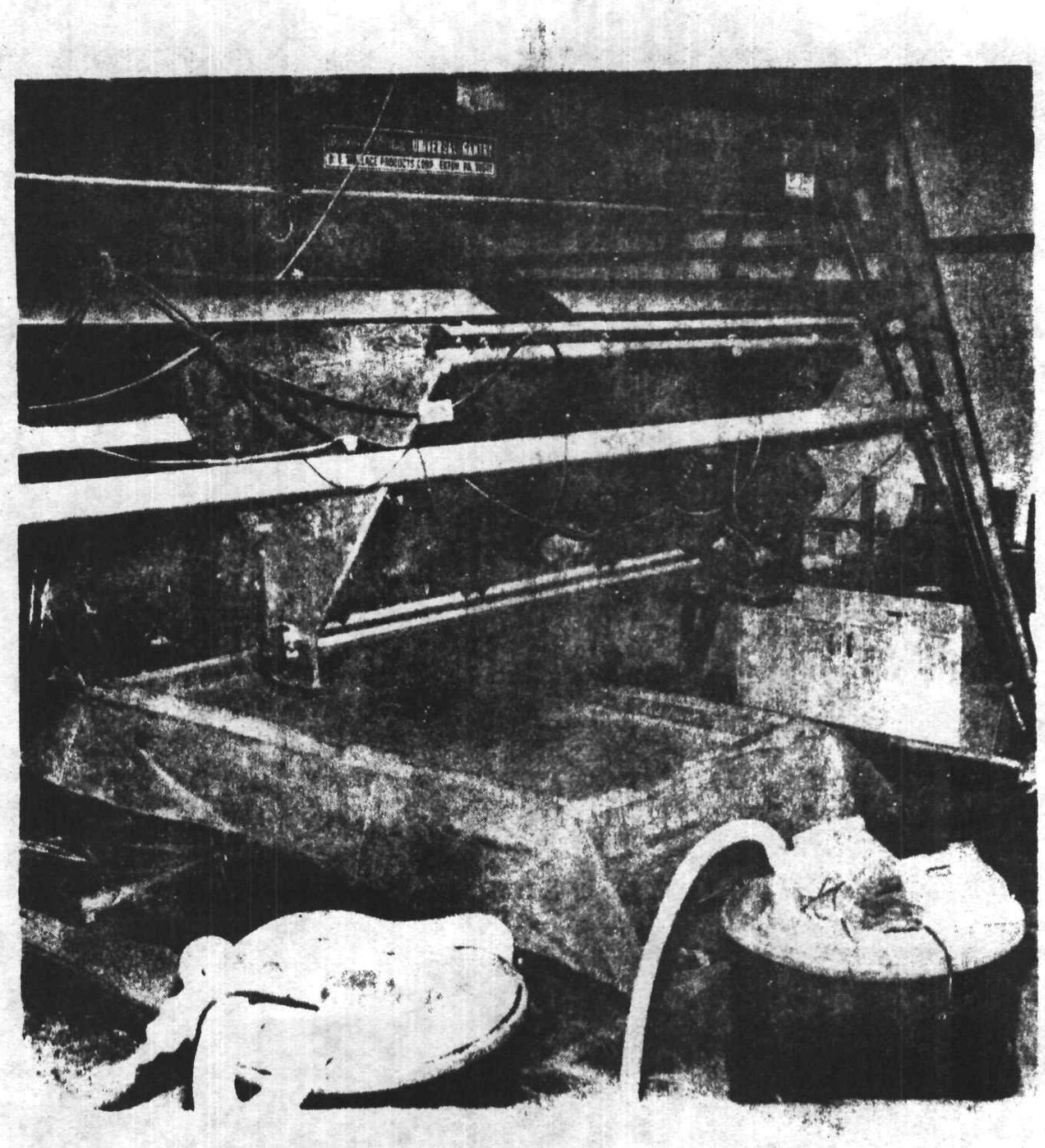

Fig. 3.4 SAND DEPOSITION USING SPREADER 


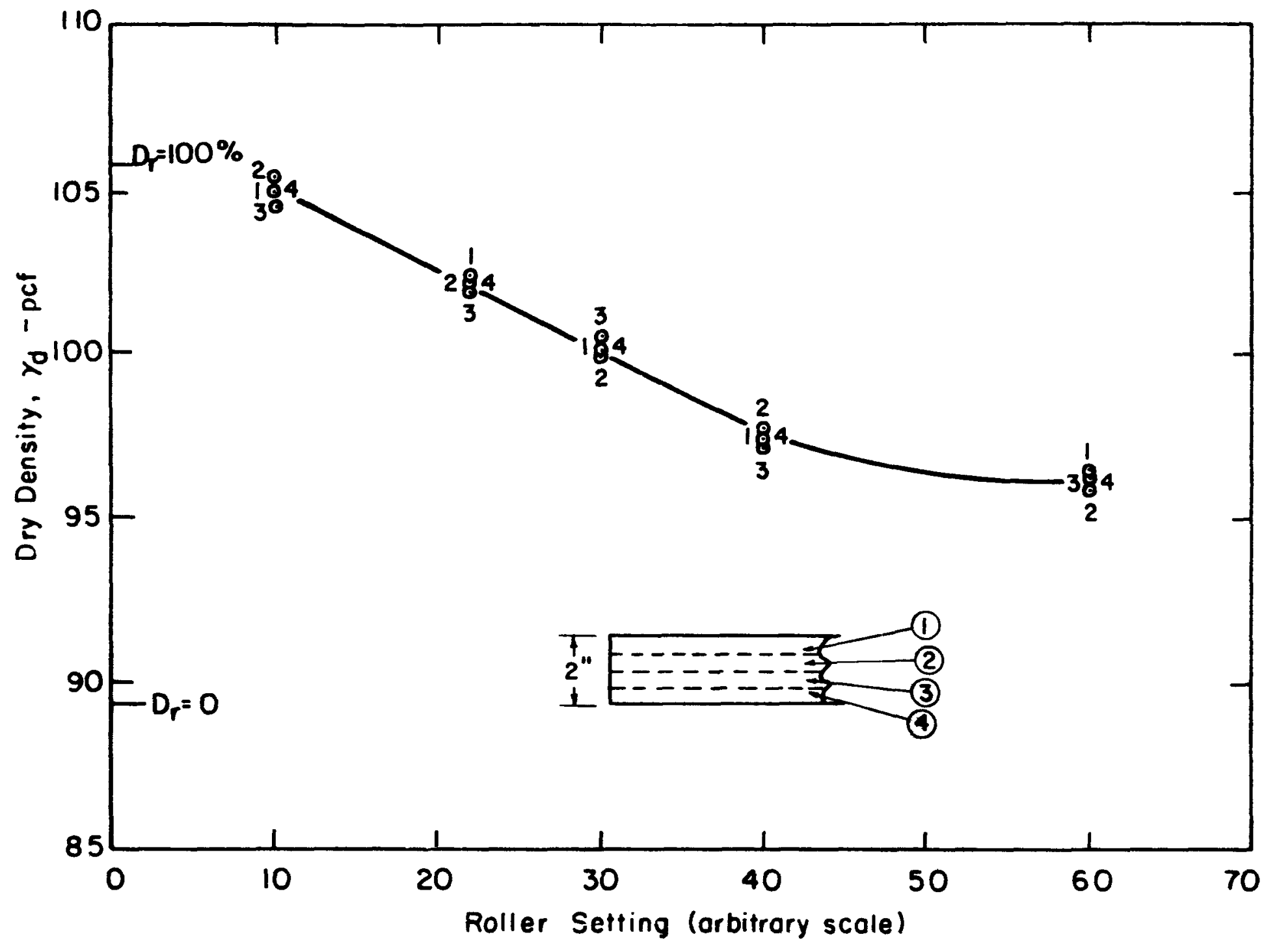

FIg. 3.5 VERTICAL DENSITY VARIATION 
In the normal rests, once the deposition process was completed, the top of the bed of sand was trimmed using a vuction system designed to cause minimum disturbance. This system io shown in operation in F18. 3.6: an aluminum blade resting on the edges of the form was drawn slowly over the top of the spectmen; sand grains trimmed off were drawn from the back of the blade by suction nozzles. The side slopes were formed uging a gimilax method, first excavating and then fring with inction blades travelling along the edges of the formin.?

Once the specimen was trimmed to its final shape, the lower membrane was clamped over it, F1g. 3.7, and a vacuum was applied to it with the dual purpose of confining the sample during final assembly and checking the membrane for leaks. Leakage was detected by connecting a bubble column on the vacuum ine.

Final assembly of the chamber consisted of placing the ballast on the specimen using the vacuum plate system described In Chapter II, FIg. 3.8; good contact was assured by spraying the rubber membrane with glue before placing the ballast; spacers on the ballast controlled its position so that $0.25^{\prime \prime}$ cushion of shot was formed between the rigid rim of the ballast. and the top of the specimen, thus avoiding stress concentrations at the rim. The TX-150 filler material was then placed on the slopes of the specimen around the ballast, Fig. 3.9, and this was covered by the upper membrane. Finally, the chamber sides and 1id were bolted onto the base, the vacuum removed, and air pressure introduced into the chamber. 


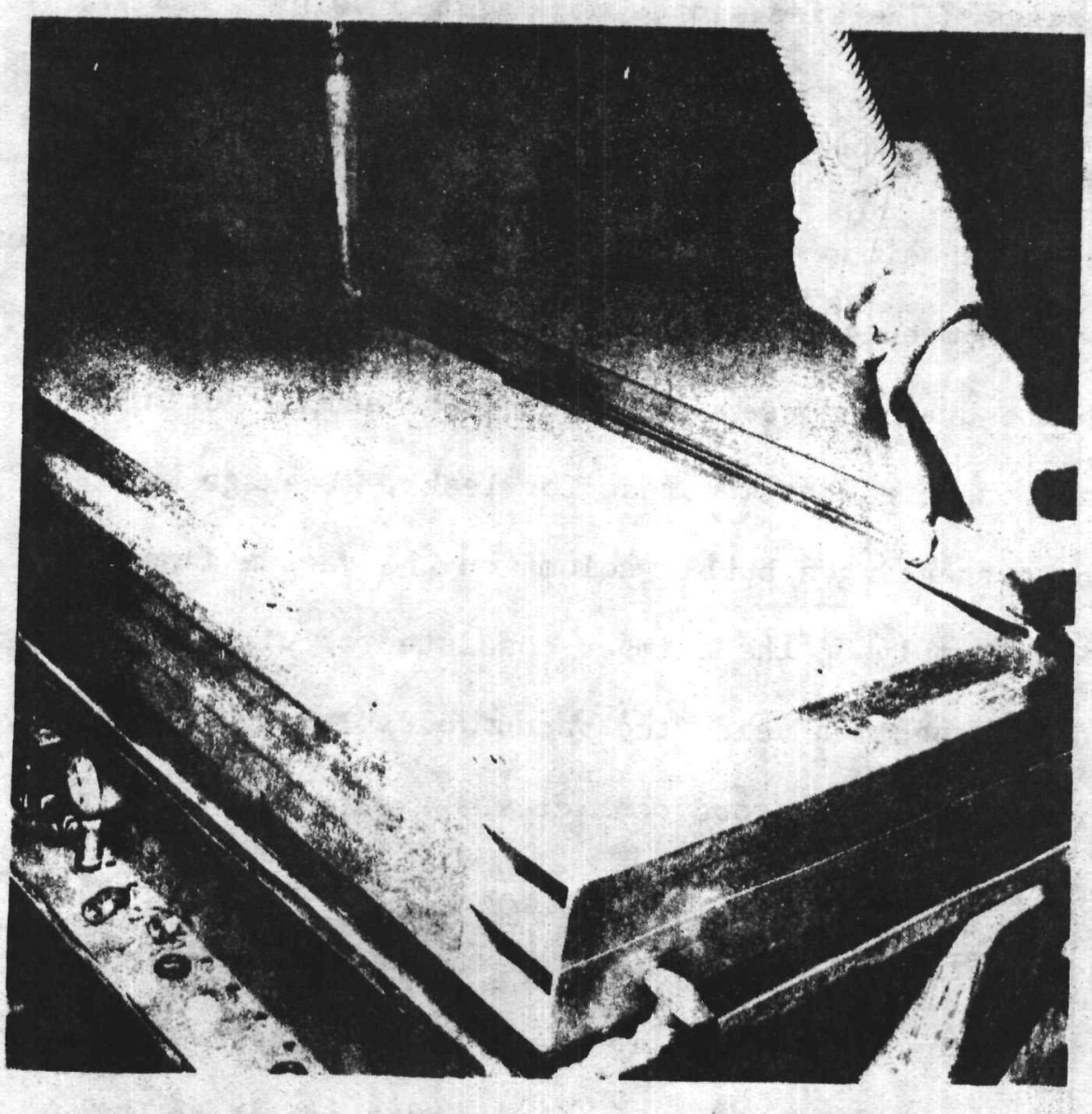

Fig. 3.6 TRIMMING THE SPECIMEN 


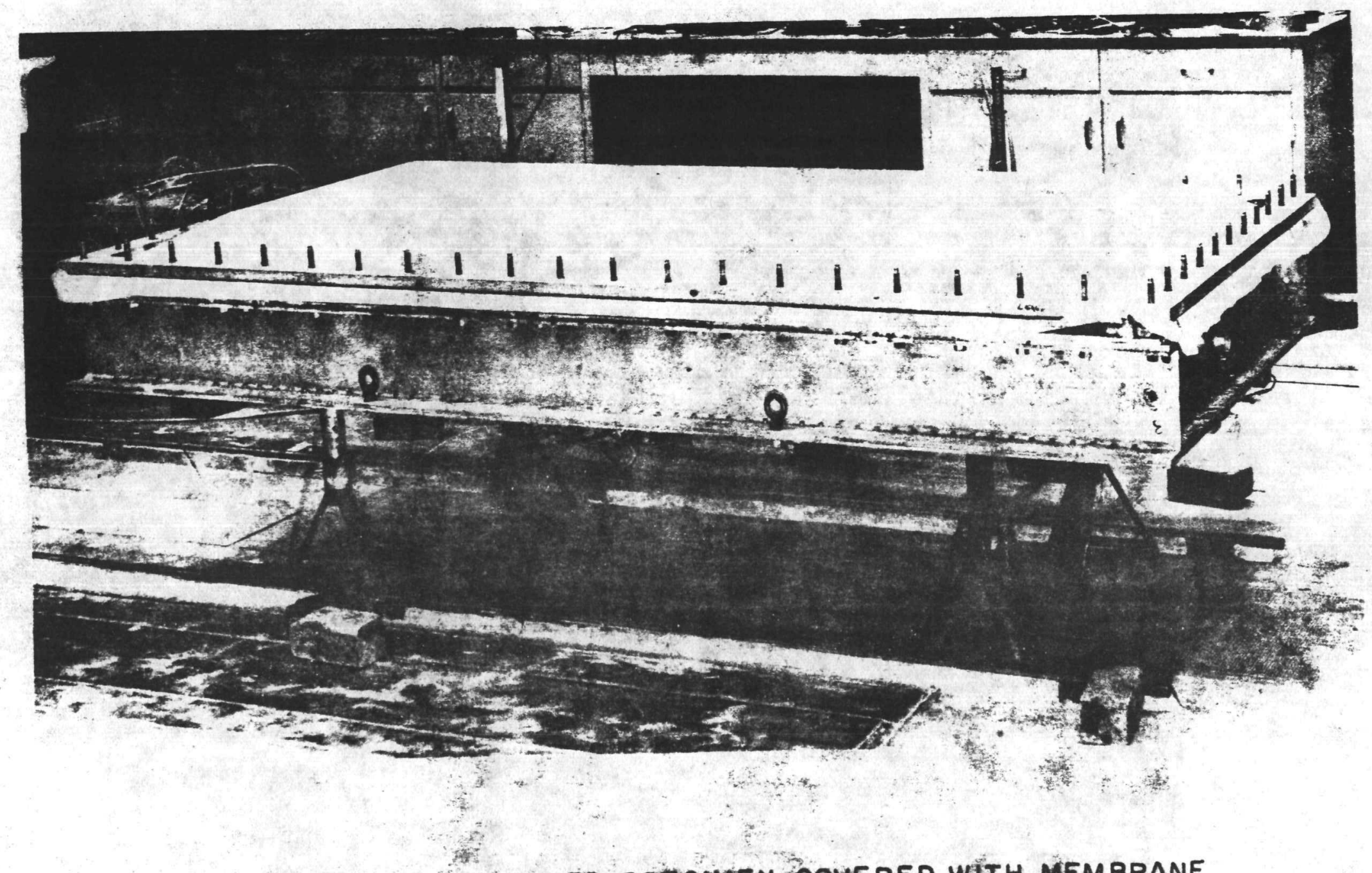

Fig. 3.7 FINISHED SPECIMEN COVERED WITH MEMBRANE 


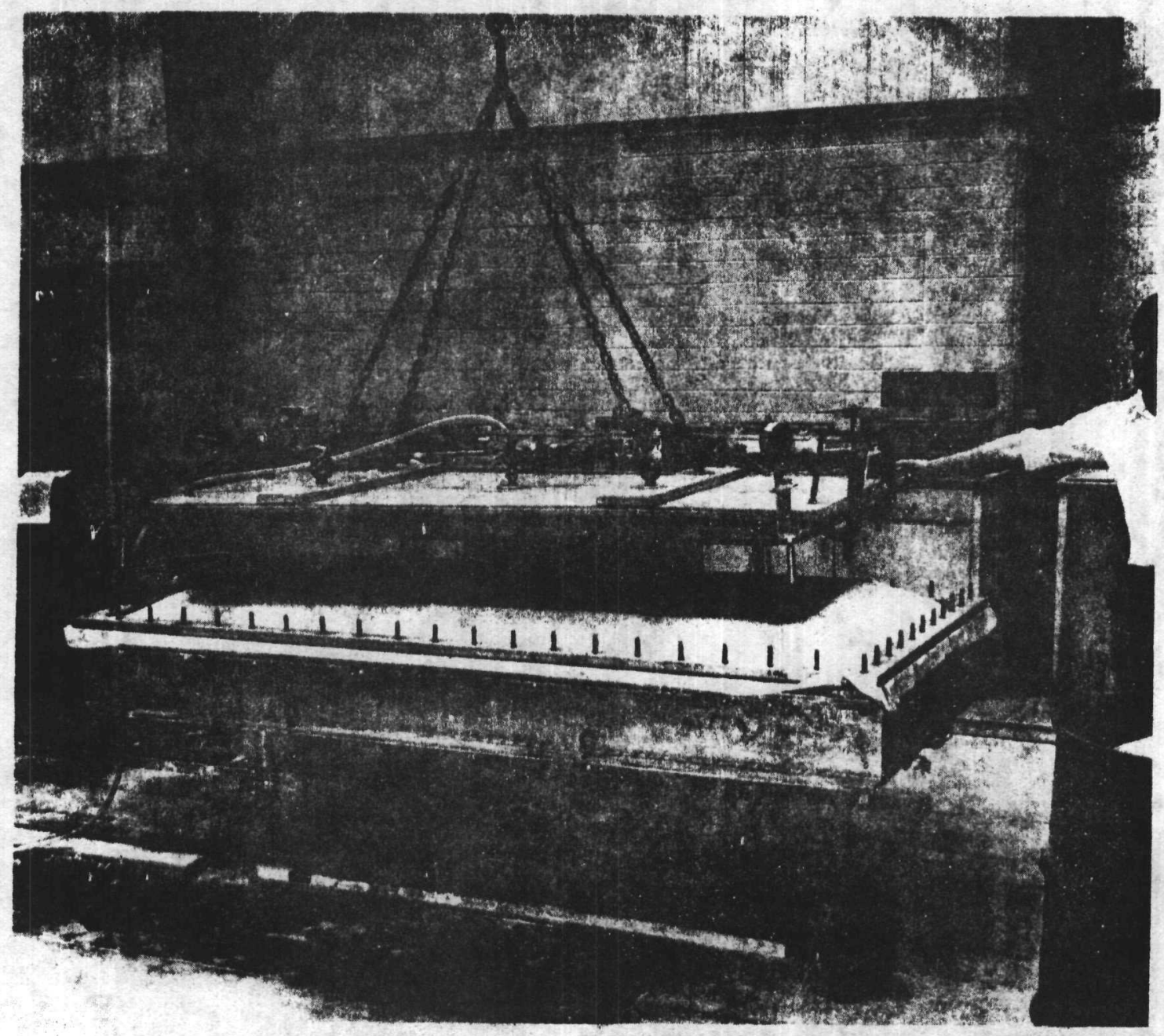

Fig. 3.8 PLACING THE BALLAST ON THE SPECIMEN 


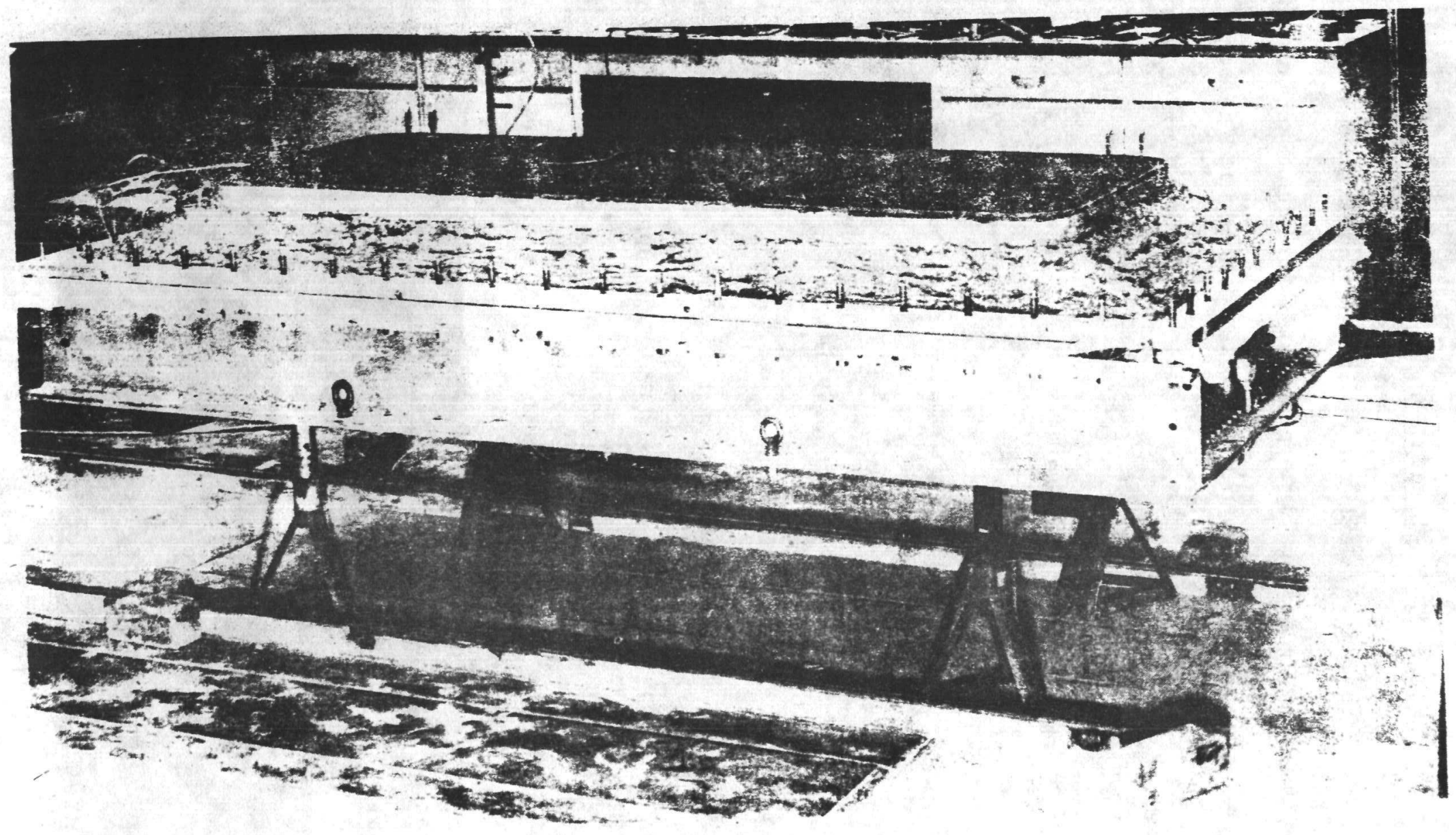

Fig. 3.9 SPECIMEN WITH BALLAST AND FILLER MATERIAL IN PLACE 


\section{Saturation}

Once the chamber was assembled, it was tipped so that the drainage valves were diagonally opposed at the highest and lowest points, Fig. 3.10, and the sand voids were flushed with carbon dioxide, introduced through the lower valve. Carbon dioxide was chosen because it is both heavier than air and considerably more soluble in water than air. The air in the volds was thus flushed out and replaced by carbon dioxide, which was more easily dissolved in water, thereby requiring smaller back pressures for saturation. An amount of gas equal at atmospheric pressure to approximately ten times the volume of voids in the sample was passed through it, after which deaired water was introduced into the specimen through the lower valve; water flow into the specimen was monitored with a bubble column attached to the upper valve as shown in Fig. 3.10; when bubbling ceased, the specimen was considered to be essentially saturated. It was then lowered into a horizontal position and put under back pressure. It was found that full saturation could be achieved using a back pressure of 10 psi applied for about four hours. The degree of saturation was checked in each test by measuring the value of Skempton's pore pressure coefficient, $B$; the details of B-value measurement are presented in Appendix III. B-values obtained ranged from 1.0 at 54 percent relative density to 0.96 at 90 percent relative density. These values were considered to Indicate full saturation, in view of the studies of Black and Lee (1973). All test results reported are from samples considered to have been completely saturated. 


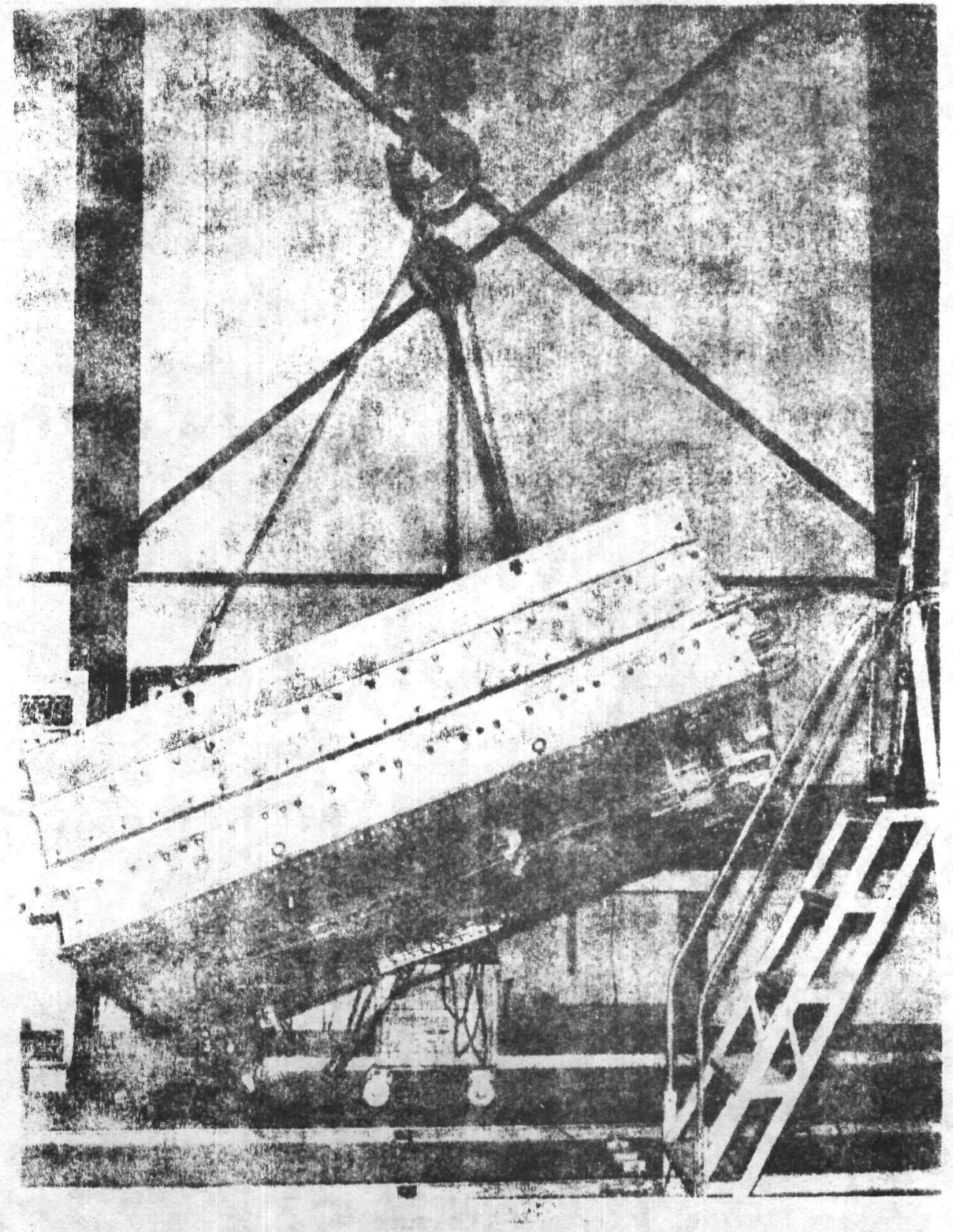

FIg. 3.10 CHAMBER IN POSITION FOR SPECIMEN SATURATION 


\section{Relative Densities}

Tests were carried out at four relative densities: 54 percent, 68 percent, 82 percent, and 90 percent. These values take into account the increase in density due to the application of confining pressure after specimen formation. The necessary corrections were obtained from a series of special tests, in which dry specimens at different placement densities were poured and trimmed in the usual way, but then covered with a single membrane and placed under an increasing vacuum, while the vertical deformation of the specimens was measured with dial guages. It was then possible to obtain, for each test, the final density as a function of placement density and final effective pressure.

It will be noted that the number of satisfactory tests decreases as the relative density increases. High-density tests proved far more difficult and time consuming, both in terms of sample preparation and testing, requiring much longer pouring times and a slower rate of trimming to avoid loosening the upper trimmed surface in contact with the ballast. Difficulties were also encountered in generating an acceptable sinusoldal acceleration signal for the required high levels of shear stress.

\section{Initial Effective Pressure}

With two exceptions, the tests under discussion were performed at initial effective pressures on the order of 8 psi, representing an element of soil at a depth of roughly 20 feet below a ground surface water table. The two exceptions were tests conducted to check the effects of the ballast on the test results, 
as explained in subsequent sections. These tests were run without the ballast and at an Initial effective stress on the order of $4 \mathrm{psi}$, in order to obtain ratios of shear stress to initial effective stress comparable to those of the 8 psi tests.

For all tests, effective pressure vaiues were obtalned by measuring the difference between chamber air pressure and back pressure with the B-value measuring device described in Chapter II and Appendix III.

\section{Cyclic Shear Stress}

As described in Chapter II, horizontal cyclic shear stresses were induced in the specimen by the inertia forces resulting from cyclic horizontal table accelerations. A sinusoidal acceleration signal was chosen, as it was considered that a specific earthquake record would limit the tests to a special case, while actual earthquake records coild always be reduced to equivalent sinusoidal waves. A constant cyclic shear stress pattern was thus produced in the specimen during the test by the inertia forces obtained from accelerating specimen and ballast. The maximum shear stress value occurred at the bottom of the specimen, and was calculated as follows: Considering a column of sand of unit cross-sectional area,

$$
\tau_{\max }=\frac{\gamma_{s} \times h_{s}+w_{b}}{g} A_{\max }
$$

\footnotetext{
$h_{8}=$ sample height

$\gamma_{s}=$ saturated unft weight of sand

$w_{b}=$ ballast deadweight pressure
} 


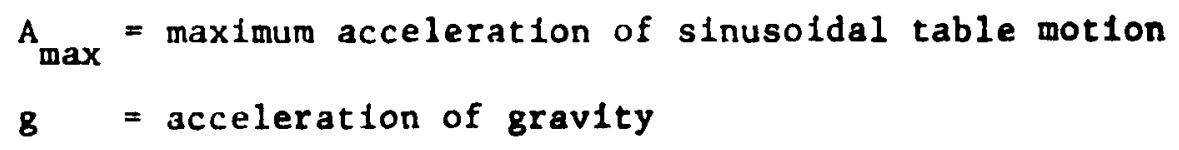

All shear stress values reported have been calculated using this expression.

\section{$\underline{\text { Results }}$}

Pore Pressure and Shear Strains. A typical pore pressure transducer record is shown in Fig. 3.11: the various traces show the response of pore pressure transducers in the base and buried in the specimen, distributed as shown in Fig. 2.5, Chapter II. This record shows that dynamically induced pore pressure built up in all sections of the specimen and became equal to the initial effective pressure simultaneously at all measuring points in the base and in the body of the specimen. It was then considered that initial liquefaction, as defined in Chapter I, had occurred. Also shown in the figure is the sudden increase in displacement between chamber and ballast, and thus in average specimen shear strain, which occurs as soon as this stage is reached.

The pore pressure records show that a cyclic pressure variation in addition to that caused by the cyclic stress application was registered at those transducers off the center line of the specimen, increasing in amplitude with increasing distance from the center. It was first thought that this might be caused by ballast rocking, and speclal tests were run without the ballast to check this posstbility. However, the same behavior was observed in these tests, and it was concluded that an effect analogous to 


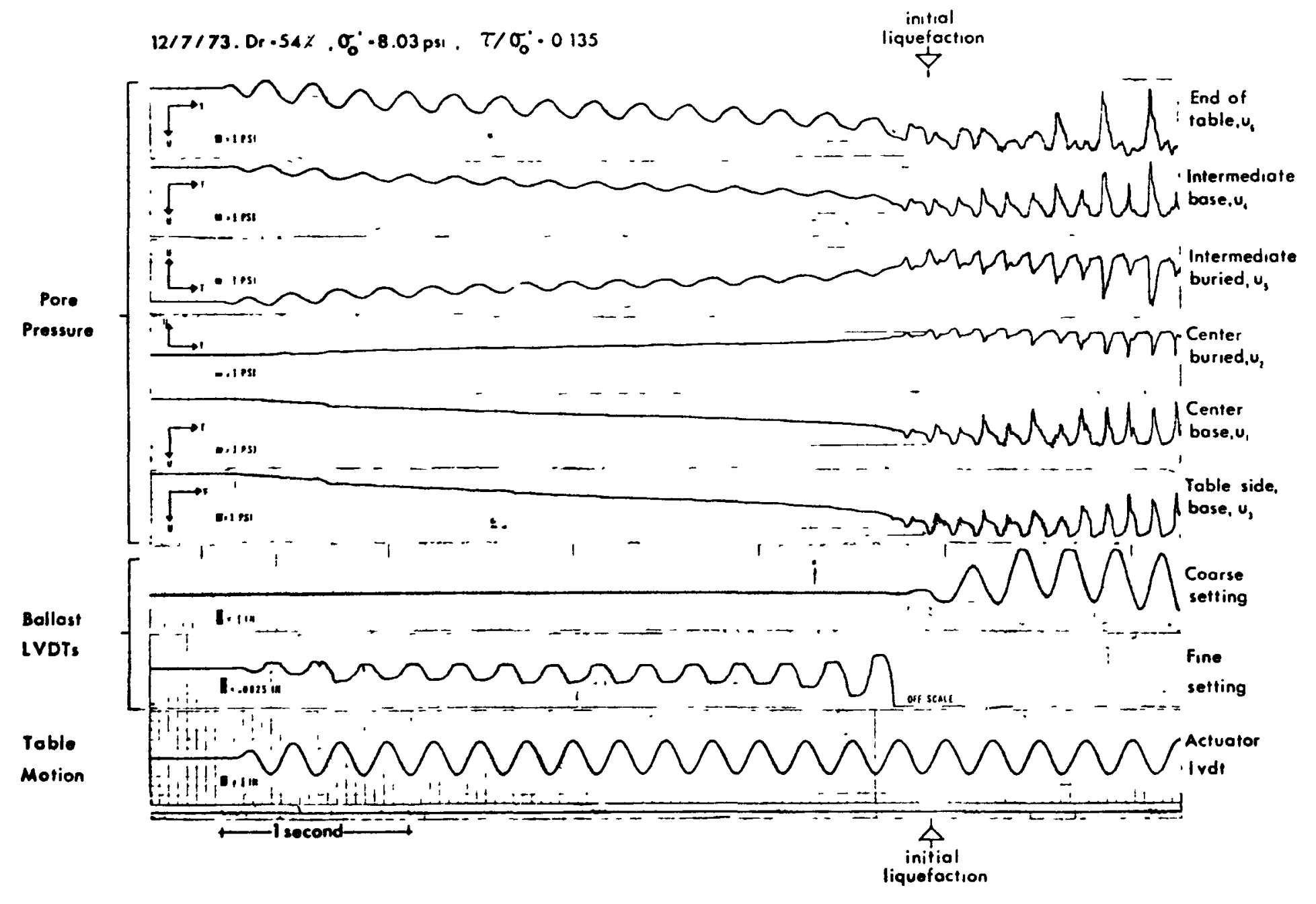

Fig $3 \|$ TYPICAL TEST RECORDS 
a standing wave was produced in the pore water as the sample was accelerated back and forth. This effect was not considered to significant 1 y affect liquefaction development, as it was very small within the free field, as may be seen in the traces of pore pressure transducers $U_{1}, U_{2}$, and $U_{3}$ of $\mathrm{Fig}$. 3.11. This figure a] so shows that dynamic pore pressure development within the free field may be adequately represented by the record of the center base transducer, $U_{1}$. Therefore, the following discussion will present the measurements obtained from this transducer as representative of the specimen. Figs. $3.12,3.13$, and 3.14 show the development of pore pressure with increasing numbers of stress cycles up to the point of initial liquefaction, and the maximum registered pressures after liquefaction in each test; as will be discussed in the following paragraphs, during parts of each post-liquefaction stress cycle, the pore pressure dropped considerably below the maximum values shown. Minimum pressures are omitted from the figures for clarity, but the complete individual pore pressure records are shown in Appendix II. It should be noted that the $\frac{T}{\sigma_{0}^{j}}$ values listed in the figures have been corrected by the procedure outlined in Chapter IV.

After initial liquefaction was reached in the tests in specimens with relative densities higher than 54 percent, the dynamically induced pore pressure varied as shown in Fig. 3.15(A), equalling the initial effective pressure during parts of each stress cycle, and decreasing considerably at other times in the cycle, as the sand tended to dilate. Figs. 3.15(A) and (B) show a typical relationship between table displacement and pore 


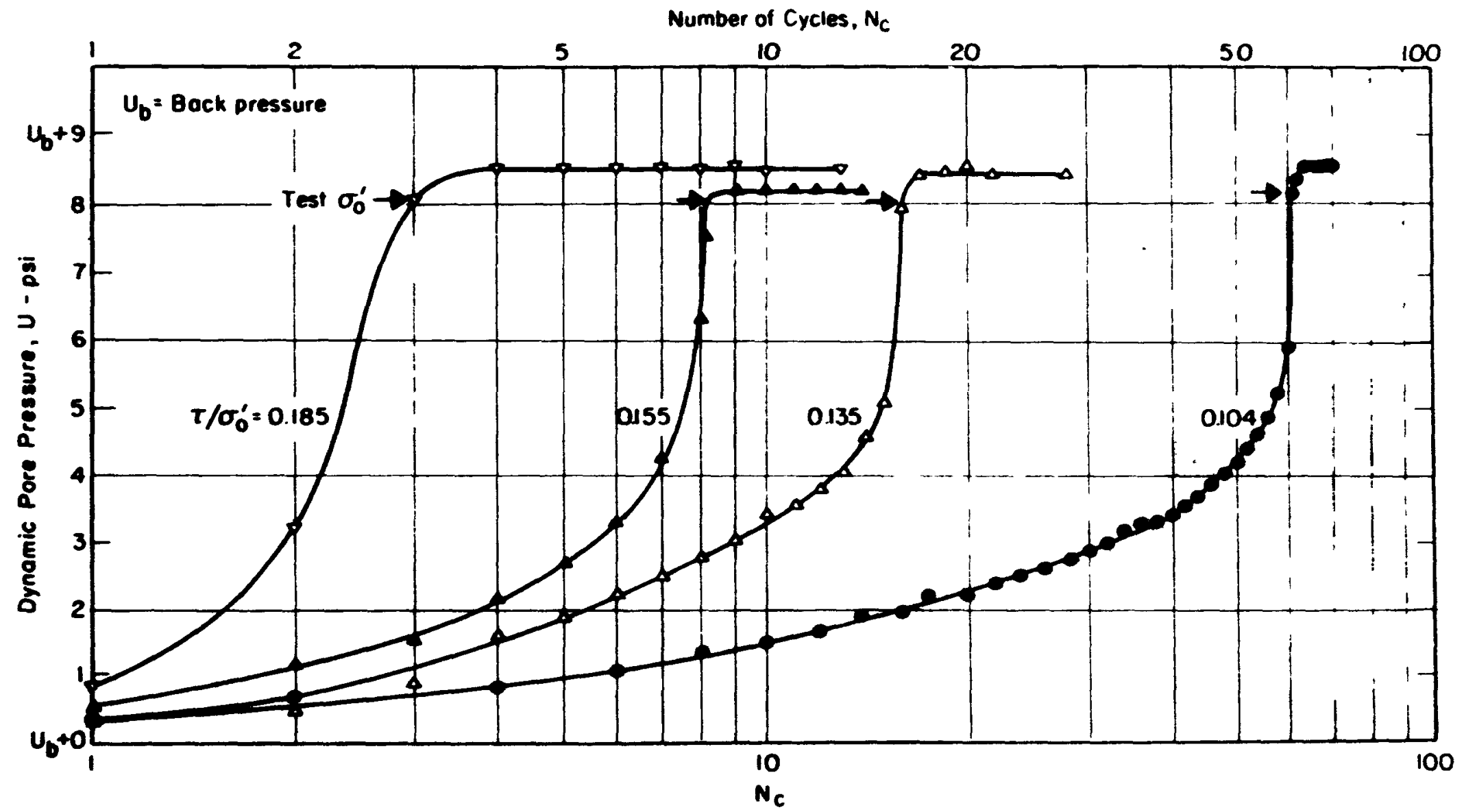

Fig. 3.12 DYNAMIC PORE PRESSURE DEVELOPMENT, RELATIVE DENSITY $=54 \%$ 


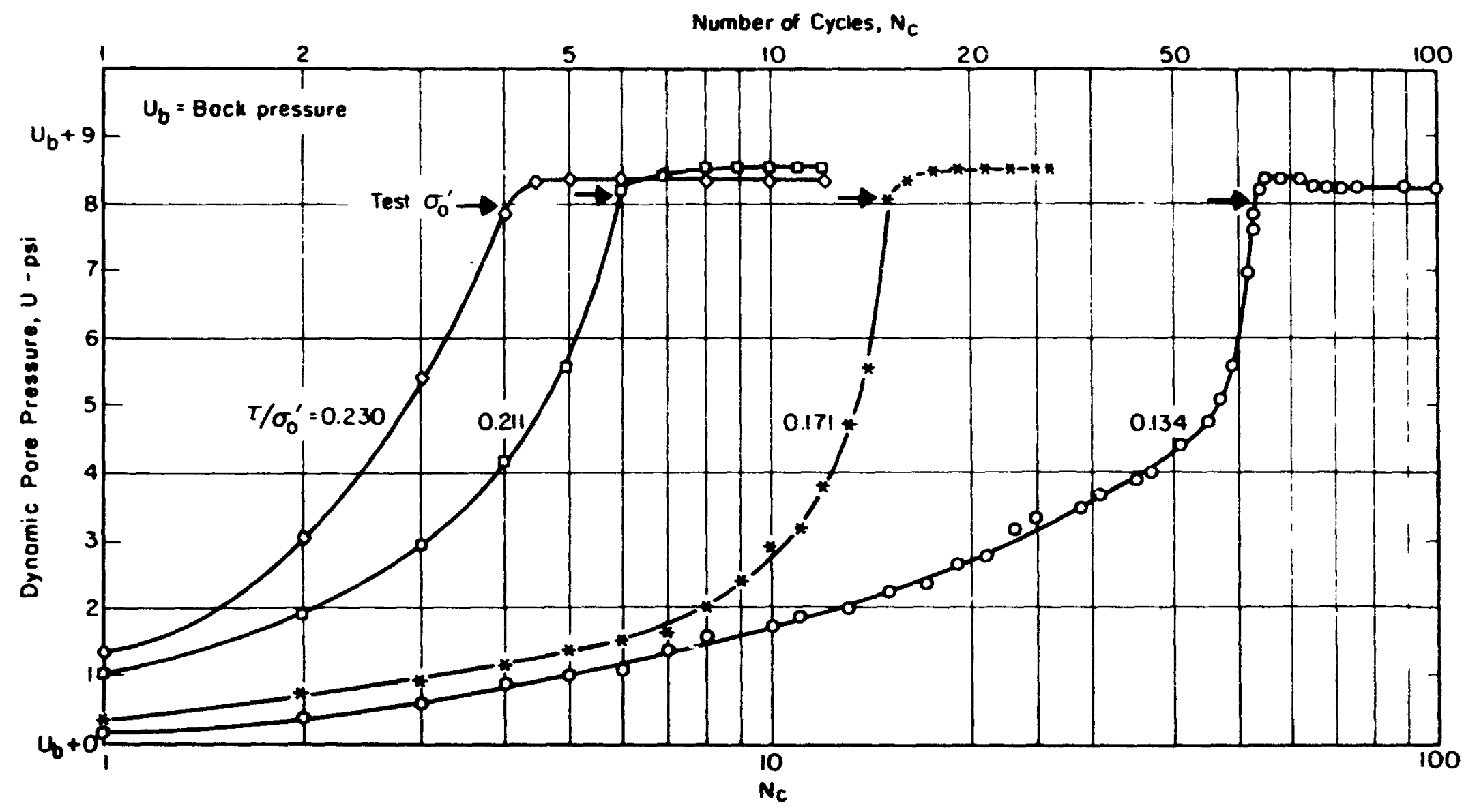

Fig. 3.13 OYNAMIC PORE PRESSURE DEVELOPMENT, RELATIVE DENSITY $=68 \%$ 


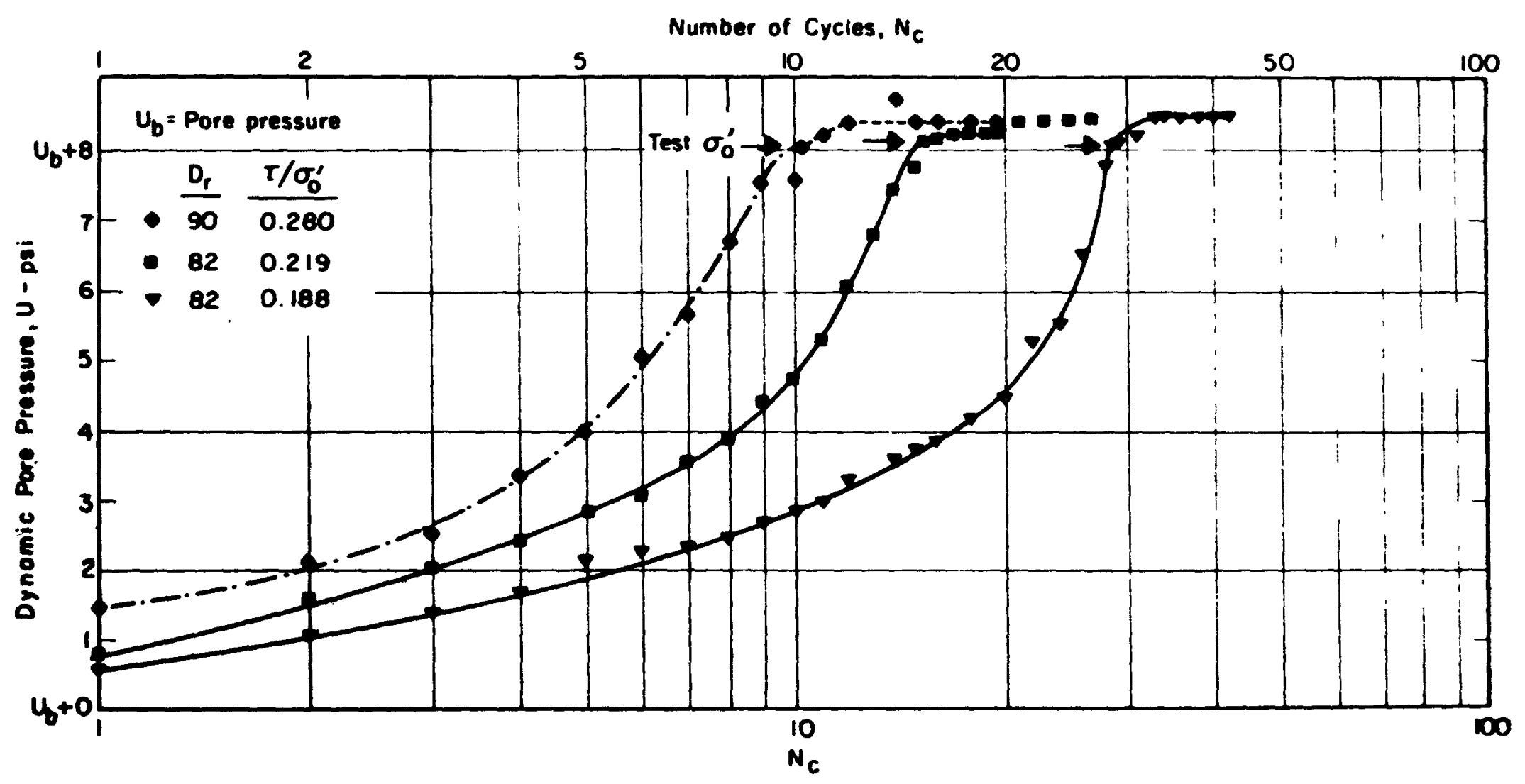

Fig. 3.14 DYNAMIC PORE PRESSURE DEVELOPMENT, RELATIVE DENSITY $=82$ AND $90 \%$ 


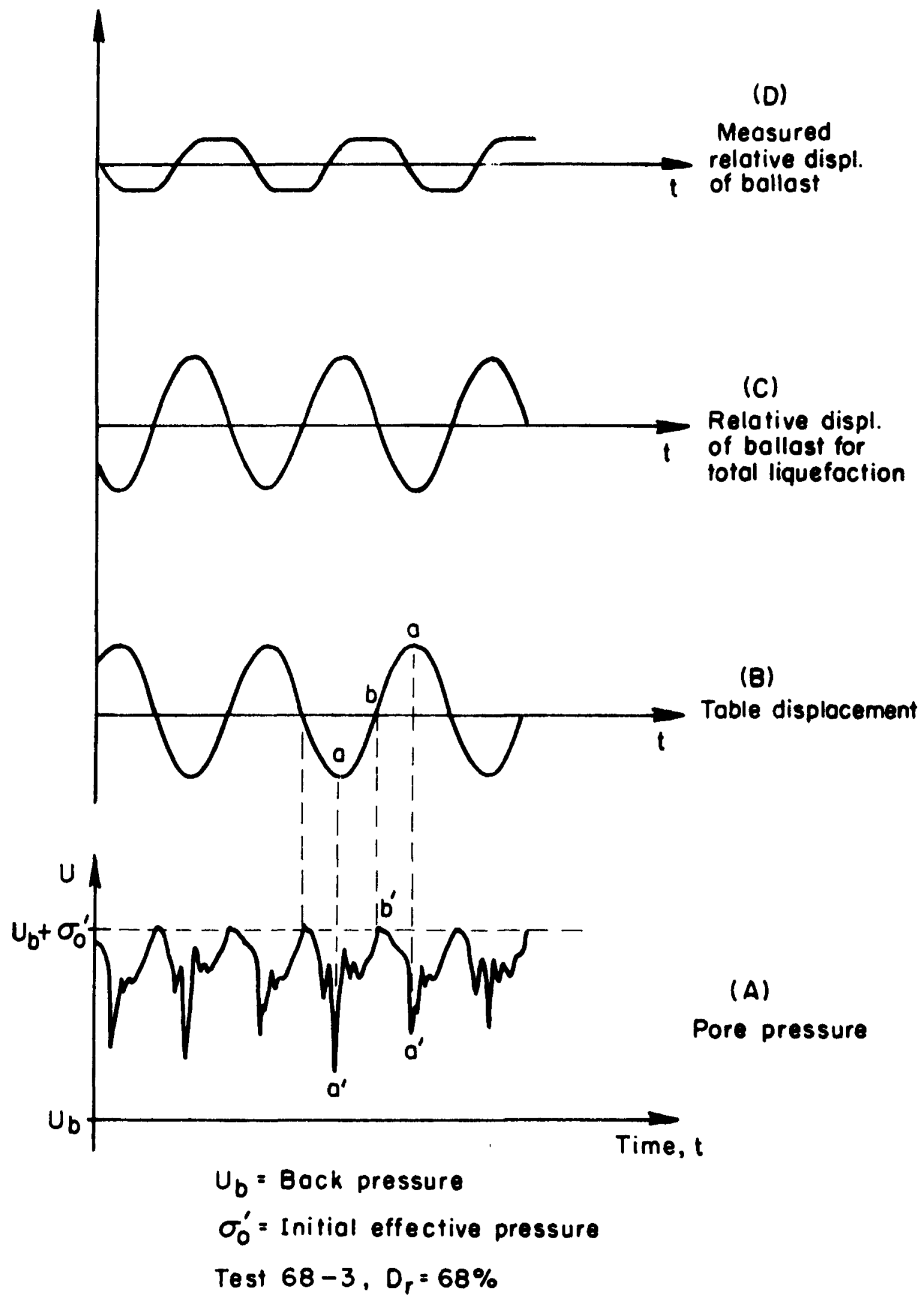

Fig. 3.15 SPECIMEN BEHAVIOR AFTER LIQUEFACTION 
pressure: at point (a), as the table reached the end of 1 to displacement stroke, the greatest tendency to dilate was induced in the specimen, and thus the lowest pore pressure, point (a'). As the table returned to the midpoint of the stroke at point (b), the pore pressure again became equal to the Initial effective pressure, overshot a small amount, point ( $\left.b^{\prime}\right)$, and then decreased agaln as the other end of the stroke was reached, returning to condition (a) - (a'). Thus the tendency of the sand to dilate 11mited the maximum shear strain that could occur in the specimen, and complete Iiquefaction, i.e., complete loss of shearing resistance, did not occur in the density range investigated. If this had occurred, the record of the ballast LVDT's would have resembled that shown in Fig. $3.15(C)$; the ballast would have remained stationary, "floating" on the completely 11quefled sand as the table moved underneath. The observed form of the relative displacenent of the ballast with respect to the specimen as measured by the ballast LVDT's, is shown in Fig. 3.15(D), to the same scale, for a test at 68 percent relative density. It is related to table displacement and pore pressure variation as shown in F18. 3.16. At point (c), the dynamically induced pore pressure became equal to the intital effective confining pressure, and relative motion between table and ballast began. This relative motion continued until the shear strain in the sand was sufficient to produce a strong tendency for dilation and a corresponding decrease in pore pressure, point ( $\left.d^{\prime}\right)$. At that point, the maximum relative displacement, and thus the maximum average shear strain, was reached, point (d). As a result of the reduction in pore pressure, the 


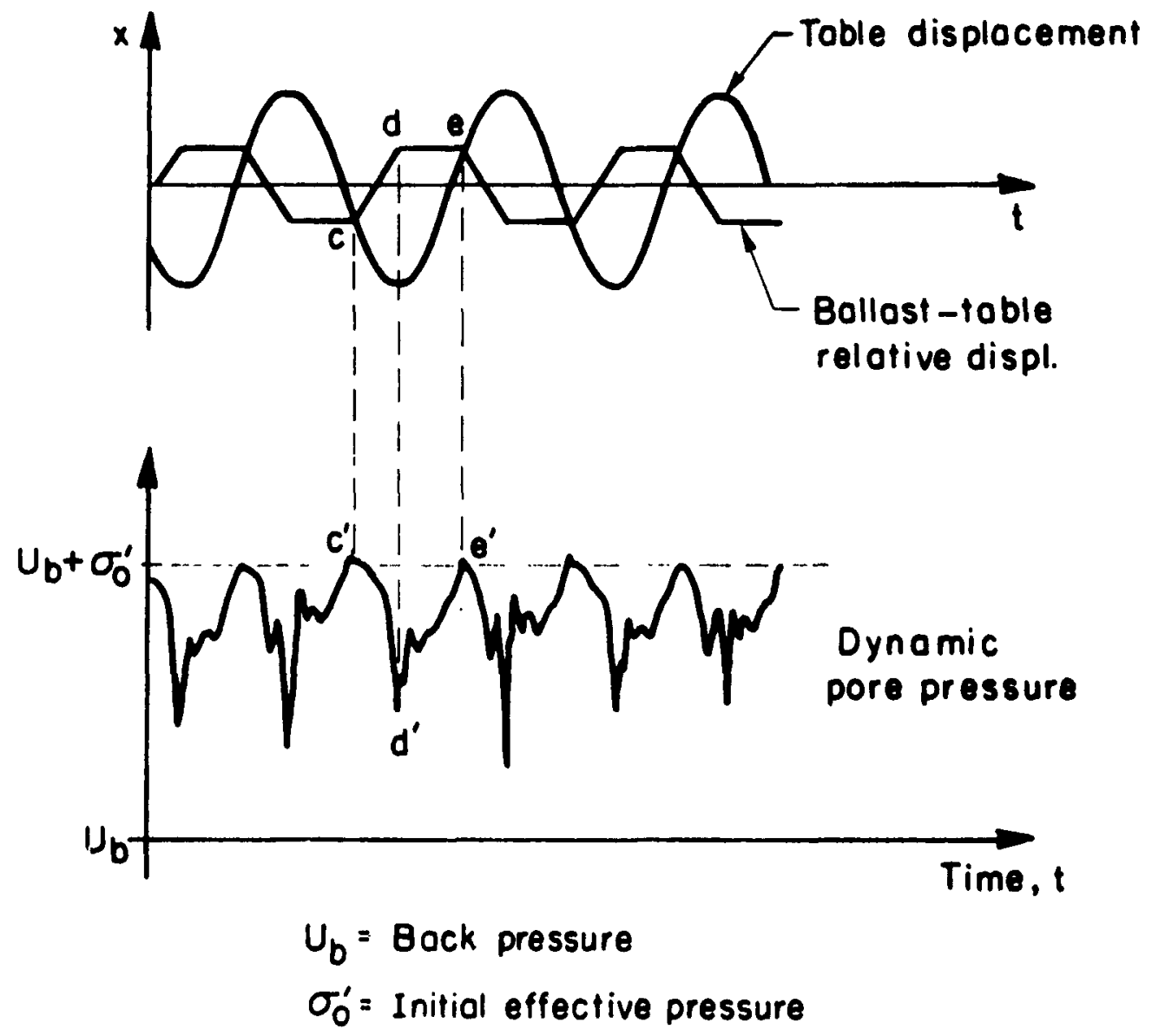

Fig. 3.16 SPECIMEN BEHAVIOR AFTER LIQUEFACTION 
specimen acquired strength, and no further movement took place until point (e), when the pore pressure once more equalled the Initial effective pressure, point $\left(e^{\prime}\right)$, and the reverse part of the strain cycle began.

From the measured relative displacements of the ballast with respect to the table, average specimen shear strains were approximated as:

$$
\gamma \doteq \frac{\Delta}{2 h}
$$

where: $\Delta=$ peak to peak amplitude of the relative displacement $\mathrm{h}=$ specimen height.

Plots showing the increase in average shear strains with increasing numbers of stress cycles in each of the tests are shown in Figs. 3.17 to 3.23 ; separate plots are presented for the small strains developed prior to liquefaction and for the much larger strains following liquefaction. The $\frac{\tau}{\sigma_{0}^{\prime}}$ values shown on these figures have been corrected following the procedure outlined in Chapter IV.

With regard to the pre-1iquefaction strains, a notable feature is the sharp increase in strain rate that occurs when the dynamically induced pore pressure reaches a value of about 50 percent of the initial effective pressure. The same effect was noted In all tests in which the pre-1iquefaction strains could be clearly plotted; that 18, tests running over seven to eight cycles. Post-1iquefaction strains are shown for only seven tests, since in the early stages of the testing program, only pre11quefaction strains were measured, and in other tests results vere lost due to instrument fallures. 


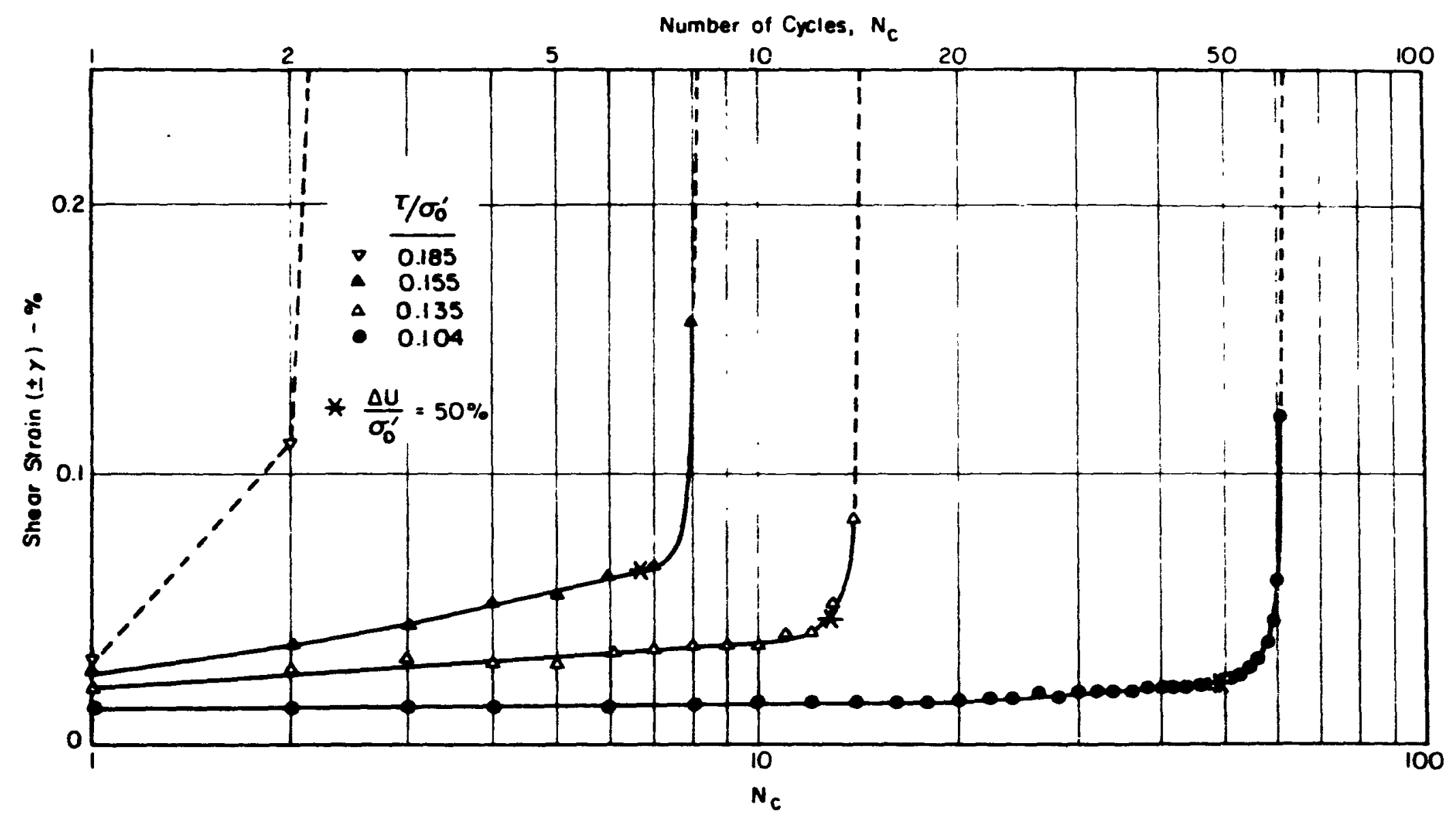

Fig. 3.17 SHEAR STRAIN DEVELOPMENT, RELATIVE DENSITY $=54 \%$ 


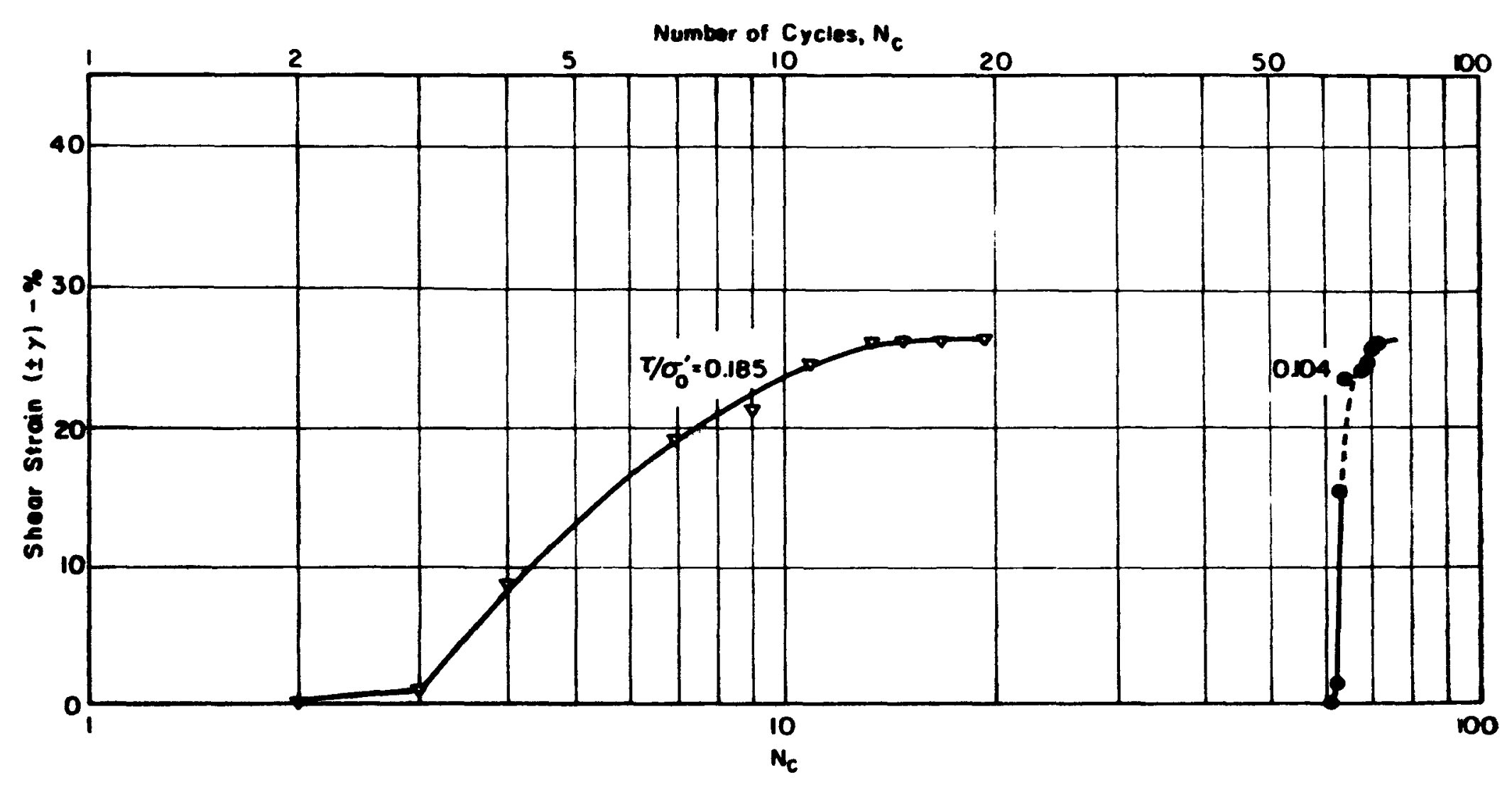

Fig. 3.18 SHEAR STRAIN DEVELOPMENT, RELATIVE DENSITY $=54 \%$ 


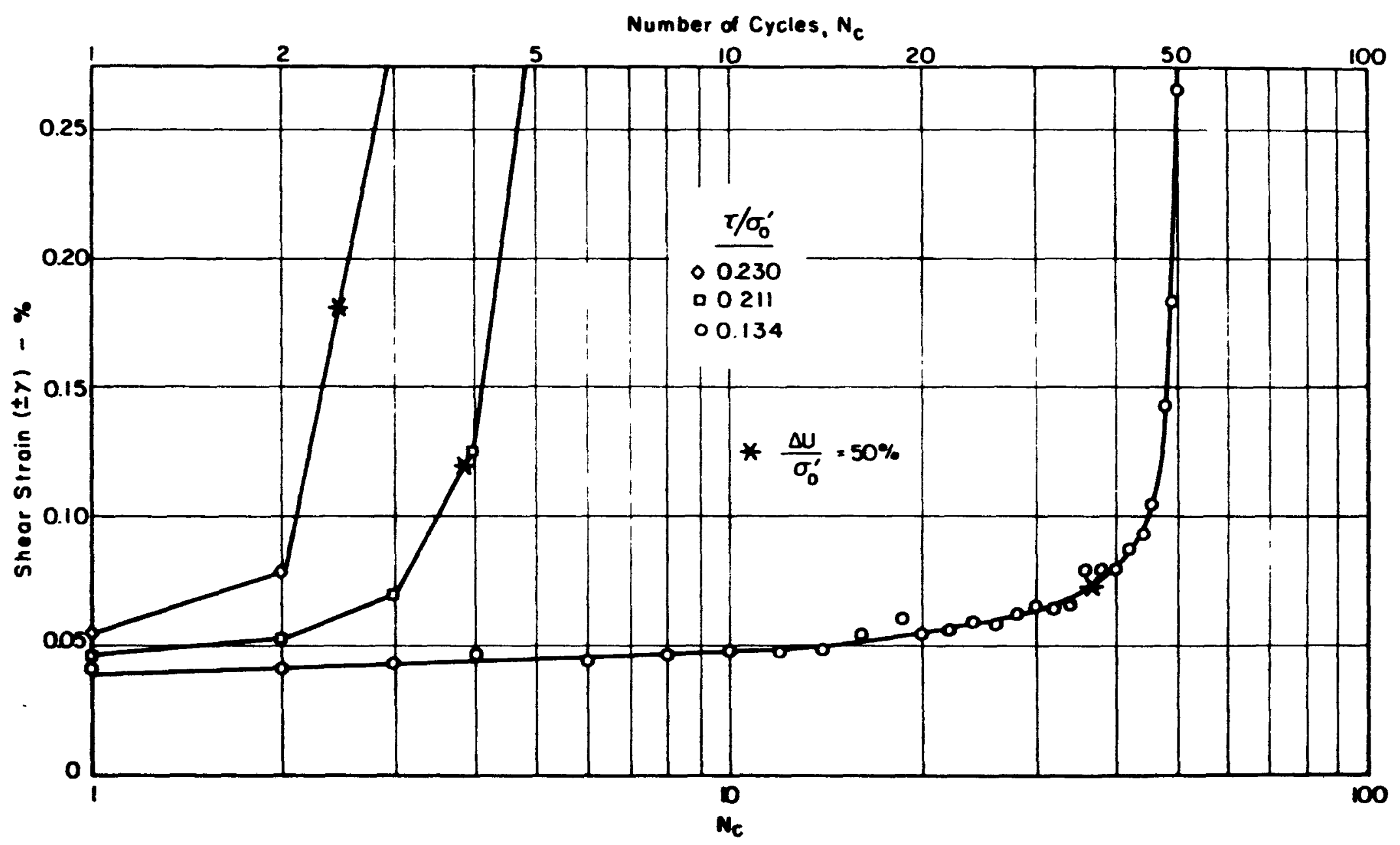

Fiq. 3.19 SHEAR STRAIN DEVELOPMENT, RELATIVE DENSITY $=68 \%$ 


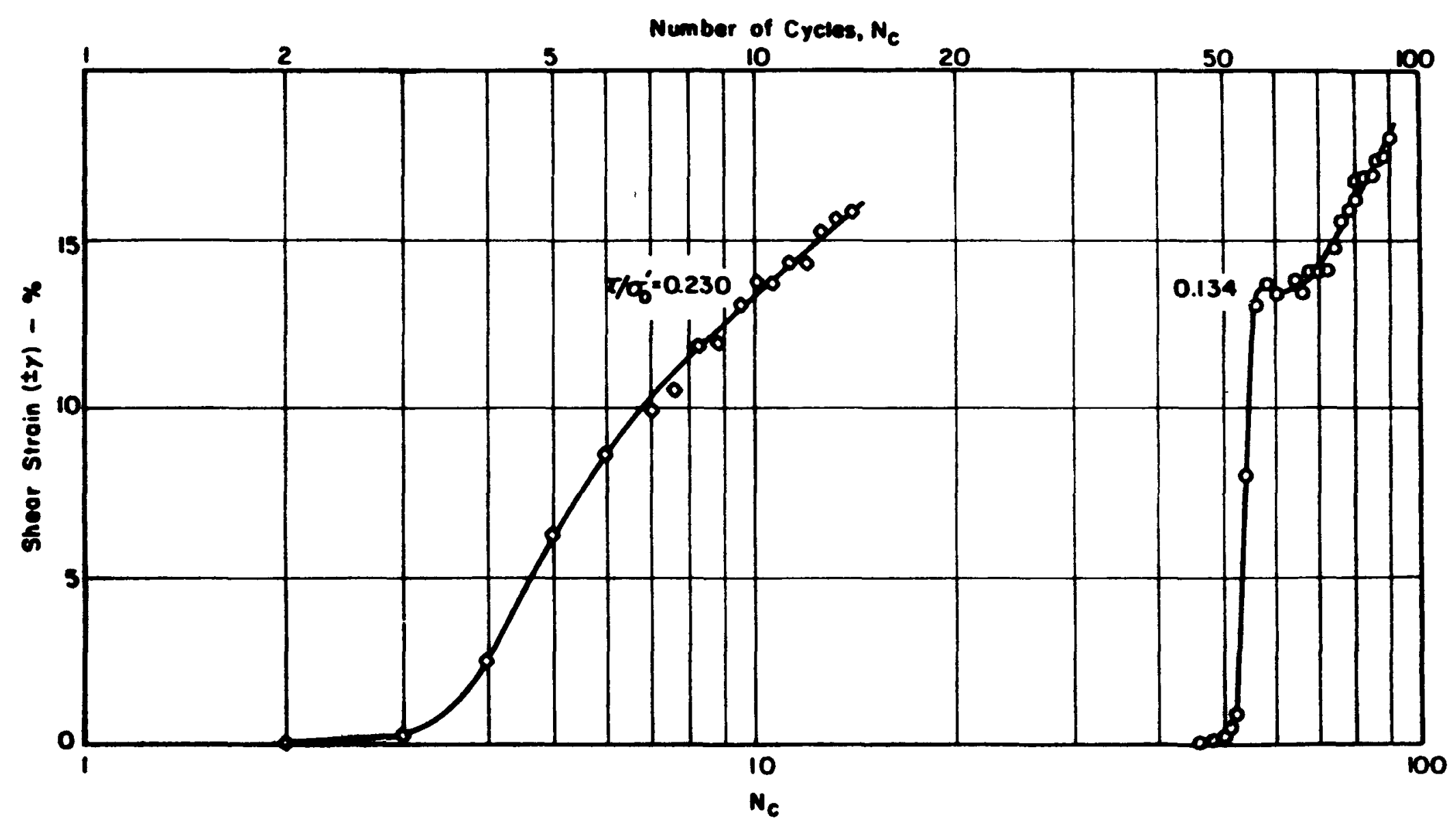

Fig. 3.20 SHEAR STRAIN DEVELOPMENT, RELATIVE DENSITY $=68 \%$ 


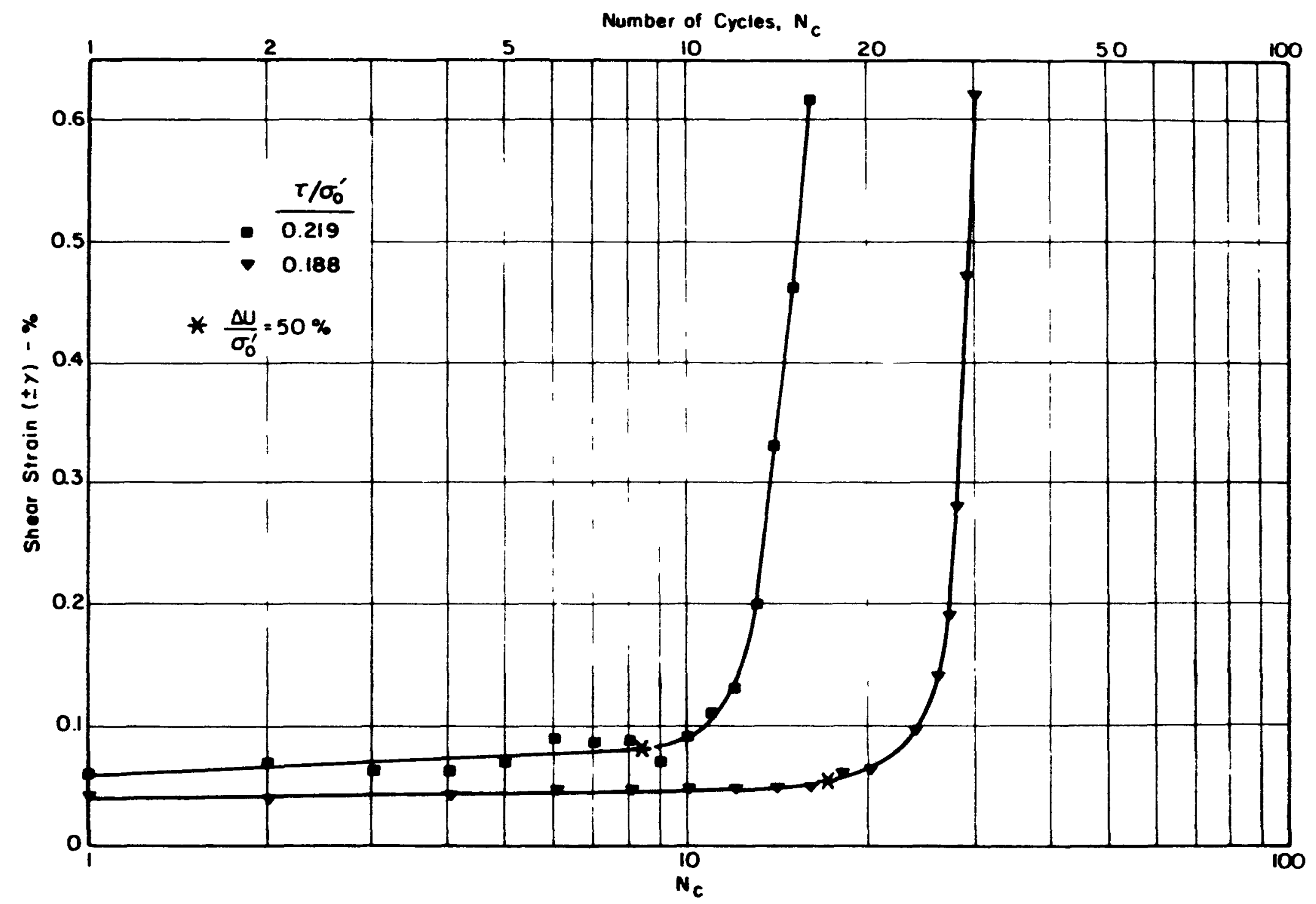

Fig. 3.21 SHEAR STRAIN DEVELOPMENT, RELATIVE DENSITY $=82 \%$ 


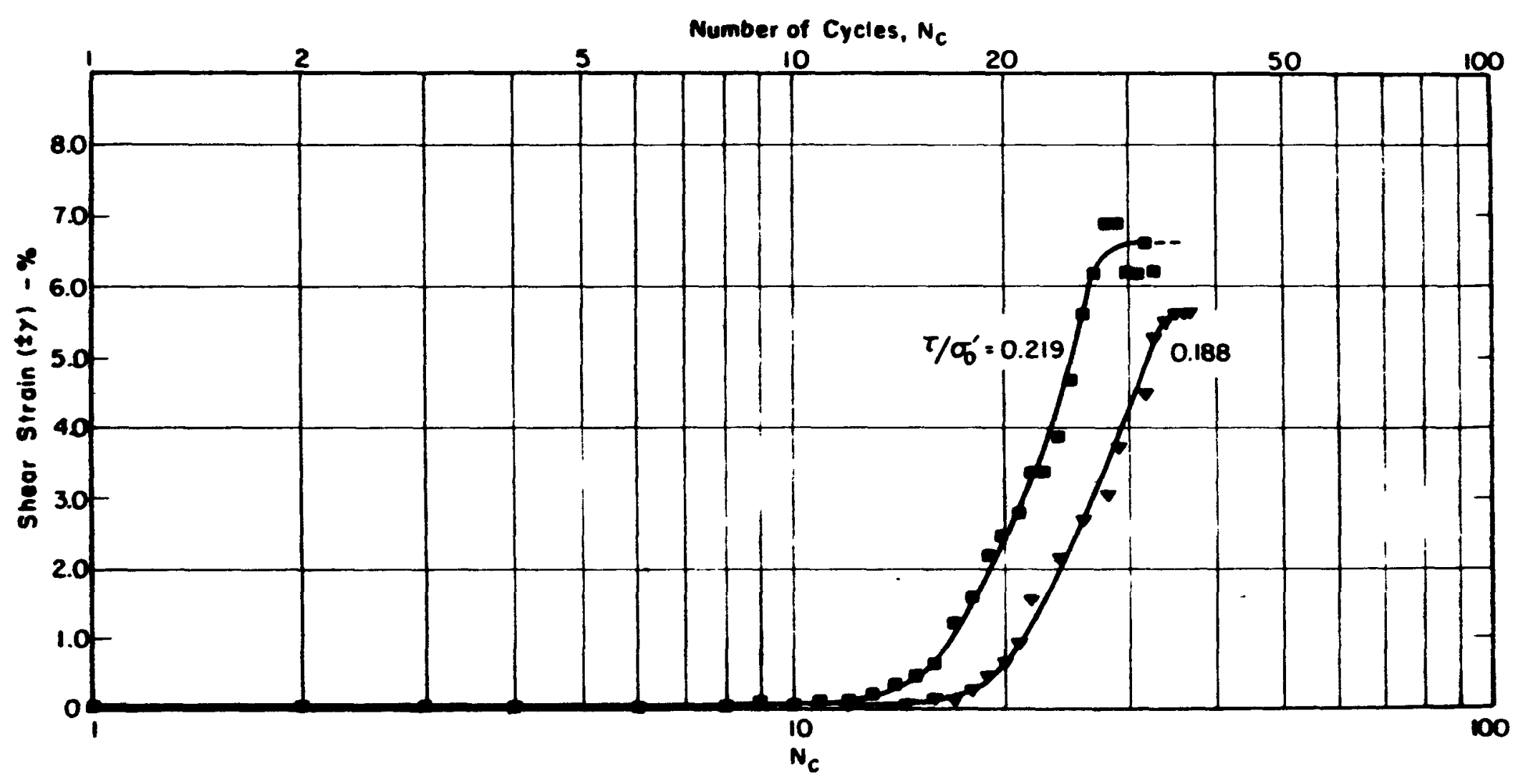

Fig. 3.22 SHEAR STRAIN DEVELOPMENT, RELATIVE DENSITY $=82 \%$ 


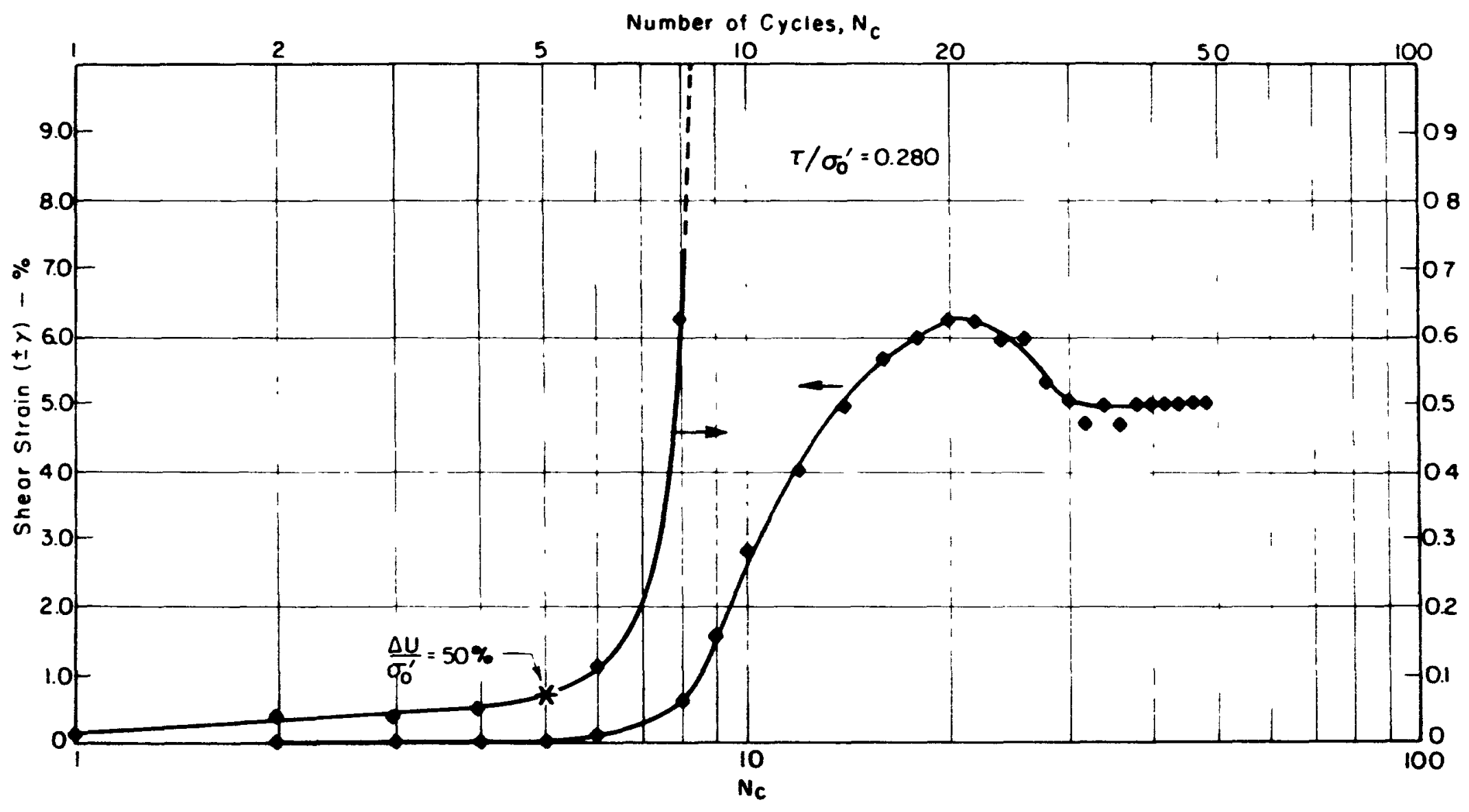

Fig. 3.23 SHEAR STRAIN DEVELOPMENT, RELATIVE DENSITY $=90 \%$ 
The extreme values of cyclic strain that developed after liquefaction were controlled by the dilatant tendency of the sand. The magnitude of these cyclic shear strains is strongly dependent on the relative density, as will be discussed further in Chapter V.

Model Footing Tests. As noted in Chapter II, the purpose of the model footing experiment was to demonstrate the loss of shearing resistance after initial liquefaction, especially in the case of dense material that might be expected to dilate under the effect of continued shear deformation and to regain resistance before significant settlement could take place. A typical record of footing settlement is shown in F18. 3.24. The two footings were usually placed at different heights in the specimen, one at approximately $1.5^{\prime \prime}$ and the other at $3.5^{\prime \prime}$ above the base. The loading applied to the footings varied from 25 ps 1 for spectmens at 54 percent relative density to 35 psi for those at $82 \%$.

Observed behavior was similar in all tests; when the dynamically induced pore pressure reached about 90 percent of the inftial effective pressure value, the first perceptible movement (1.e., greater than $0.01 ")$ was observed in the upper footing, followed after a time interval of 0.05 to 0.01 second by movement of the lower footing. The rate of settlement would increase sharply after initial liquefaction, and the footings would continue to settle unt1l the end of the loading piston stroke was reached, or unt11 the table movement stopped. It may be seen in Fig. 3.24 that the rate of settlement was not smooth; but showed a step pattern. In that part of the strain cycle where the sample dilated after 


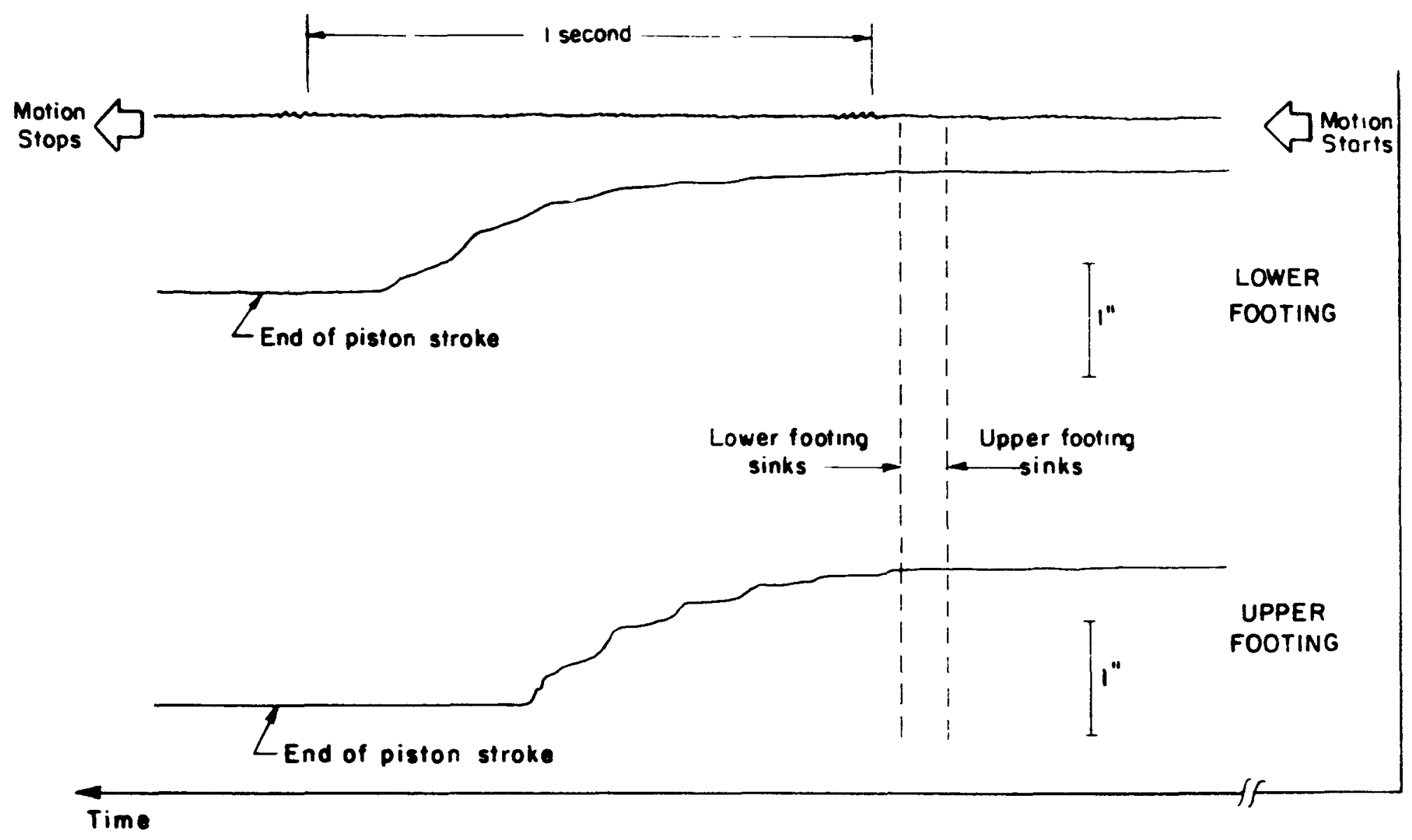

Fig. 3.24 SECTION OF FOOTING SETTLEMENT RECORD 
liquefaction, settlement was greatly slowed; when dilation crased, settlement speeded up again as the pore pressure rose to equal the effective pressure. This dilation effect will be discussed in more detail in subsequent sections.

The fact that the footings did not sink simultaneously was at first disconcerting, and thought to be indicative of liquefaction progressing from the top downward, perhaps due to stress concentrations at the contact between sample and ballast. However, the same effect was observed in tests run without the ballast, and this lag is more likely due to the fact that the lower footing produced both a higher degree of local confinement of the sand between it and the rigid bottom plate and also more local densification than did the upper footing. The behavior of the upper footing is therefore considered to be less influenced by the rigid base, and average rate of settlement curves for this footing, for the tests at different relative densities, are shown in Fig. 3.25. The step effect mentioned above is not shown; it should be noted that the 90 percent relative density curve represents one test only. Since the applied footing pressure, $q$, varied according to the relative density, the curves in Fig. 3.25 cannot all be directly compared, as the rate of settlement is clearly dependent on both relative density and the applied pressure. In Fig. 3.26, a linear pressure correction has been applied to the curves at 68 percent and 82 percent relative density to approximate the results that would be obtained from an applied pressure, $q$, of 25 psi in all cases. In this figure it may be seen that there 1s a considerable difference between the number of cycles necessary 


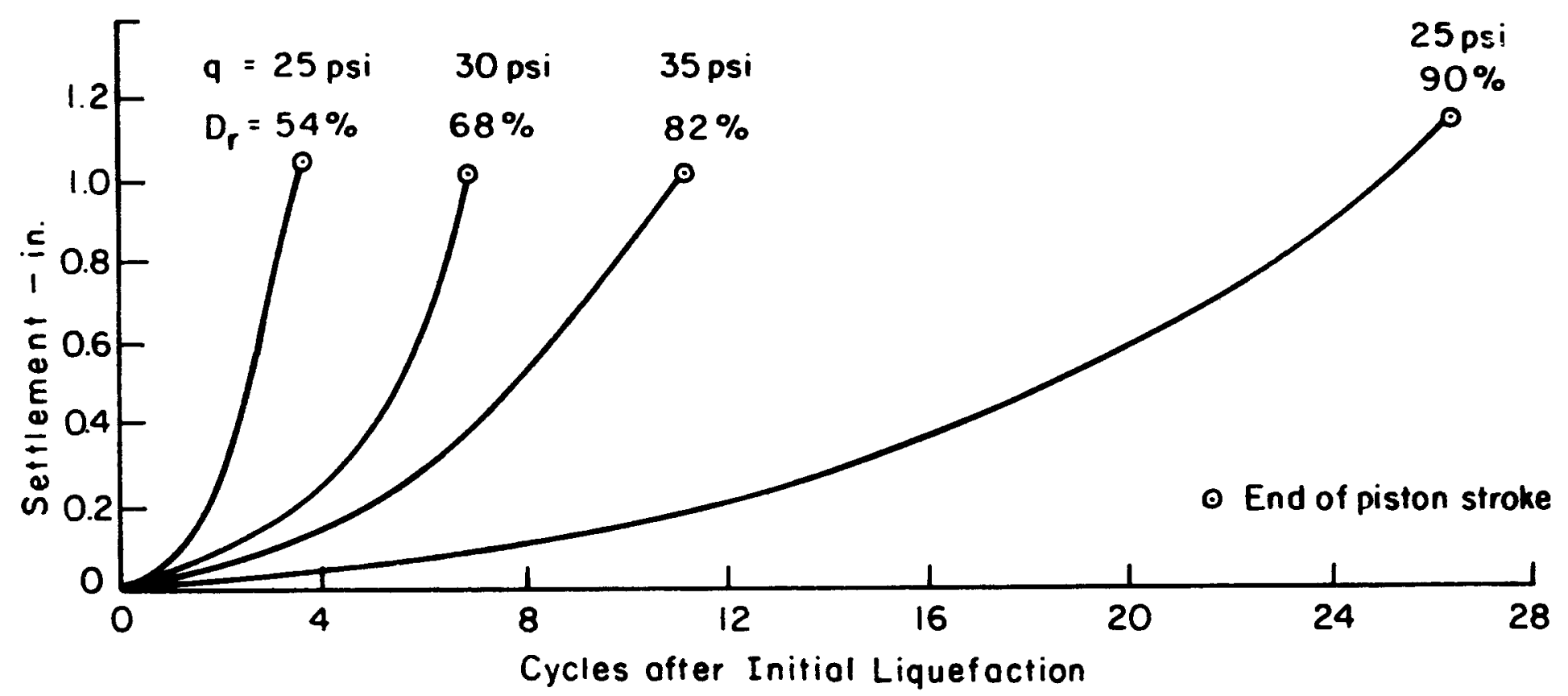

Fig. 3.25 UPPER FOOTING SETTLEMENT 


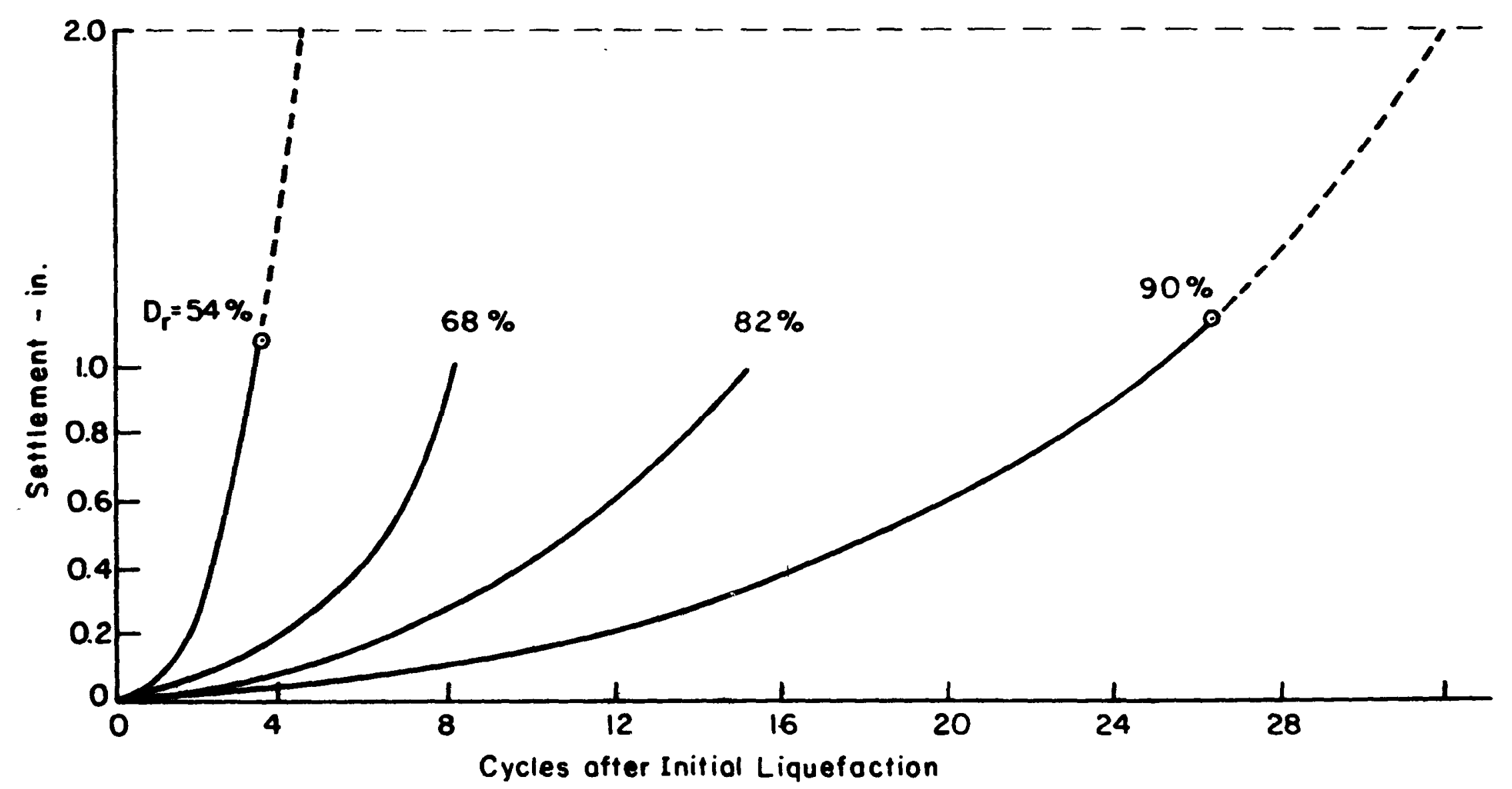

Fig. 3.26 FOOTING SETTLEMENT (RESULTS CORRECTED TO $q=25 p \mathrm{pi}$ ) 
Reproduced from

best available copy.

\section{c)}

to reach l" $^{\prime \prime}$ setilement at dlfferent donslties, and that the rate

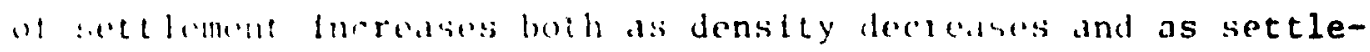
mont prof,ring: ior example, at 54 percent density, one Inch of settlement is $\ddot{*}$ sched in about 3.5 cycles after initial liquefaction, but, extrapolating from the curves, an additional inch of settlement would be observed within the fourth cycle, whereas at 90 percent densicy, 20 cycles of post-liquefaction shaking are required to produce $1^{\prime \prime}$ of settlement, and eight additional cycles to obtain another inch of settlement.

Stres; Ratios at Liquefaction. As may be seen from the preceding discussion, initial liquefaction, defined as the time at which the dynumically induced pore pressure, $\Delta \mathrm{U}$, reached the value of the initial effective vertical stress, $\sigma_{0}^{\prime}$, marked a drastic lhange in the behavior of the specimens; after this condition was reached, large shear strains developed quickly, as well as rapid settlement of the loaded footings. It was therefore considered that the results of the tests described in this chapter could be most effectively summarized in a plot showing the number of cycles required to cause initial liquefaction for different values of the parameter $\frac{\tau}{\sigma_{0}^{1}}$; that is, the ratio of the applied shear stress to the initial effective stress. This plot, which brings together the effects of the principal variables involved in liquefaction, is shown in Fig. 3.27.

However, as explained in Chapter II, the shaking table system could not be made absolutely free from small volume changes and had a certain rompliance due primarily to membrane penetration. 


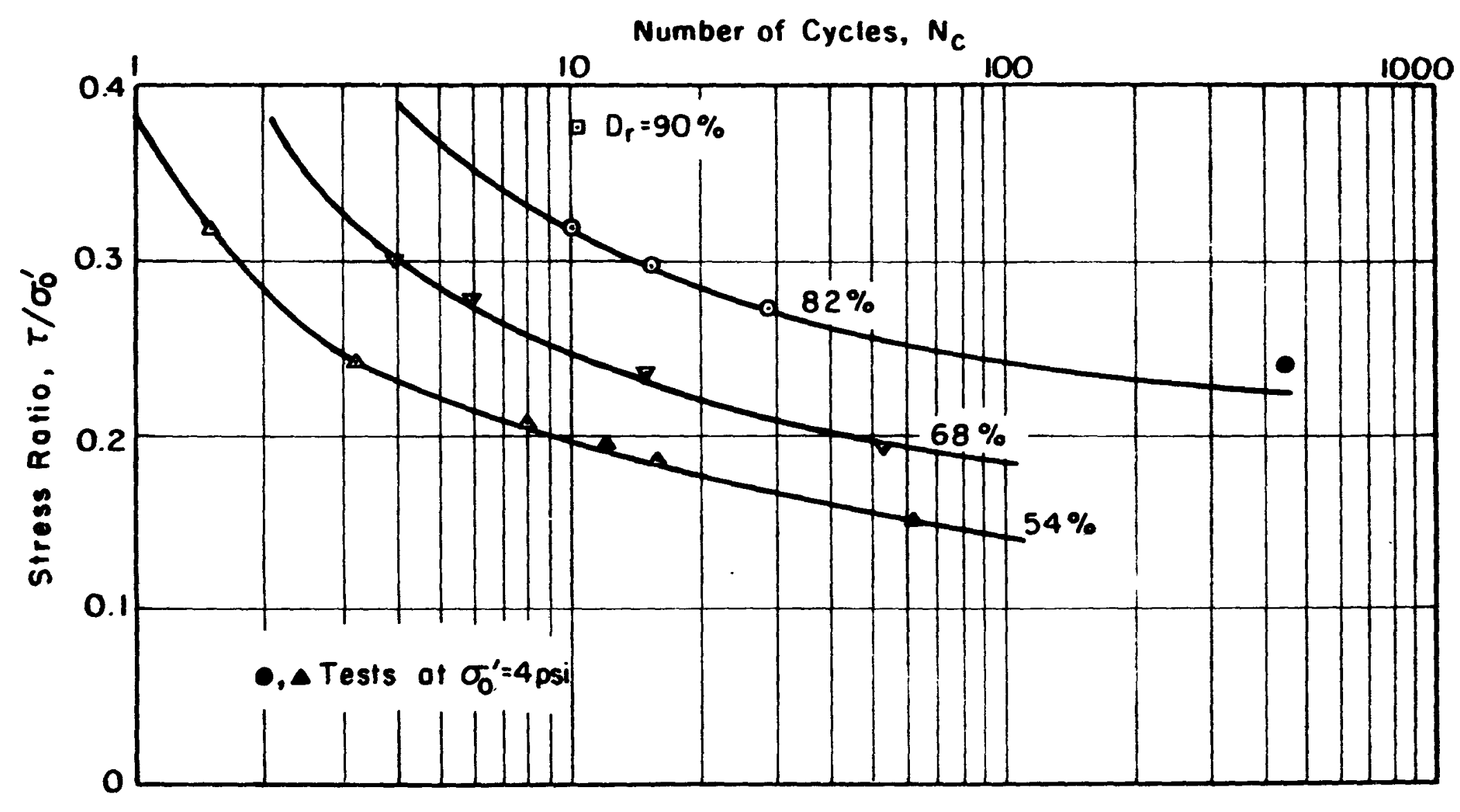

Fig. $3.27 \tau / \sigma_{0}^{\prime}$ VS. Ne FOR INITIAL LIQUEFACTION 
This additional volume change affected the test results by slowing the buildup of pore pressure, thus making the specimens less vulnerable to liquefaction. Accordingly, it was necessary to apply a correction to the test data in order to determine the results that would be produced by an ideal non-compliant system, as described in the following chapter. 


\section{STRESS RATIO CORRECTION FOR COMPLIANCE EFFECTS}

In order to study the effect of system compliance on liquefaction, it was necessary to first have an analytical model of soll behavior in undrained cyclic loading. Such a model has been proposed by Martin et al. (1974) based on the relationship between the volume change of dry sand subjected to cyclic shear stress, and the increase in pore pressure of saturated undrained sand under the same stress conditions. A simplified version of this model is described in the following paragraphs.

In the case of a dry sand specimen subjected to cyclic loading under constant normal stress conditions, in each cycle there will be a decrease in volume producing a volume strain $\Delta \varepsilon_{v d}$, which is a function of the shear strain amplitude and previous strain history. If an equivalent undrained specimen of unit volume is now considered, subjected to the same loading conditions, it will tend to reach the same compressive volume strain, $\Delta \varepsilon_{v d}$; however, this volume reduction tendency will in turn produce an increase in pore pressure, $\Delta U$, and a corresponding decrease in effective stress, $\Delta \sigma_{n}^{\prime}=\Delta U$. This stress change w111 then cause a tendency for volume increase as follows: (a) the reduction in effective stress, $\Delta \sigma_{n}^{\prime}$, will be accompanied by a release of recoverable strain energy, producing a rebound volume increase, $\Delta \varepsilon_{v r}$, and (b) if the system is confined by a flexible membrane, the increase in pore pressure, $\Delta U$, will reduce membrane penetration and produce an additional volume increase $\Delta \varepsilon_{\mathrm{v}}$. 
Thus, the final volume decrease will be:

$$
\Delta \varepsilon_{v t}=\Delta \varepsilon_{v d}-\Delta \varepsilon_{v m}-\Delta \varepsilon_{v r} . . . . . . . . . . . . . .
$$

This volume change will cause a corresponding decrease in volume of the pore water, $\Delta \varepsilon_{w}$, where:

$$
\begin{aligned}
\Delta E_{w} & =\Delta U \cdot n / k_{w} \\
k_{w} & =\text { bulk modulus of water } \\
n & =\text { porosity }
\end{aligned}
$$

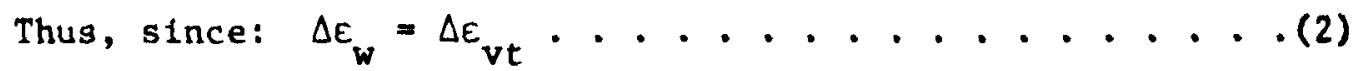

It follows that: $\quad \frac{\Delta U . n}{k_{w}}=\Delta \varepsilon_{v d}-\Delta \varepsilon_{v m}-\Delta \varepsilon_{v r}$

If the following are defined for the conditions at the beginning of a cycle:

$$
k_{r}=\frac{d \sigma^{\prime}}{d \varepsilon_{v r}} ; \quad k_{m}=\frac{d U}{d \varepsilon_{v m}}
$$

Then, from Eq. 1, the volume change $\Delta \varepsilon_{\text {vd }}$ may be expressed as:

$$
\Delta \varepsilon_{v d}=\Delta \mathrm{U}\left(\frac{\mathrm{n}}{\mathrm{k}_{\mathrm{w}}}+\frac{1}{\mathrm{k}_{\mathrm{r}}}+\frac{\mathrm{l}}{\mathrm{k}_{\mathrm{m}}}\right) \ldots \ldots . . . \ldots . . . .
$$

from which the pore pressure increase in that cycle may be obtained:

$$
\Delta \mathrm{U}=\frac{\Delta \varepsilon_{\mathrm{vd}}}{\frac{\mathrm{n}}{\mathrm{k}_{\mathrm{w}}}+\frac{1}{\mathrm{k}_{\mathrm{r}}}+\frac{1}{\mathrm{k}_{\mathrm{m}}}} \ldots \ldots \ldots \ldots
$$

This expression clearly shows the effects of membrane penetration on pore pressure increase; if membrane penetration effects are large, $k_{m}$ w111 be small, and $\Delta U$ w111 be proportionately smaller. 
If the pore water is considered to be incompressible, then the following simplified expression may be written:

$$
\Delta U=\frac{\Delta \varepsilon_{v d}}{\frac{1}{k_{I}}+\frac{1}{k_{m}}}
$$

Eq. 5 permits the calculation of the pore pressure increase in every cycle, taking into account the membrane penetration, if the behavior of an equivalent drained sample is known. $k_{r}$ represents the rebound modulus of the material for the appropriate stress level and boundary conditions, and $k_{m}$ is the gradient of volume change due to membrane penetration for the testing system.

This model gives considerable insight into the liquefaction process, and a method for simulating the process analytically. A computer program was developed by G.R. Martin to perform this simulation. This program, as modified by Pyke (1974), was considered to offer the best way to correct the test results obtained; analyses could be made including both compliance and rebound effects, and for material rebound only, thereby obtaining plots of stress ratio, $\frac{\tau}{\sigma^{\prime}}$ vs number of cycles, $N_{c}$, for both the actual system and the ideal, non-compliant system; correction factors could then be established for the shaking table test results.

Essentially, the liquefaction program operates as shown schematically in Fig. 4.1, performing the following steps in each cycle:

(1) For a known applied shear stress, $\tau$, normal effective stress at the end of the previous cycle, $\sigma_{\text {no }}^{\prime}$, and 


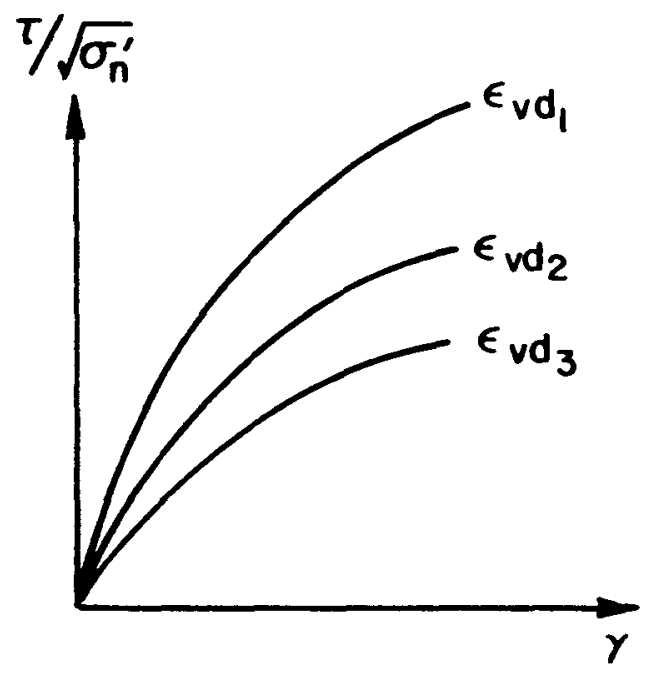

(a)

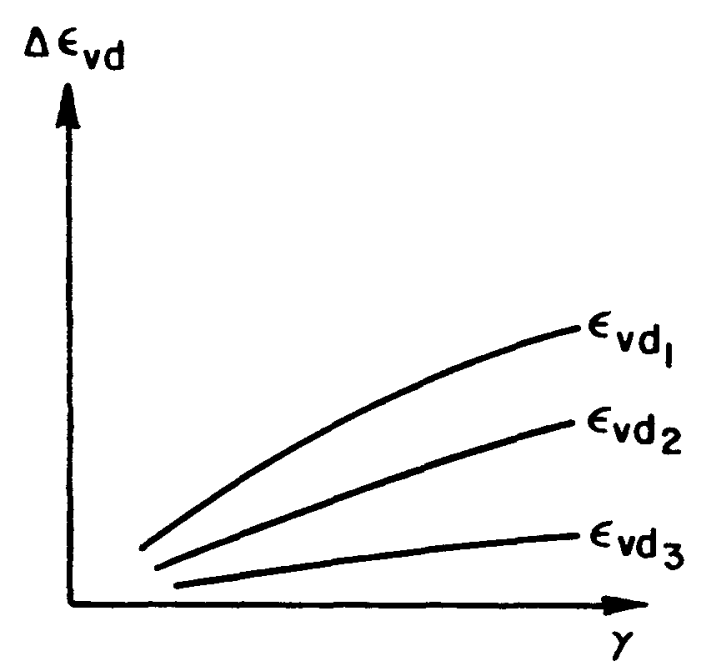

(b)

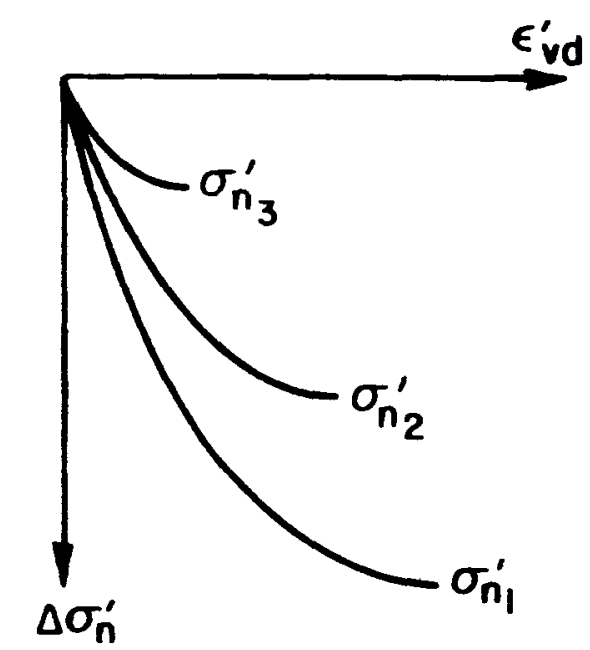

(c)

FIg. 4.1 BASIC INPUT DATA FOR LIQUEFACTION MODEL 
total accumulated volume change up to the previous cycle, $\varepsilon v$, the value of shear strain, $\gamma$, for the cycle is determined, F1g. 4.1.a.

(2) For the value of $\gamma$ obtained from step (1), and for the known value of $\varepsilon_{\mathrm{vd}}$, the incremental volume change for that cycle $\Delta \varepsilon_{\mathrm{vd}}$ is obtained from Fig. 4.1.b and added to the previous $\varepsilon_{v d}$ to obtain $\varepsilon_{\text {vd }}^{\prime}$.

(3) For the value of $\varepsilon_{v d}^{\prime}$ obtained from step (2), the value of stress release due to unloading, $\Delta U=\Delta \sigma_{n}^{\prime}$, is obtained from Fig. 4.1.c and a new value of normal effective stress is calculated:

$$
\sigma_{n f}^{\prime}=\sigma_{\text {no }}^{\prime}-\Delta \sigma_{n}^{\prime}
$$

Thls value is then used in step (1) of the next cycle. Step (3) is where additional volume change due to compliance may be introduced, using modified rebound curves that include both material rebound and system compliance.

In the actual computation, Figs. 4.1.a, 4.1.b and 4.1.c are represented by hyperbollc and exponential functions. As part of the input data, the parameters necessary to obtain these functions are read in; these parameters are obtained from shear modulus, G, vs shear strain, $\gamma$, curves, $\Delta \varepsilon_{\text {vd }}$ vs $\gamma$ curves and rebound tests, all developed from the results of experiments on equivalent sand specimens in dry or drained conditions. The necessary curves relating $G$ vs $Y$ and $\Delta \varepsilon_{\text {vd }}$ vs $\gamma$ were obtained by Pyke (1973). Values of total volume change due to 
compliance and rebound were obtained from tests on saturated specimens as described in Chapter II and Appendix I. In order to separate the effects of system compliance and rebound in these results, a number of special tests were carried out, in which material rebound was reduced to negligible proportions by using specimens $0.125 \mathrm{in}$. high, tested in the same manner as the normal 4" specimens. The basic volume change data obtained from these special tests are also shown in Appendix I. With the volume change information for two specimen helghts, F1g. 4.2 was prepared, in which volume change was plotted against spectmen height, and the system compliance obtained by projecting to zero specimen height, as shown. Finally, Figs. 4.3 and 4.4 show the separated values of system compliance and materlal rebound. The program was then run for the appropriate values of applied shear and material parameters at each density. Perfect agreement with the test results was not expected, and in fact substantial differences were found between the test results and the computer calculations including system compliance; the $\frac{\tau}{\sigma_{0}}$ vs $N_{c}$ curves obtained analytically were much steeper than the experimental ones. This discrepancy is probably attributable to a more complex coupling of effects in each stress cycle than that proposed in the model. In order to obtain approximate agreement, it was necessary to modify the input data in such a way as to increase the value of the shear modulus, $G$, in effect waking the specimen stiffer. The increment required Increased with increasing density, reach1ng 60 percent at 82 percent 


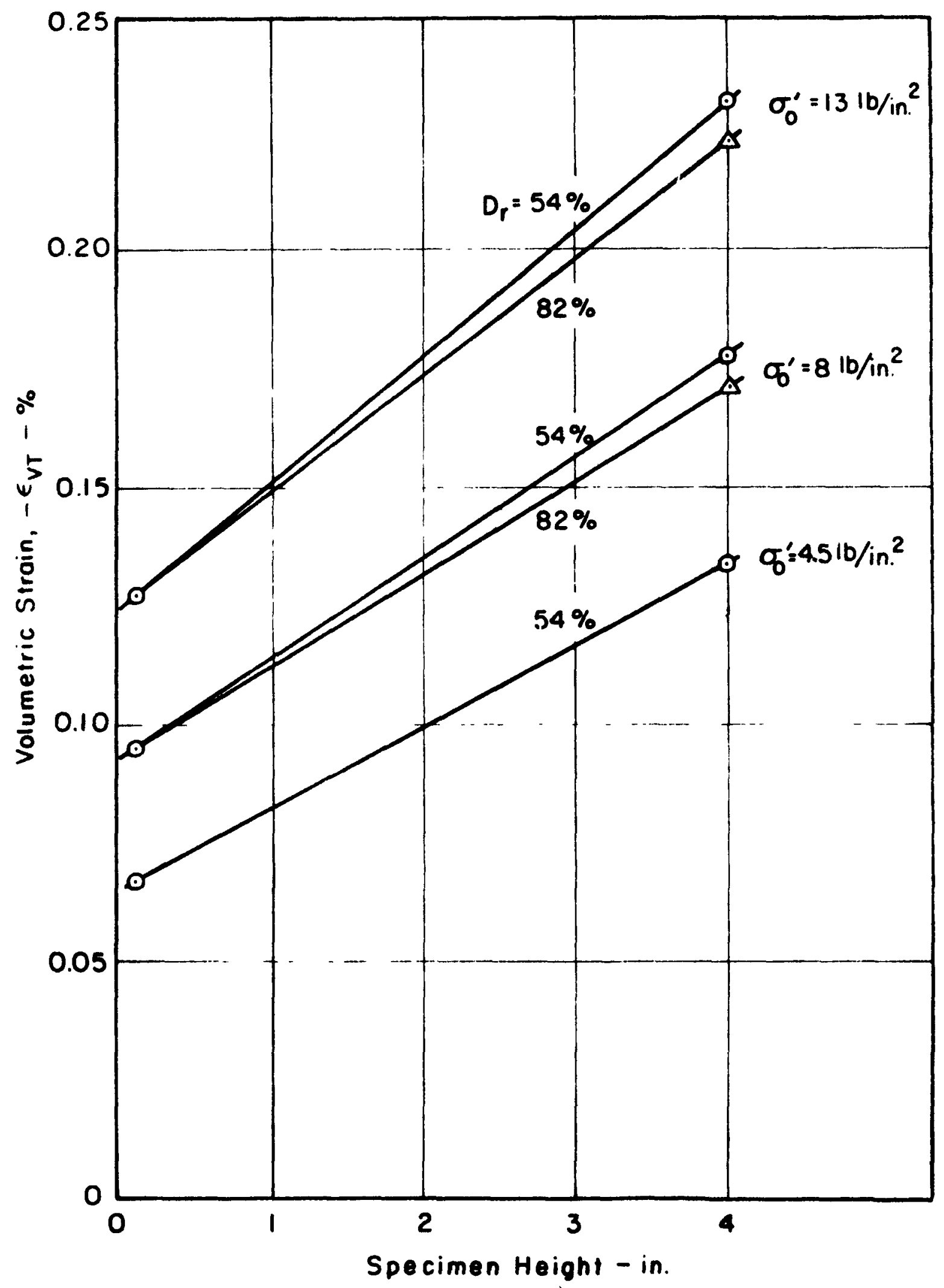

Fig. 4.2 VOLUMETRIC STRAIN VS. SPECIMEN HEIGHT 


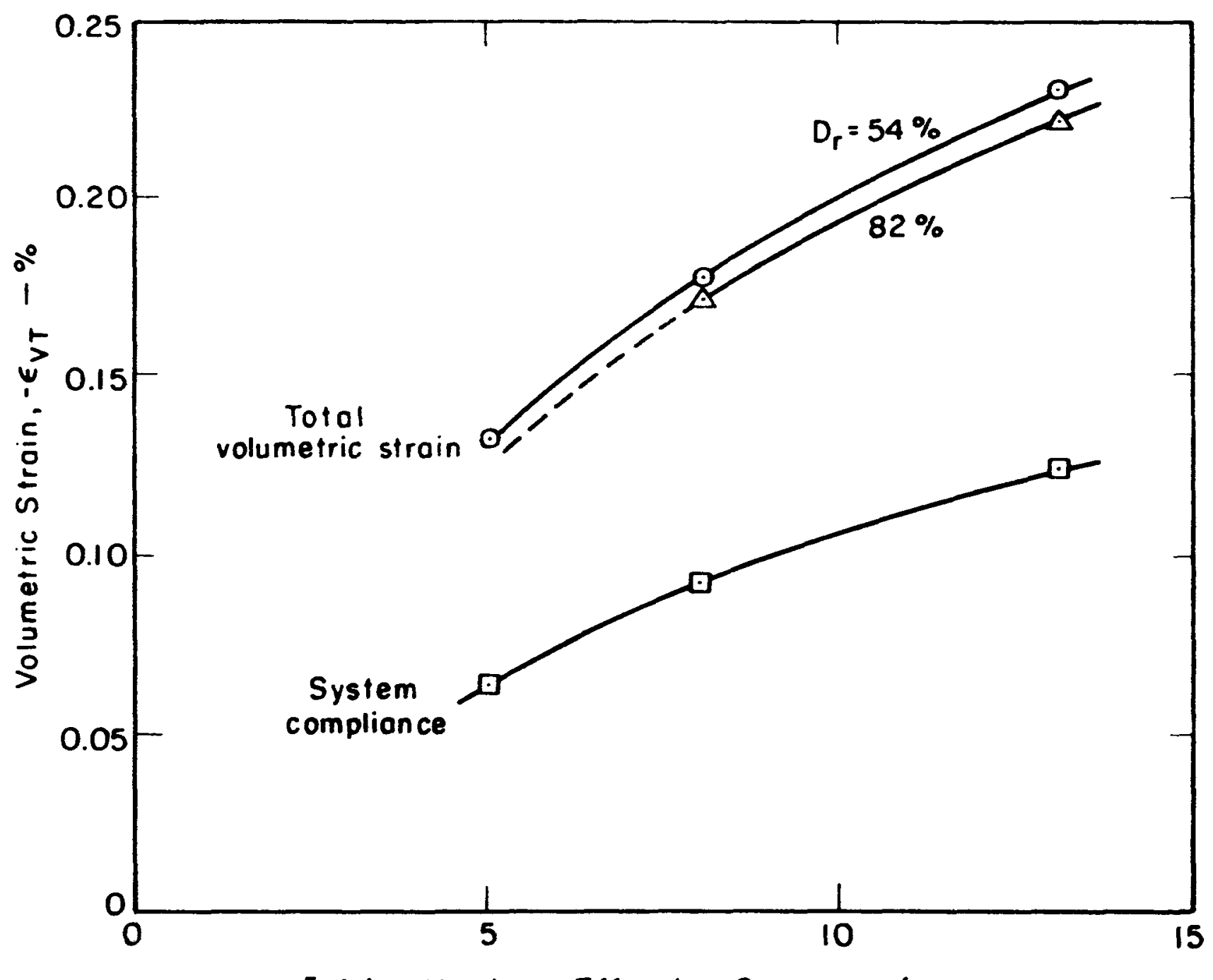

Initial Vertical Effective Stress, $\omega^{\prime}-p s i$

$\stackrel{\infty}{N}$

Fig. 4.3 TOTAL VOLUMETRIC STRAIN AND SYSTEM COMPLIANCE 


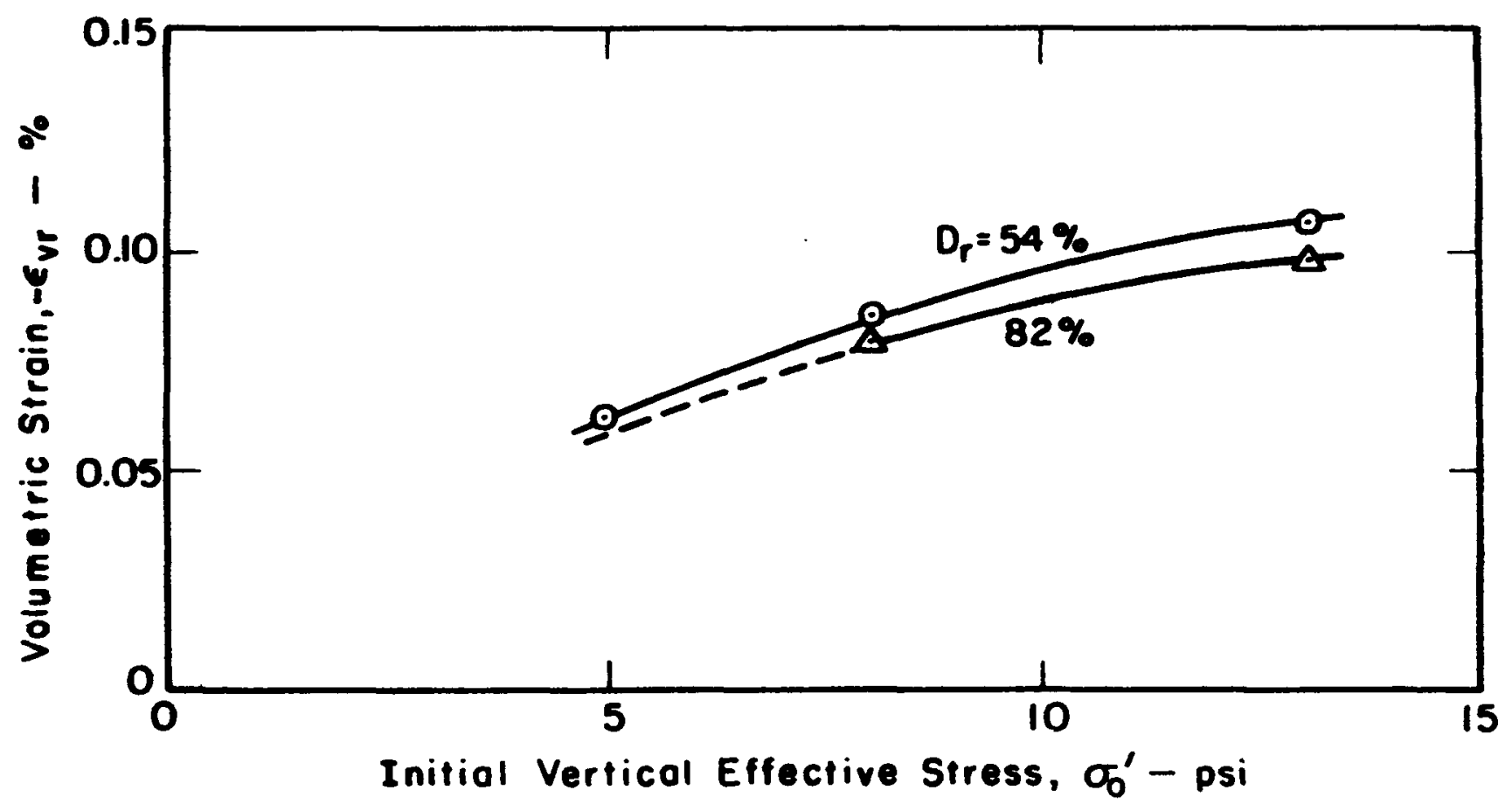

Fig. 4.4 MATERIAL REBOUNO VS. INITIAL EFFECTIVE STRESS 
relative density. Fig. 4.5 shows the calculated and measured variation of $\frac{\tau}{\sigma_{0}^{1}}$ vs $N_{c}$ for 54,68 and 82 percent density; the required modification to the shear modulus is shown in each case.

For each density, once a reasonable agreement with the experimental data was obtained, a second run was made for an ideal non-compliant system. The ratio of $\frac{\tau}{\sigma_{0}^{\prime}}$ for the ideal system to that of the compliant system, at the approprlate number of cycles, was taken as the correction factor for each experimental result. The correction factors obtained are summarized in Fig. 4.6. It may be seen that these can be adequately represented by a single correction curve, as shown.

Since substantial modification of the input shear moduli was required at both 68 and 82 percent relative density in order to obtain reasonable agreement of the model with the observed data, some doubt remained as to the validity of the correction obtained. A second correction method was therefore explored, which was based directly on the measured results from cyclic shear tests on dry sand, as described below.

In the liquefaction test, previous discussion has shown that membrane penetration will reduce the pore pressure increase per cycle by introducing a volume change, $\Delta \varepsilon_{\mathrm{vm}}$ in each cycle, so that at inftial liquefaction when $\Delta U=\sigma_{0}^{\prime}$, the volume change due to compliance will be $\varepsilon_{v m}=\Sigma \Delta \varepsilon_{v m}$. This will have the effect of retarding liquefaction in such a way that if for an ideal system Iiquefaction would occur in $\mathrm{N}$ cycles at a stress ratio $\left(\frac{\tau}{\sigma_{0}^{\prime}}\right)_{1}$, for a compliant system a larger stress 


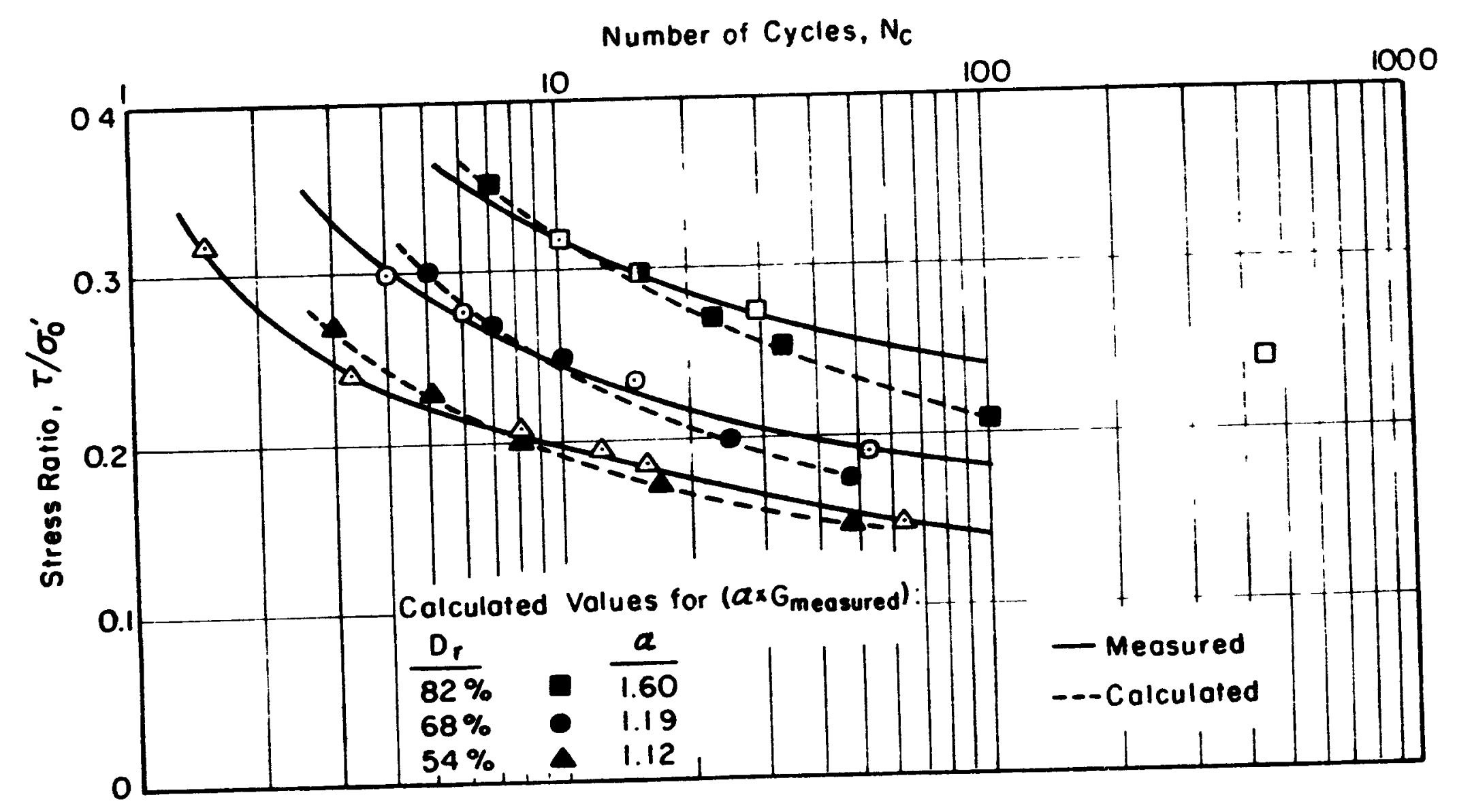

Fig. 4.5 CALCulated VS. meAsured $\tau / \sigma_{0}^{\prime}-N_{c}$ CuRVES 


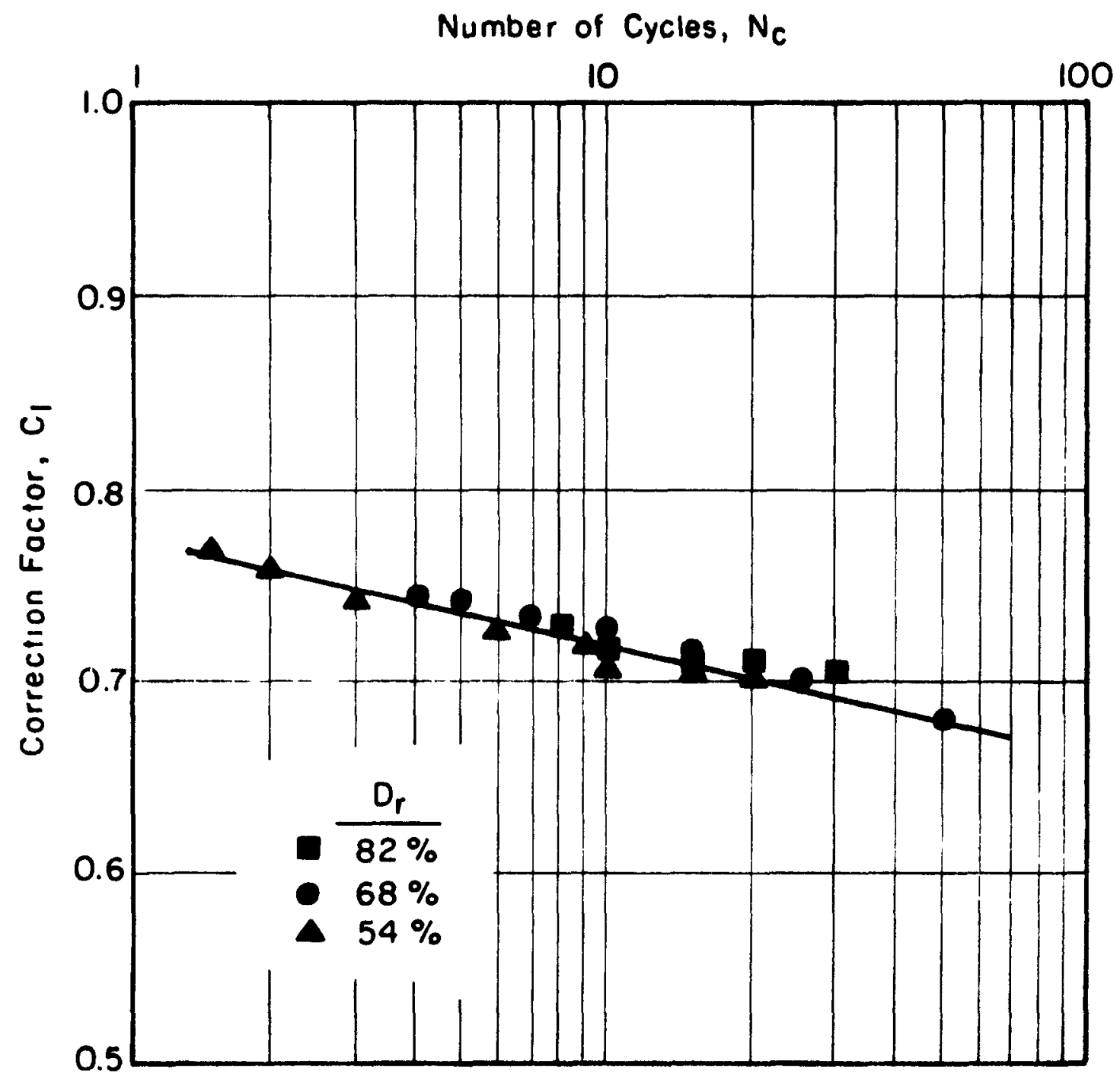

Fig. 4.6 CORRECTION FACTORS FROM MARTINS MODEL 
ratio $\left(\frac{\tau}{\sigma_{0}^{\prime}}\right)_{2}$ would be necessary to produce liquefaction in the same number of cycles. This difference in stress ratios must be closely proportional to the compliance volume change, $\varepsilon_{\mathrm{vm}}$. Now from the point of view of volume change, ideal liquefaction $\left(\Delta U=\sigma_{0}^{\prime}\right)$ may be characterized by the recoverable volume strain $\varepsilon_{v r}$ that would occur for the complete release of initial effective stress $\sigma_{0}^{\prime}$ in a drained test, while the real test could be represented by the volume change $\varepsilon_{v r}+\varepsilon_{v m}$. It is further suggested that the ratio of $\left(\frac{\tau}{\sigma_{0}^{\prime}}\right)_{1}$ to $\left(\frac{\tau}{\sigma_{0}^{\prime}}\right)_{2}$ as defined above will be approximately the same as that obtained for the stress ratios that will produce compressive volume changes of a magnitude equal to $\varepsilon_{\mathrm{vr}}$ and $\varepsilon_{\mathrm{vr}}+\varepsilon_{\mathrm{vm}}$ in drained cyclic loading tests and in the same number of cycles as the liquefaction test, Fig. 4.7, so that:

$$
\frac{\left(\frac{\tau}{\sigma_{0}^{\prime}}\right)_{3}}{\left(\frac{\tau}{\sigma_{0}^{\prime}}\right)_{4}}=\frac{\left(\frac{\tau}{\sigma_{0}^{\prime}}\right)_{1}}{\left(\frac{\tau}{\sigma_{0}^{r}}\right)_{2}}
$$

In order to determine the magnitude of the correction, it was necessary to determine, (a) the $\frac{\tau}{\sigma_{0}^{j}}$ vs $\varepsilon_{v}$ relationships for the same sand in a dry state, and at the same densitles as would be used in the Iiquefaction tests, and (b) the volume changes in the liquefaction testing syatem due to compliance and material rebound at the initial effective pressures selected for the Iiquefaction tests. 


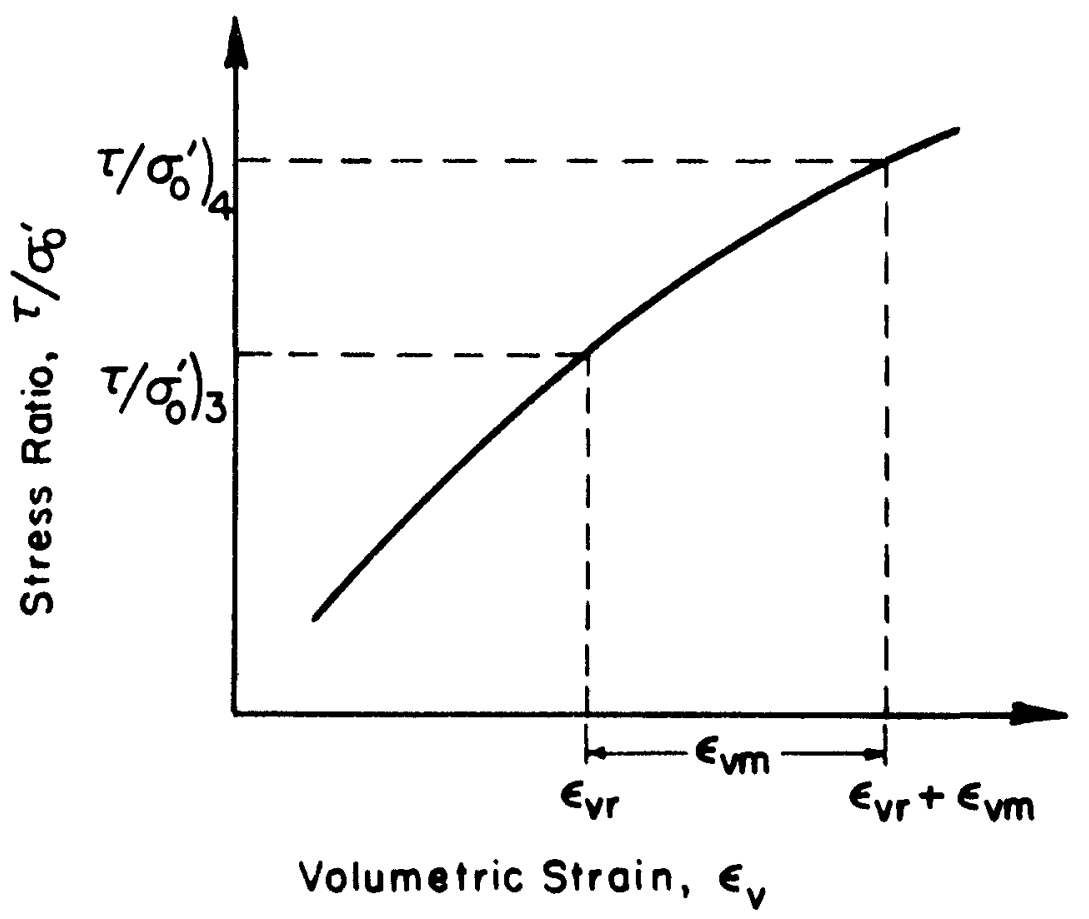

Fig 4.7 STRESS RATIOS FOR ALTERNATE CORRECTION METHOD 
The necessary information on $\frac{\tau}{\sigma_{0}^{\prime}}$ vs $\varepsilon_{v}$ for Monterey no. 0 sand was developed by Pyke (1973) as mentioned above, for denstties of 40, 60 and 80 percent, and for 5, 10 and 30 applled stress cycles. Fig. 4.8 summarizes this information. Values of the total volume change due to compliance and rebound were obtained as described in preceding paragraphs.

With this information, it was possible to correct the liquefaction test results in the following steps:

(1) For the given initial effective pressure $\sigma_{0}^{\prime}$, the total volume change $\varepsilon_{v r}+\varepsilon_{v m}$ and material rebound $\varepsilon_{v r}$ were obtained from Figs. 4.3 and 4.4 .

(2) For each of these values $\varepsilon_{v r}+\varepsilon_{v m}$ and $\varepsilon_{v r}$, the corresponding stress ratios $\left(\frac{\tau}{\sigma_{0}^{\prime}}\right)_{3}\left(\frac{\tau}{\sigma_{0}^{\prime}}\right)_{4}$ were obtained from Pyke's results according to the density of the specimen and the number of cycles to initial liquefaction. Interpolation or extrapolation from the curves shown in Fig. 4.8 was obviously required in each case; many auxiliary curves were prepared, which are not shown.

(3) The last step was to calculate the correction factor $C$ for each test and apply it to the stress ratio obtained in the test:

$$
\left(\frac{\tau}{\sigma_{0}^{\top}}\right)_{c}=C \times\left(\frac{\tau}{\sigma_{0}^{1}}\right)_{\text {Test }}
$$




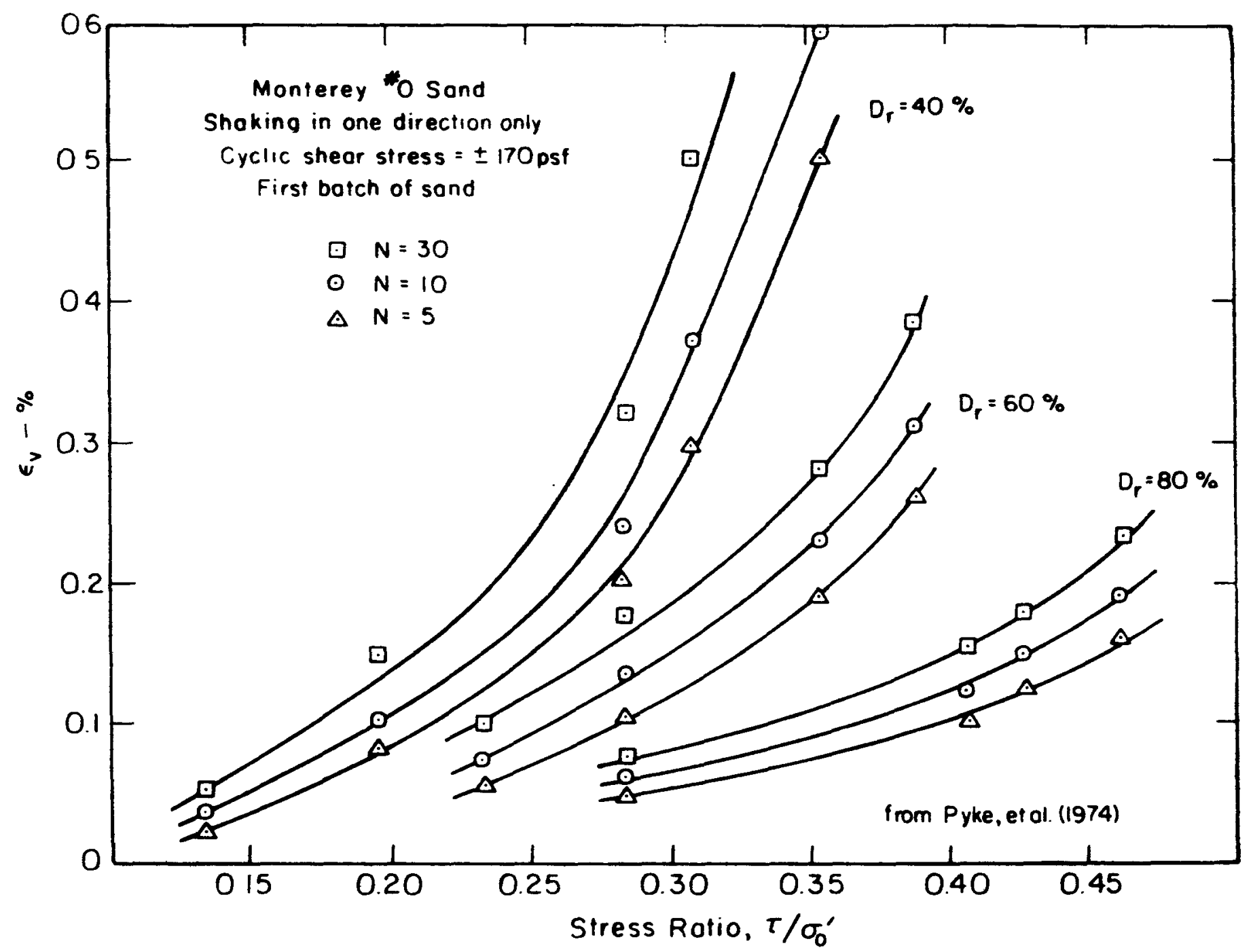

FIg 48 EFFECT OF DENSITY AND NUMBER OF CYCLES ON $\epsilon_{V}$ 
Table IV.1 shows the correction procedure for all tests Included in this study.

The correction values obtained by this second method are shown in F1g. 4.9, where they are also compared with the values obtained from the analytical model. It may be seen that this alternate correction gives somewhat higher values. However, the corrections generally remain between 0.7 and 0.8 in the 30 stress cycle range which is of primary interest, and both show the same general trend. In view of the relatively small differences involved, it was finally decided to use the average of the correctIon factors determined by the two procedures. Applying these to the test results, a final corrected plot of $\frac{\tau}{\sigma_{0}^{\prime}}$ vs $\mathrm{N}_{c}$ was obtained, Fig. 4.10. This is considered to be a very good approximation of the results that would be obtained in an ideal, non-compliant testing system, and effectively summarizes the effects of the principal variables on the liquefaction process. In Chapter V, these results will be discussed at some length, and compared with those obtained in other tests, and in the fleld. 
TABLE IV. 1

CORRECTION VALUES - METHOD 2

\begin{tabular}{|c|c|c|c|c|c|c|c|c|c|}
\hline $\begin{array}{l}\mathrm{D}_{\mathrm{r}} \\
(\%)\end{array}$ & $\begin{array}{c}\sigma_{0}^{\prime} \\
(p s i)\end{array}$ & $\begin{array}{l}\varepsilon_{\mathrm{vr}} \\
(\%)\end{array}$ & $\begin{array}{c}\varepsilon_{v r}+\varepsilon_{v m} \\
(\%)\end{array}$ & $\begin{array}{c}\mathrm{N}_{c \ell} \\
\text { Cycles to } \\
\text { Liquefaction }\end{array}$ & $\left(\frac{\tau}{\sigma_{0}^{\prime}}\right)_{3}$ & $\left(\frac{\tau}{\sigma_{0}^{\prime}}\right)_{4}$ & C & $\left(\frac{\tau}{\sigma_{0}^{i}}\right)_{\text {test }}$ & $\left(\frac{\tau}{\sigma_{0}^{\top}}\right)_{t} \times C$ \\
\hline 54 & 8.07 & 0.086 & 0.179 & 8 & 0.287 & 0.226 & 0.773 & 0.207 & 0.160 \\
\hline 54 & 8.03 & 0.085 & 0.178 & 3 & 0.342 & 0.280 & 0.806 & 0.240 & 0.194 \\
\hline 54 & 4.53 & 0.063 & 0.127 & 12.5 & 0.262 & 0.20 & 0.771 & 0.195 & 0.150 \\
\hline 54 & 8.02 & 0.085 & 0.178 & 16 & 0.287 & 0.220 & 0.766 & 0.185 & 0.142 \\
\hline 54 & 8.14 & 0.086 & 0.180 & 63 & 0.252 & 0.187 & 0.725 & 0.148 & 0.107 \\
\hline 54 & 7.53 & 0.081 & 0.170 & 1.5 & 0.420 & 0.340 & $0.8 \mathrm{C} 2$ & 0.319 & 0.256 \\
\hline 68 & 8.09 & 0.082 & 0.174 & 15 & 0.375 & 0.287 & 0.765 & 0.233 & 0.178 \\
\hline 68 & 7.99 & 0.082 & 0.174 & 4 & 0.404 & 0.310 & 0.767 & 0.299 & 0.229 \\
\hline 68 & 8.08 & 0.083 & 0.175 & 53 & 0.340 & 0.258 & 0.759 & 0.191 & 0.145 \\
\hline 68 & 8.06 & 0.083 & 0.175 & 6 & 0.404 & 0.310 & 0.767 & 0.278 & 0.213 \\
\hline 82 & 8.00 & 0.079 & 0.172 & 10 & 0.460 & 0.355 & 0.773 & 0.318 & 0.246 \\
\hline 82 & 8.03 & 0.080 & 0.173 & 28.5 & 0.438 & 0.315 & 0.719 & 0.271 & 0.202 \\
\hline 82 & 8.08 & 0.081 & 0.174 & 15.5 & 0.458 & 0.341 & 0.744 & 0.298 & 0.222 \\
\hline 82 & 3.90 & 0.054 & 0.107 & 430 & 0.294 & 0.224 & $0.675^{\star}$ & 0.240 & 0.162 \\
\hline 90 & 8.04 & 0.078 & 0.174 & 10.5 & 0.530 & 0.413 & 0.779 & 0.377 & 0.294 \\
\hline
\end{tabular}

*extrapolated 


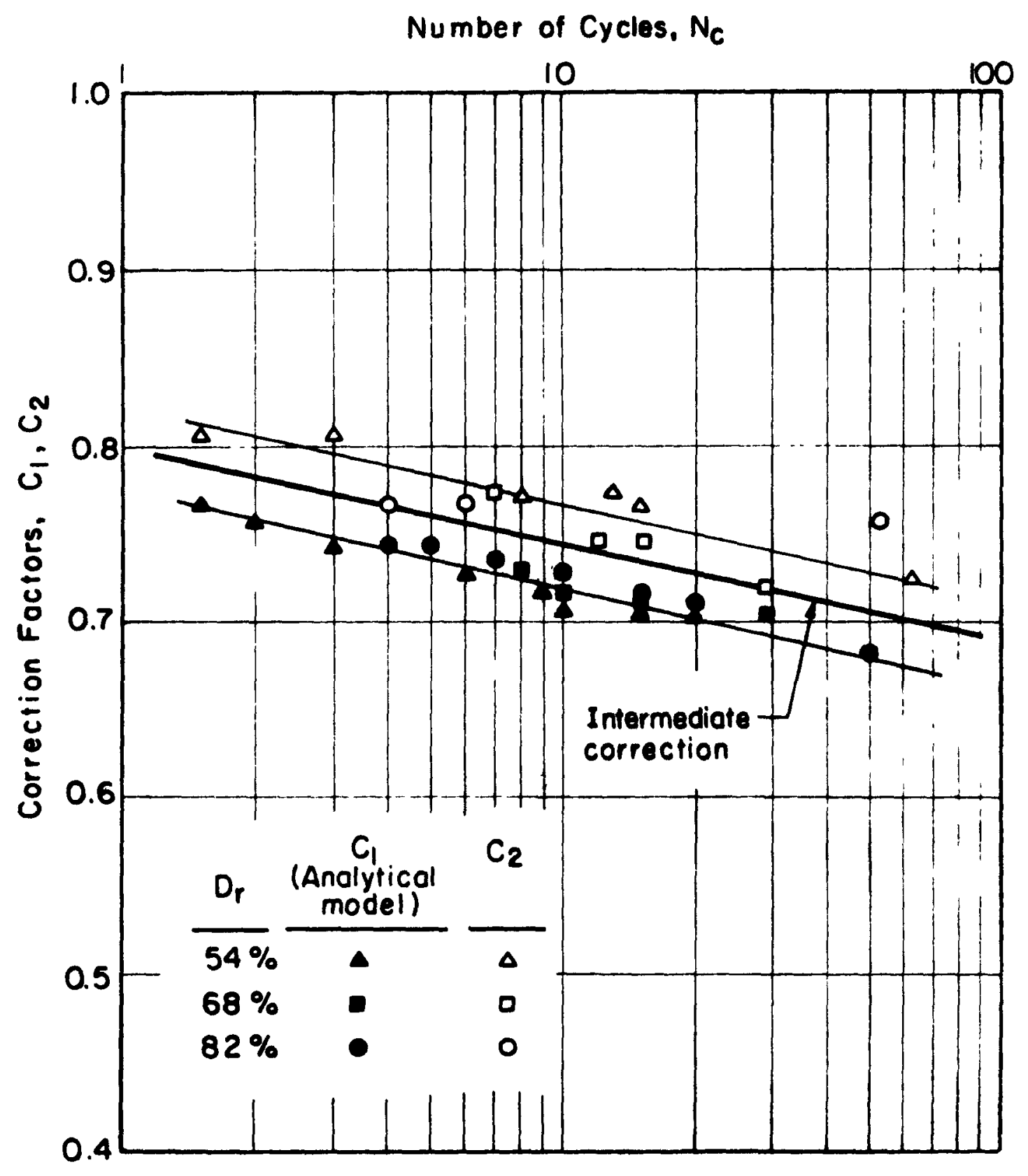

Fig. 4.9 CORRECTION FACTORS - COMPARISON 
Number of Cycles, $N_{C}$

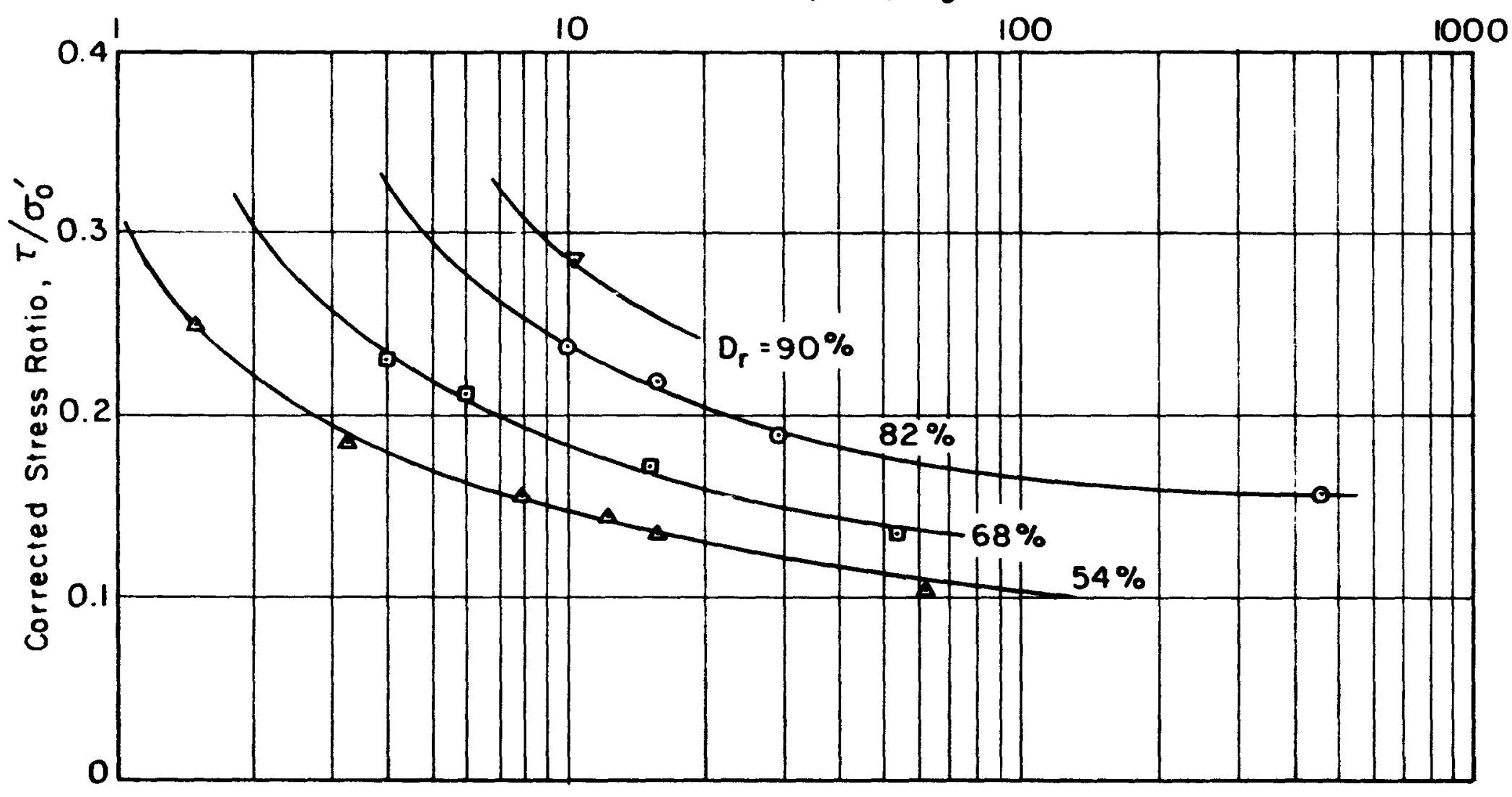

Fig. 4.10 CORRECTEO $\tau / \sigma_{0}^{\prime}$ VS. $N_{c}$ FOR INITIAL LIQUEFACTION 


\section{v. DISCUSSION}

\section{Pore Pressure Development During Shaking}

More generally applicable curves of pore pressure development during strong ground shaking may be obtained if the results shown in Figs. 3.12 to 3.14 are normalized and plotted as $\frac{\Delta \mathrm{U}}{\sigma_{0}^{r}}$ versus $\frac{\mathrm{Nc}}{\mathrm{Nc}_{\ell}}$, where:

$$
\begin{aligned}
& \Delta U=\text { dynamic pore pressure increase } \\
& \sigma_{0}^{\prime}=\text { initial effective pressure } \\
& N_{c}=\text { number of cycles to cause pore pressure increase } \\
& N c_{l}=\text { number of cycles to initial liquefaction }
\end{aligned}
$$

Fig. 5.1 shows such a normalized plot for tests at relative densities ranging from 54 to 90 percent; it may be seen that the general shape of the curves is the same for all tests and that the results fall within a relatively narrow band. In Figs. 5.2 and 5.3 the same data are divided into two groups, data for relative densities of 82 and 90 percent being shown in F18. 5.2 and data for relative densities of 54 and 68 percent in F1g. 5.3. Upper and lower bounds for these grouped data are also shown. It is evident that for a given value of $\frac{N c}{N c_{l}}$ higher values of the ratio $\frac{\Delta U}{\sigma_{0}^{\prime}} \quad$ are observed at the higher relative densities; representative average pore pressure development curves for the different relative densities are shown in Fig. 5.4 . 


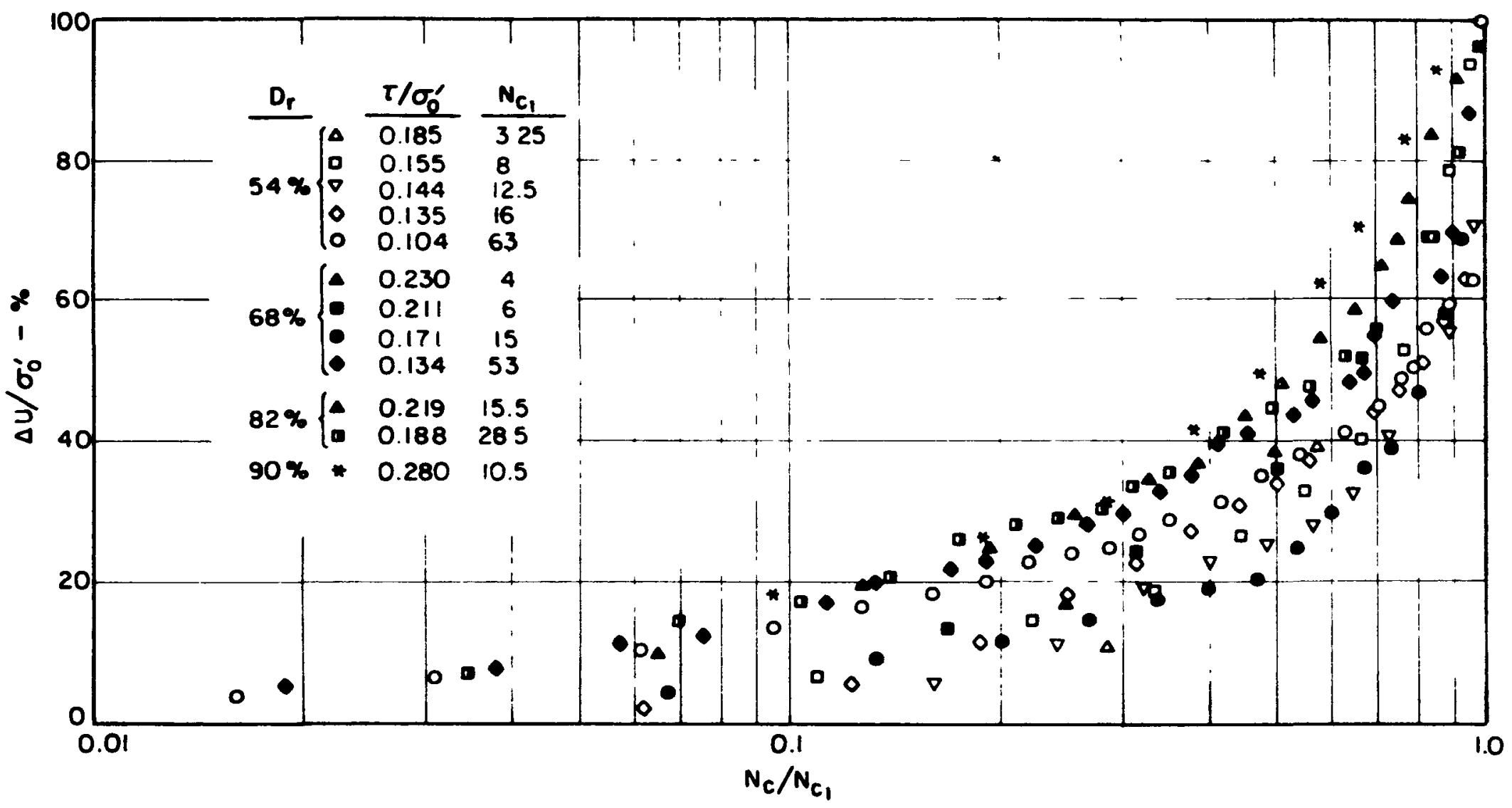

Fig. 5.I NORMALIZED DATA - DYNAMIC PORE PRESSURES 


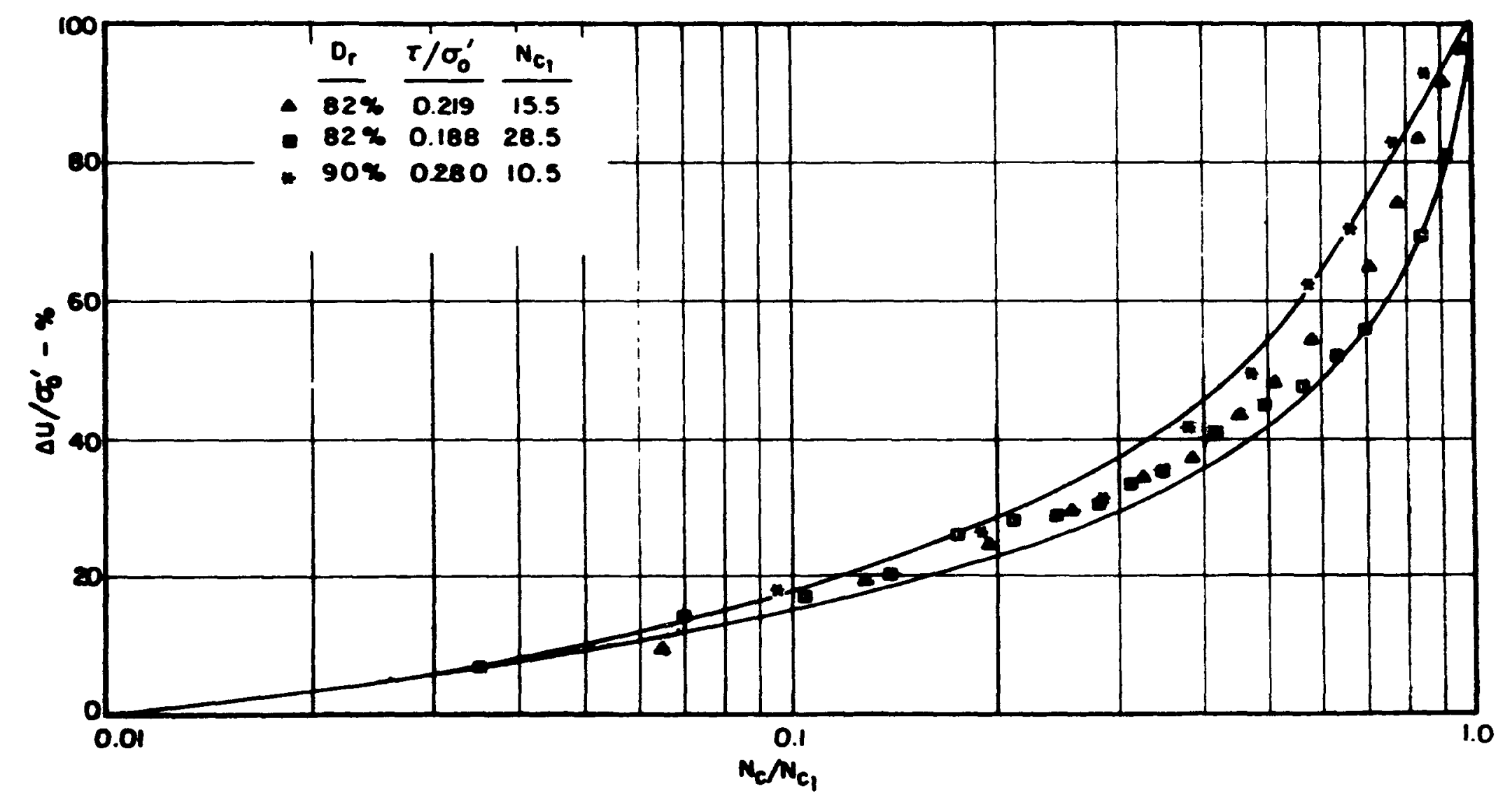

Fig. 5. 2 NORMALIZED DATA - DYNAMIC PORE PRESSURES 


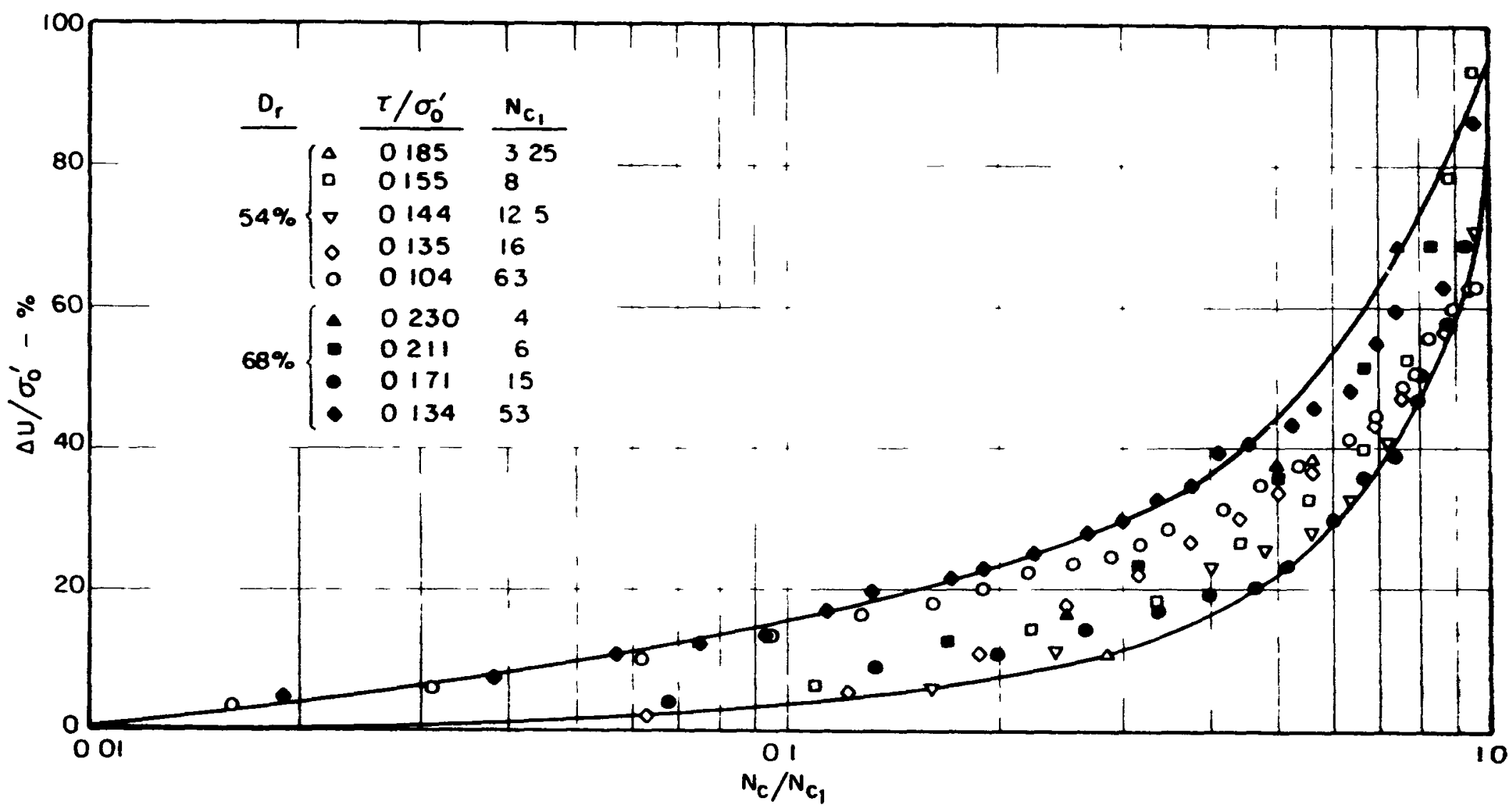

FIg 53 NORMALIZED DATA - OYNAMIC PORE PRESSURES 


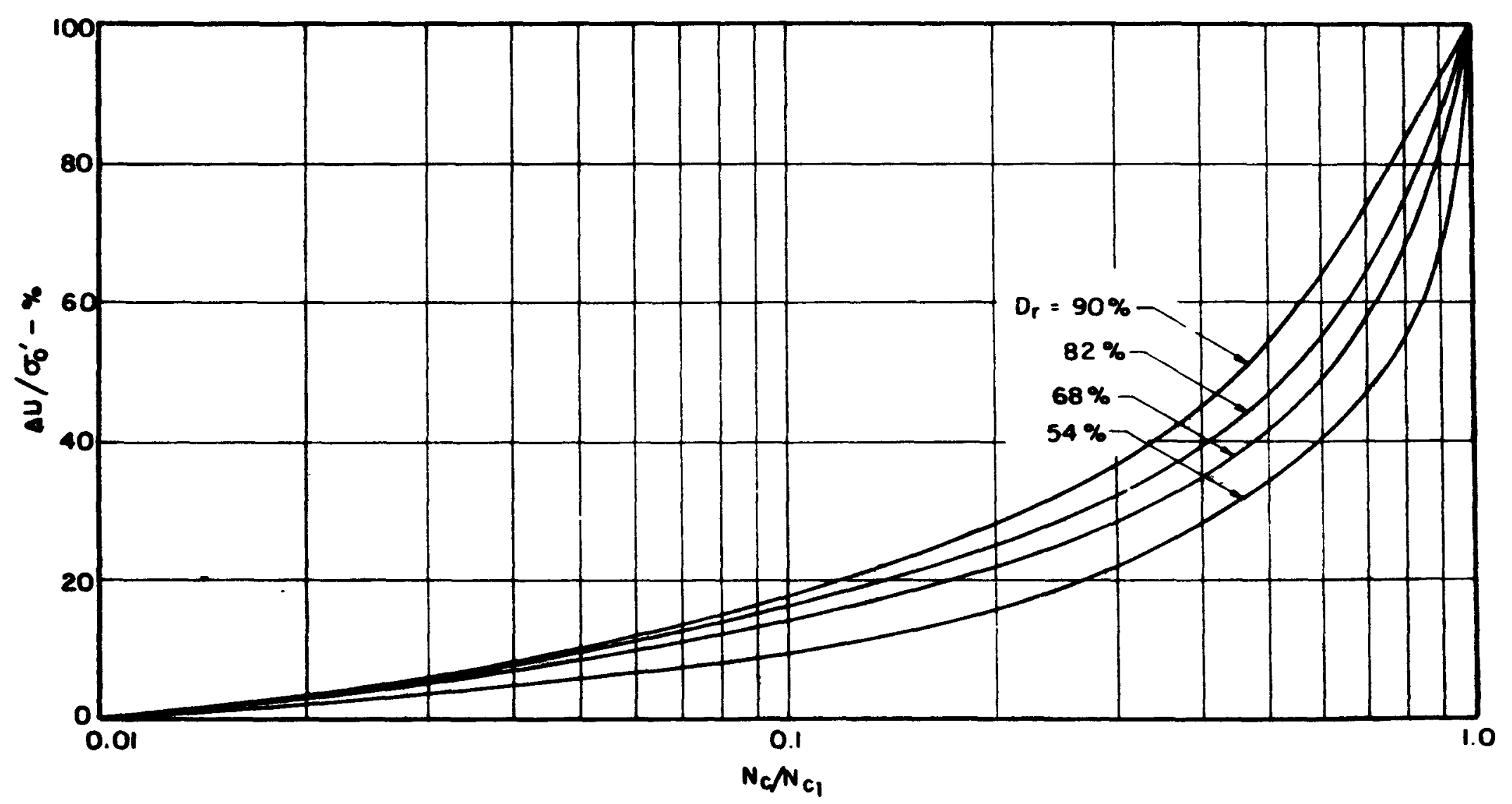

FIg 5.4 NORMALIZED DYNAMIC PORE PRESSURE CURVES 
Thisc curves may be usid together with the data in Fig.

4.10 to estimate the rate of pore pressure development in sands subjected to cyclic shear stress applications as follows: with $\frac{\tau}{\sigma_{0}^{\prime}}$ obtained from ground response analysis or the simplified method proposed by Seed and Idriss (1970), the number of cycles required to cause initial liquefaction, $\mathrm{Nc}_{\ell}$, may be obtained for any given relative density from the data in Fig. 4.10. For appropriate values of $\frac{\mathrm{Nc}}{\mathrm{Nc}_{\ell}}$, corresponding values of $\frac{\Delta \mathrm{U}}{\sigma_{0}^{1}}$ may then be read from Fig. 5.4 .

\section{Comparisons with Results of Previous Shaking Table Tests}

For purposes of comparison, representative results of previous shaking table liquefaction studies have been assembled in Fig. 5.5; in each case the results are shown for a relative density of 50 percent. The effect of specimen container proportions on the results is readily apparent; as the ratio of specimen length to helght increases, the stress ratio required to produce liquefaction in a given number of cycles decreases. Clearly, it is important to avoid stiff boundary effects in determining results representative of free field conditions. There is some suggestion from the data that for length to helght ratios greater than $10: 1$ boundary effects may not greatly influence the results. The difference between the results of the present study at 50 percent relative density and those extrapolated from the tests of Finn et al. (1971) at 30 percent relative density might be due largely to the difference in end restraint conditions, $1 . e .$, in the latter study the specimen was 


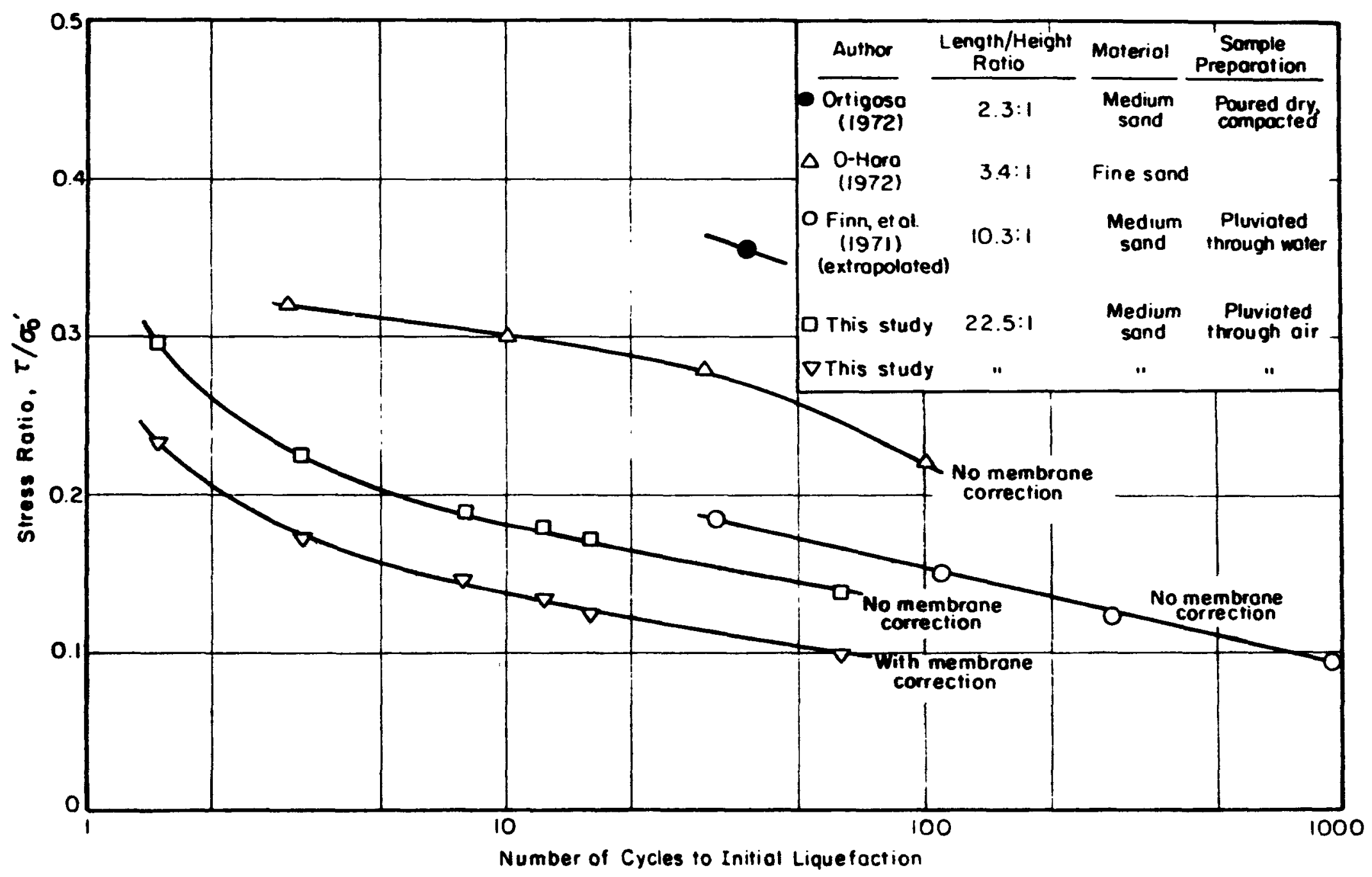

Fig. 5.5 COMPARISON OF SHAKING TABLE TEST RESULTS FOR $D_{r}=50 \%$ 
placed in contact with the rigld end walls of the testing chamber and could not deform freely. Thus, the small differences in these results may indicate that a length to helght ratio of $10: 1$ may provide adequate results for many purposes, although a larger ratto is desirable to obtain free field dimenstons such that a variety of instruments may be installed in the sample to measure soil behavior free of boundary effects.

\section{Comparison with Results from Laboratory Appartus}

As shaking table tests will obviously not be performed in soils laboratories on a routine basis, it is interesting to compare the results of the present study with the results of smallscale liquefaction tests carried out with different types of apparatus. Fig. 5.6 summarizes the results obtained in different simple shear testing programs for evaluating the 11quefaction characteristics of medium sands at 50 percent relative density and with various specimen preparation methods. The Finn et al. and Seed and Peacock results, which most closely approximate the corrected values for this study, were obtained using Roscoetype simple shear devices (Roscoe 1953). Th1s type of test eliminates some of the basic difficulties of loading and boundary conditions encountered in the triaxlal liquefaction test. It should be noted, however, that in this apparatus complementary shear stresses on the ends of the test specimens cannot be fully developed, a situation leading to some degree of non-uniformity in the boundary stresses. Nevertheless, the 


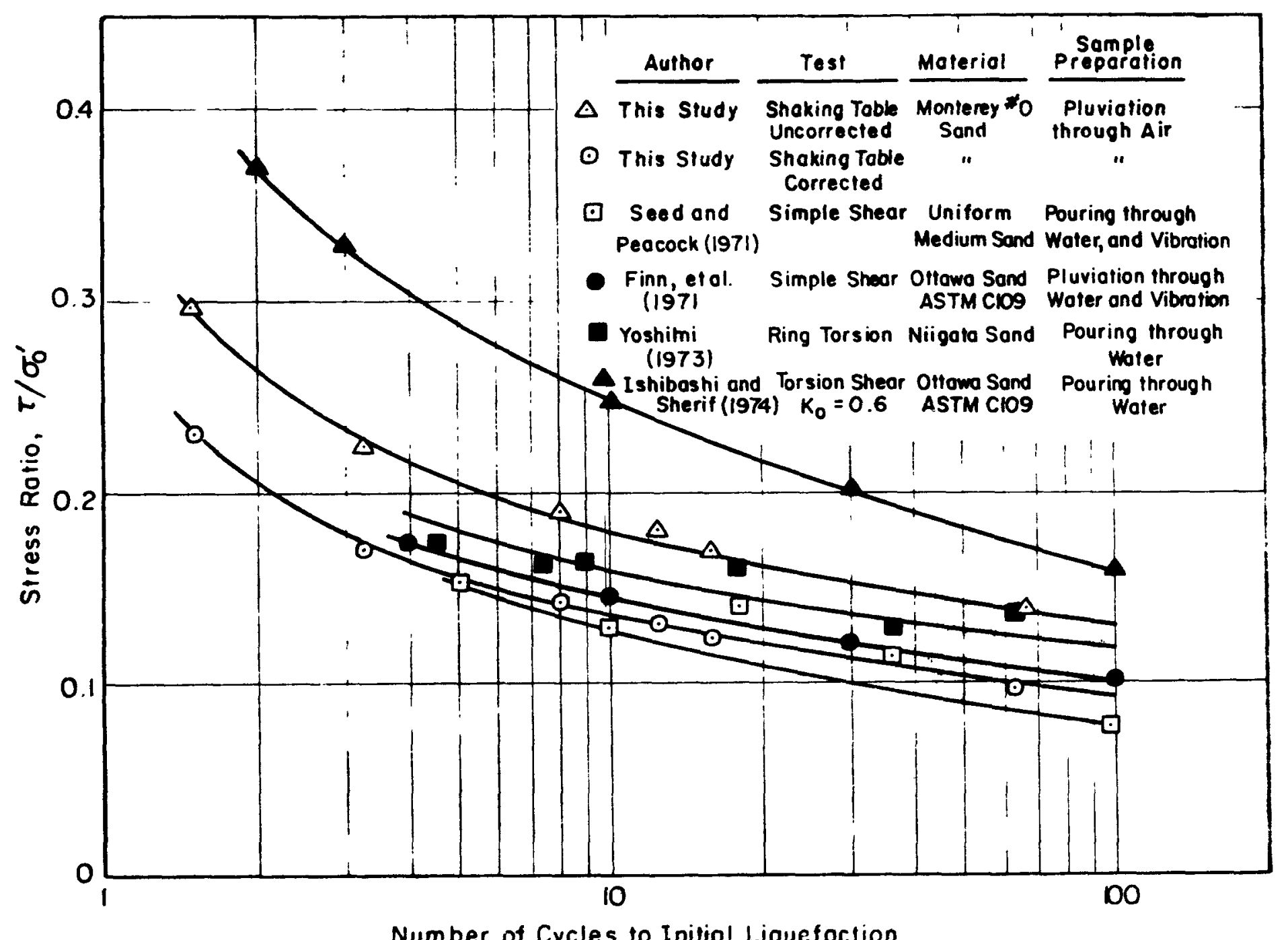

Number of Cycles to Initiol Liquefoction

Fig. 5.6 COMPARISON OF SHAKING TABLE AND SIMPLE SHEAR LIQUEFACTION TEST RESULTS FOR $D_{r}=50 \%$ 
results do not seem to be greatly affected by this drawback, and carefully conducted simple shear tests seem to give the closest approximation to the large-scale test results.

End effects are eliminated in the ring torsion device which was proposed by Yoshimi and Oh-Oka (1973) for Iiquefaction testing and which is attractive from a theoretical point of view. The published results, however, may be seen to be somewhat high compared to the corrected values from the shaking table tests. Ishibashi and Sherif (1974) using a similar device have published results for a relative density of 27 percent and an initial coefficient of lateral earth pressure at rest, $\mathrm{K}_{0}$, of 0.6 . If these results are extrapolated to 50 percent relative density, the curve shown in Fig. 5.6 is obtained; the high value of $k_{0}$ used in these tests is no doubt partly responsible for the very high results obtained.

As in the case of the simple shear device, the preparation and execution of liquefaction tests with the torsion shear apparatus seems to be too complex for general application in engineering practice.

Thus it is considered that the comparative simplicity of triaxial liquefaction tests may well outweigh the theoret1cal and practical difficulties associated with these tests, and the calculation of empirical correction factors for the triaxial test results, based on the shaking table results, will be the subject of Chapter VI. 


\section{Sho,dr Strains Aftor Initial Liquefaction}

The plots of shear strain versus number of cycles presented in Chapter III suggest that there are limits to the strains that may be developed after liquefaction, the limiting shear strains being strongly dependent on the relative density of the specimen.

Fig. 5.7 shows the number of cycles at which different levels of shear strain were reached for a given applied stress ratio, $\frac{\tau}{\sigma_{0}^{1}}$, at each of the relative densities tested. Only one point was available to define the curve for 90 percent, and the curve for this density was therefore drawn to fit the general trend of the data. Where no curve is shown for a partial strain level, that strain level was not developed in the tests at the indicated relative density. If the information from these curves is replotted in terms of $\frac{T}{\sigma_{0}^{1}}$ versus relative density for a given number of cycles, then curves such as those shown in Fig. 5.8 to 5.10 are obtained. These figures show the values of the stress ratio causing initial liquefaction and different levels of shear strain for different relative densities in 5,10 and 30 stress cycles. The data strongly suggest that each of the curves shown will be asymptotic to a certain relative density value and that a curve of limiting shear strain versus density may be established for each of these plots; such curves are shown in the upper parts of the figures. As might be expected, these limiting strain curves are virtually identical in each case, although the stress ratio necessary to induce liquefaction 


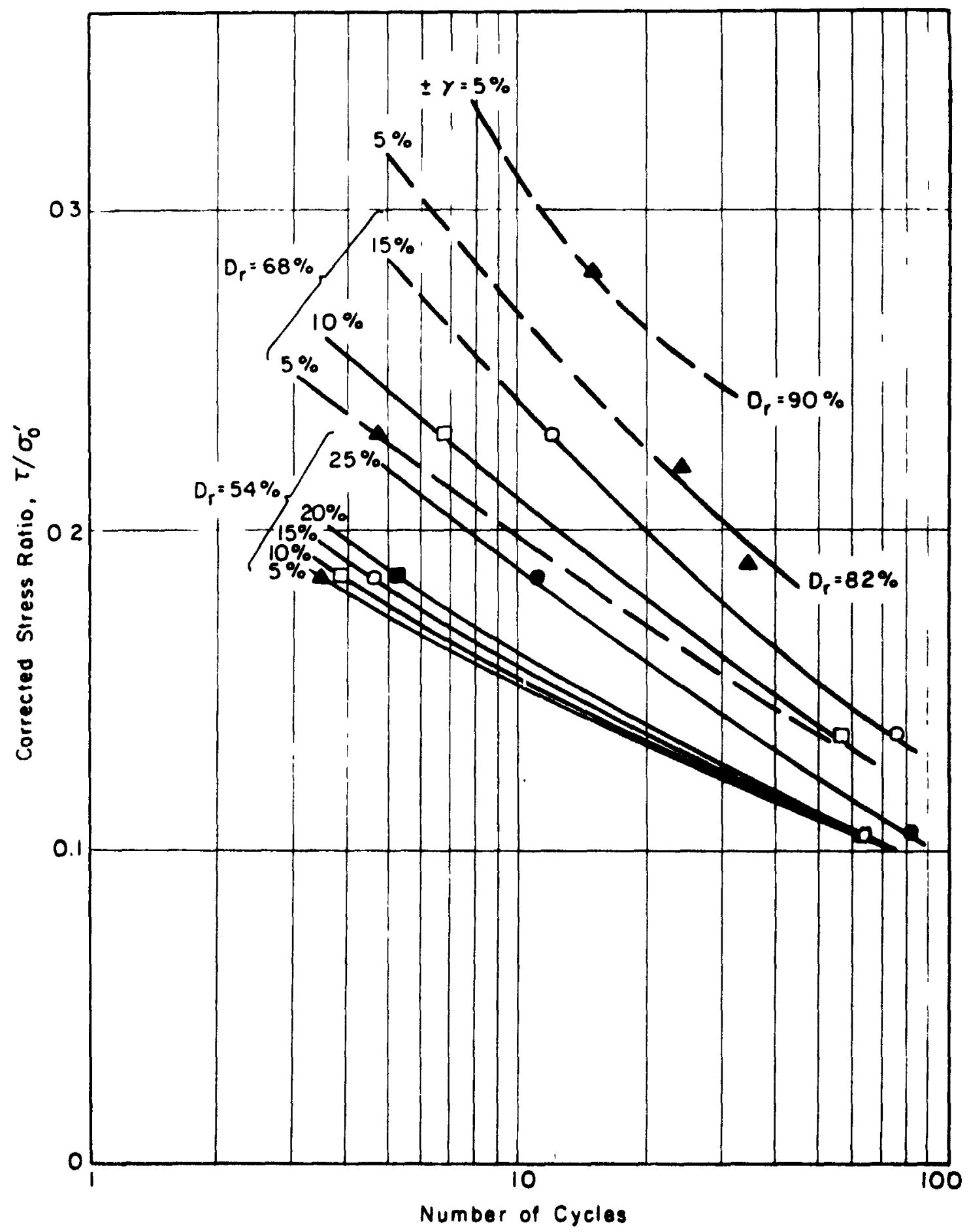

FIg 5.7 RELATIONSHIP BETWEEN $T / \sigma_{0}^{\prime}$ AND NUMBER OF CYCLES CAUSING DIFFERENT LEVELS OF STRAIN 

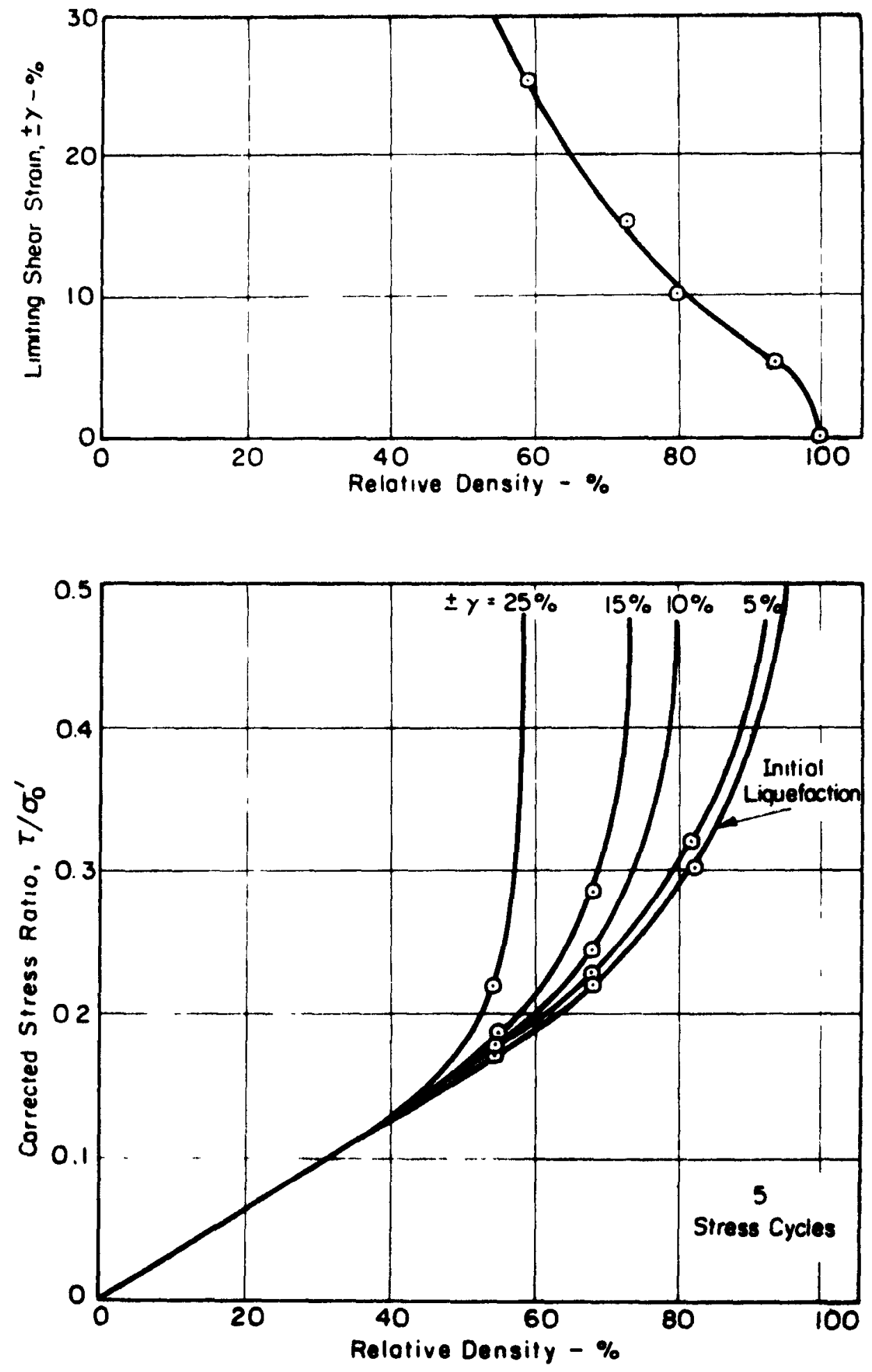

Fig. 5.8 LIMITING SHEAR STRAINS - 5 STRESS CYCLES 

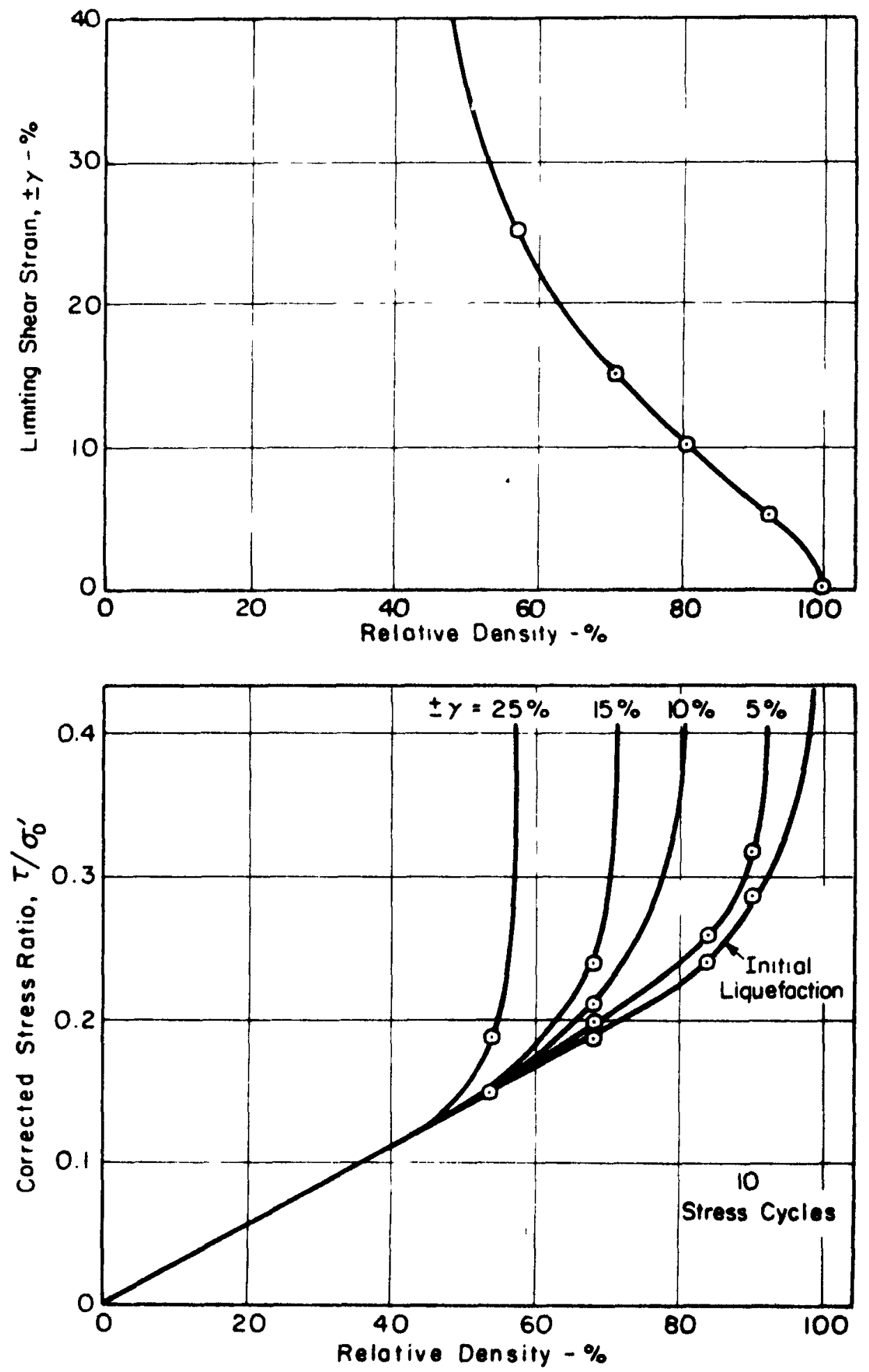

FIg 5.9 LIMITING SHEAR STRAINS - 10 STRESS CYCLES 

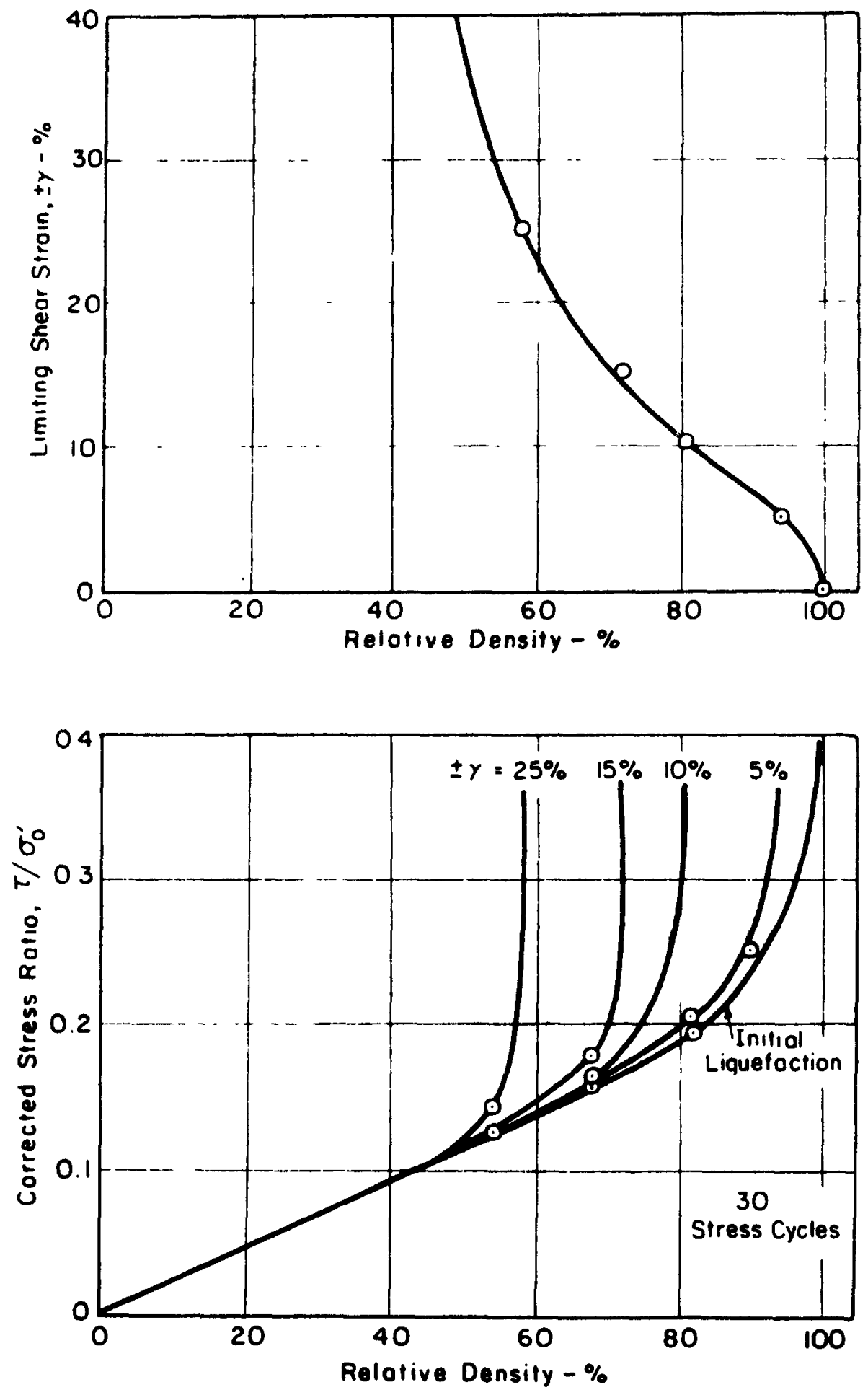

Fig. 5. 10 LIMITING SHEAR STRAINS - 30 STRESS CYCLES 
varios with the number of cycles Involved. Thus, the tendency of a specimen to dilate will limit the maximum shear strain that may be induced in the sand in relation to its relative density: While shear strains of 25 percent or more may be produced by ground shaking in liquefied soil at 50 percent density, it is unlikely that more than 6 percent shear strain will occur if the initial relative density is on the order of 90 percent. The ability of sands to undergo liquefaction at high densitles is thus a matter of definition. The tests show that inftial liquefaction, defined as a condition where $\Delta U=\sigma_{0}^{\prime}$, may be induced in dense specimens; however, if a tolerable level of shear strain is not exceeded, then complete liquefaction, as defined in Chapter I, will not take place; for example, if a 10 percent shear strain level is considered acceptable, then complete liquefaction will not occur at relative densities greater than about 80 percent.

However, the footing experiment shows that settlement of Joaded footings, once liquefaction has occurred, will take place as long as strong ground motion continues at all relative densities studied, although for the same bearing pressure the rate of settlement was about eight times slower for sand at 90 percent relative density than for sand at 54 percent relative density, as shown in F1g. 5.11.

Further, it has been observed that although there is a fluctuation of excess pore pressure in each stress cycle after initial liquefaction, once shaking stops the excess pore water 


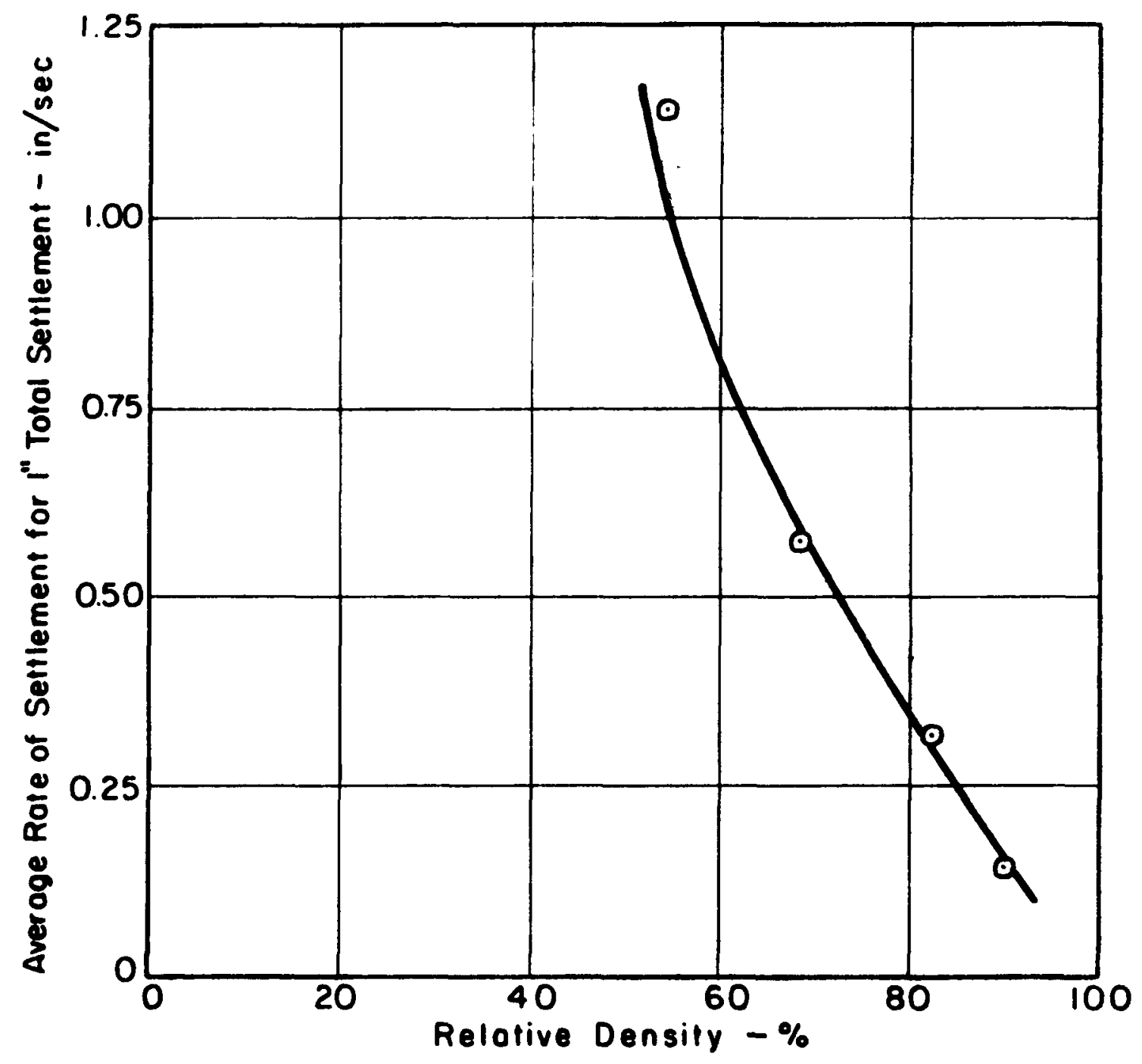

Fig. 5.II AVERAGE RATE OF FOOTING SETTLEMENT 
pressure remains at the value of the initial effective pressure; dissipation of this excess pore pressure may produce an upward flow of water and a resulting loss of strength in overlying deposits, even in the case of dense layers which suffered relatively small deformations during shaking.

\section{Comparison with Field Results}

Comparison of the results from the present testing program with data from field liquefaction cases may be prefaced by a number of observations:

(a) The present series of tests was carried out with specimens formed by pluviation through air; In nature, liquefaction-susceptible saturated sand deposits are more likely to have been placed through water; small but important differences in fabric may exist between the two deposition methods.

(b) Sand deposits in areas subjected to frequent earthquake shaking will have been vibrated, and perhaps even liquefied, repeatedly; the effect of previous vibration and Iiquefaction history may influence the resistance to 11quefaction of the sand.

(c) The tests described in this report have been carrled out using shaking in one horizontal direction only, whereas earthquake-induced ground motion has three orthogonal components at any given moment. The effect of multidirectional shaking may be inferred from the comparison 
made by Pyke et al. (1974) of volume changes in dry sand resulting from one-directlonal and multi-directional shaking; the results of this study indicate that a reduction on the order of 10 percent should be applied to the stress ratio obtained in one-directional shaking to account for this effect.

Available field liquefaction data (Seed and Peacock, 1971.) are presented in Fig. 5.12. The best-documented point on the proposed lower boundary in this figure is that obtained from the Niigata earthquake of 1964. Superimposed on these data are the results of the shaking table study, reduced by 10 percent to account for multi-directional shaking and for 10, 15, and 20 stress cycles, which is in the range of uniform stress cycles considered to be equivalent to the actual ground shaking at Nifata. The data shown are the stress ratios at which inftial liquefaction occurred in the shaking table tests. Fig. 5.13 shows similar results using 5 percent shear strain as a fallure criterion for the shaking table tests. Agreement between the shaking table test data and the field liquefaction data is good, taking into account the approximations involved in determining the field Ilquefaction conditions, and the differences in fabric and previous strain history between liquefaction test specimens and natural depos1ts.

The results obtained in this study, corrected for multidirectional shaking, are thus seen to give a reasonable approximation of observed fleld liquefaction behavior. 


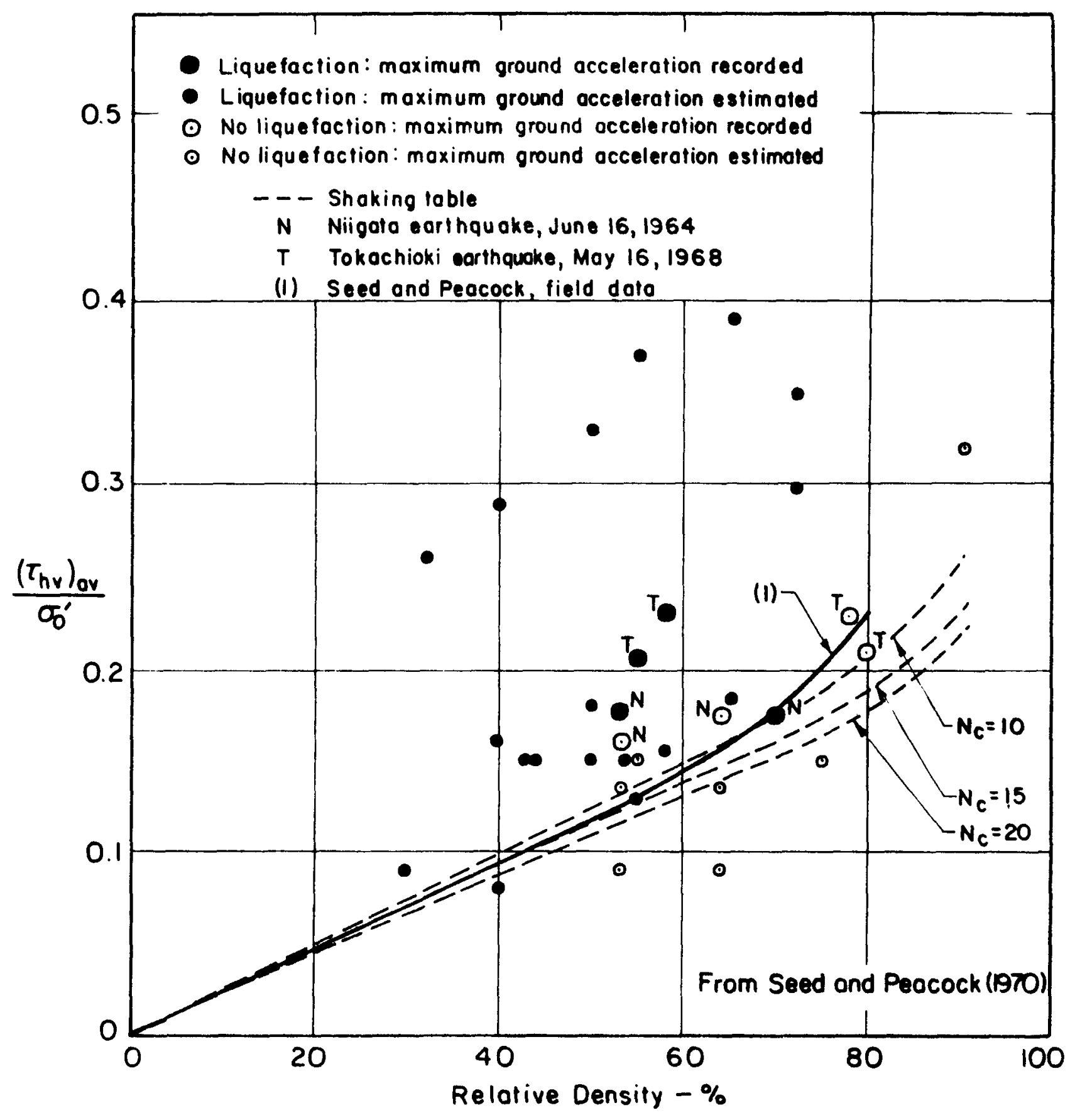

Fig. 5.12 COMPARISON OF FIELD DATA WITH SHAKING TABLE RESULTS FOR INITIAL LIQUEFACTION AT $N_{c}=10,15,20$ CYCLES 


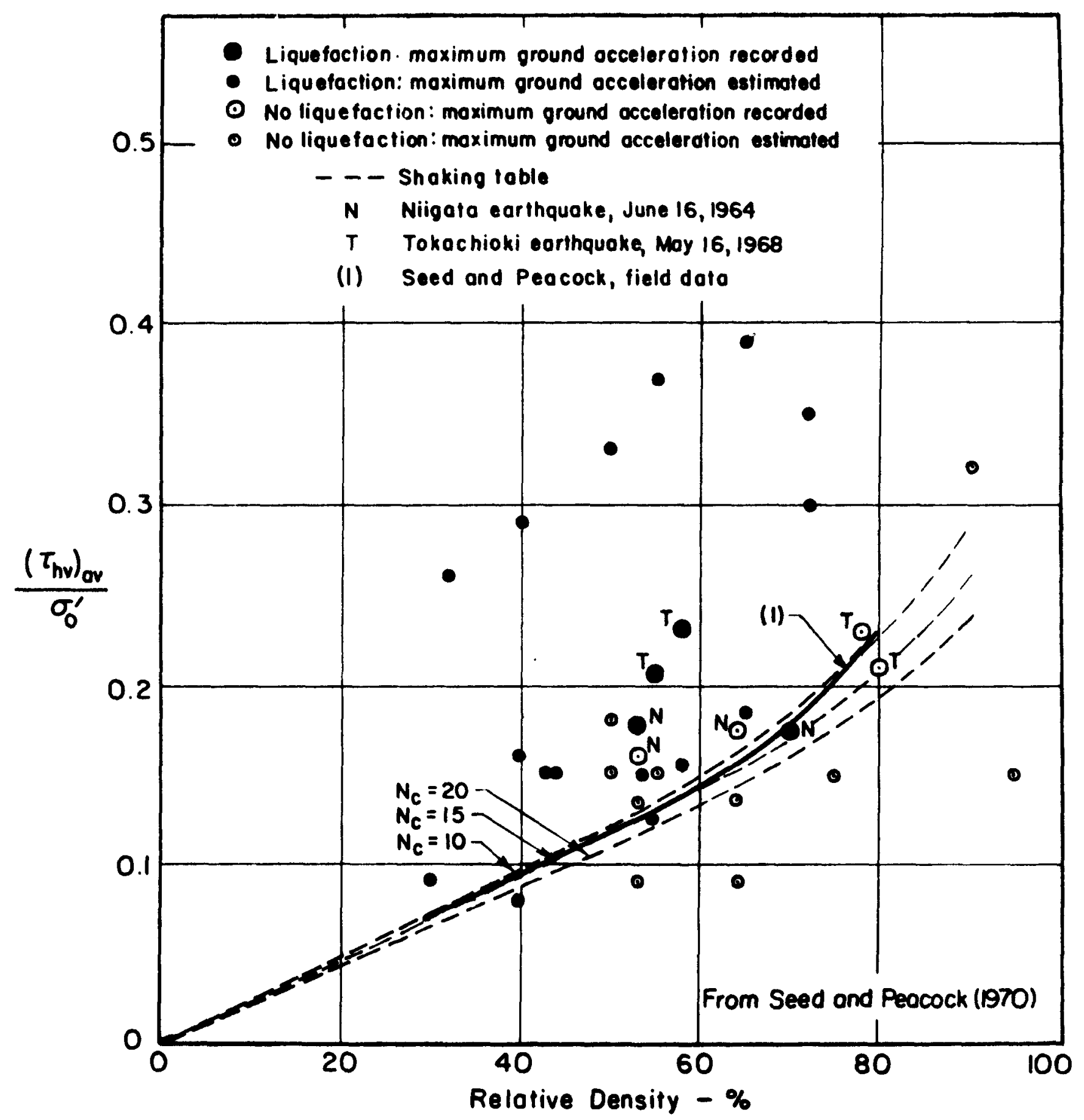

Fig. 5.13 COMPARISON OF FIELD DATA WITH SHAKING TABLE RESULTS FOR $\pm \gamma=5$ PERCENT AT $N_{c}=10,15,20$ CYCLES 
VI. COMPARISON WITH CYCLIC TRIAXIAL TESTS

The shaking table tests described in this report were part of a larger research program studying the general behavior of sands under cyclic loading. Another aspect of this program was the development of an improved cyclic loading triaxial apparatus for liquefaction tests. One application of this new equipment was to carry out a serles of tests on the same material and for similar stress conditions to those used'in the shaking table tests, with the object of relating the triaxial test results to the shaking table results.

It was pointed out in Chapter I that a triaxial 11quefaction test imposes particular loading and boundary conditions on the specimen which are different from the field conditions. Seed and Peacock (1971) have listed these as follows:

1. $\mathrm{K}_{\mathrm{o}}$ - condition. In order to produce a symmetrical cyclic shear stress condition on one plane of a trlaxial test specimen, it is necessary to subject the sample to an initial ambient pressure $\left(\mathrm{K}_{0}=1\right)$ condition. Laboratory simple shear tests have shown that liquefaction resistance increases with the initial value of $\mathrm{K}_{0}$ used in the tests. Thus an initial $\left(\mathrm{K}_{0}=1\right)$ condition can be expected to contribute to higher liquefaction resistance values than those that would be obtained for field conditions, in which $x_{0}$ is typically on the order of 0.4 . 
2. Applied Shear Stress. The cyclic shear stress on the $45^{\circ}$ plane w111 be the maximum shear stress on the spectmen, $\tau_{m}$, while for a horizontal layer subjected to cyclic loading, the horizontal cyclic stress, ' $\tau_{\mathrm{hv}}$ ' on any soll element is considerably lower than the maximum shear stress on that element. Further, it should be noted that the results of triaxial tests are reported in terms of $\frac{\tau_{m}}{\sigma_{3 c}^{\prime}}$ where $\sigma_{3 c}^{\prime}$ is the Inttial ambient pressure, while field and shaking table results are given as a function of $\frac{\tau_{h v}}{\sigma_{0}^{\top}}$ where $\sigma_{0}^{\prime}$ is the initial effective vertical pressure.

3. Principal Stress Directions. Under earthquake loading conditfons in the field the major principal stress direction for a horizontal soil element will rotate cyclically about the vertical, reaching a maximum angle of perhaps $40^{\circ}$. In the triaxial test, the major principal stress will rotate by $90^{\circ}$ in each half cycle.

4. Intermediate Principal Stress. For the simplified onedirectional earthquake loading considered in this study, a soll element w11l deform in plane strain conditions, with an Intermediate principal stress of $\sigma_{2}=v\left(\sigma_{1}+\sigma_{3}\right)$, whereas in the triaxial test the intermediate principal stress will be equal to $\sigma_{1}$, for half of the stress cycle and $\sigma_{3}$ for the other half.

The combined effect of these factors on triaxial 1iquefaction tests is to give results in terms of $\frac{\tau_{\mathrm{m}}}{\sigma_{3 c}^{\prime}}$ which are 
considerably higher than the $\frac{\tau_{h v}}{\sigma^{\prime}}$ values producing liquefaction in the field or in shaking table tests. However, if reduction factors could be established relating the triaxial tests results to those from the shaking table, which more closely approach the field conditions, then triaxial tests could be used directly for determining liquefaction potential of soil deposits, rather than the much more costly and time-consuming shaking table tests. With this idea in mind, an improved cyclic triaxial testing system was developed (Chan, 1975). Essentlally, it consists of a pneumatic system which applied a sinusoidal load to a 2.8-in diameter specimen, $7 \mathrm{in}$. high. The specimen is enclosed by a rubber membrane 0.012 in. thick, and placed in a triaxial chamber, where it is confined by air pressure under $K_{0}=1$ conditions. The test results that will be presented in this chapter were obtained from saturated specimens of Monterey no. 0 sand prepared by a pluviation procedure analogous to that used in the shaking table study. This process, as described by Pyke (1973), consists of pouring sand into the specimen mold from a flask fitted with a nozzle, the diameter of which is calibrated to give the required density of deposition. The flask is moved by hand with a circular action, to build up the specimen continuously. Density results reproducible within 0.5 pcf are reported. The specimens were saturated by a procedure similar to that used in the shaking table tests, and full saturation is reported for all tests presented in this chapter.

The results of cyclic triaxial liquefaction tests carried 
out by Mulilis (1975) using this method, for relative densities of 50,70 and 87 percent, are presented in Fig. 6.1; the curves show the relationships between $\frac{\tau_{m}}{\sigma_{3 c}}$ and the number of cycles required to cause inftial liquefaction of the test specimens. Based on these values and the shaking table results summarized in Fig. 4.10, plots such as those shown in Figs. 6.2 and 6.3 were prepared, comparing the cest data for different relative densities at a given number of cycles to liquefaction. Values of a correction factor, $C_{r}$, defined as:

$$
c_{r}=\frac{\tau_{h v}}{\delta !} / \frac{\tau_{\max }}{\sigma_{3 c}^{T}}
$$

were calculated at different densities for $2,5,10,30$ and 50 eycles to intial liquefaction. It was found that $C_{r}$ is essentially constant at a given number of cycles, but decreases slight ly as the number of cycles increases. Fig. 6.4 shows that the factor for reducing the results of triaxial iqquefaction tests on pluviated specimens, reported in terms of $\frac{\tau_{m}}{\sigma_{3 c}}$ to shaking table results in terms of $\frac{\tau_{h v}}{\sigma !}$, will vary between 0.66 and 0.61 in the 2 to 30 cycle range. This reduction, applied to the triaxial test results, will give stress ratio values which closely approximate the results of one-directional shaking table tests. A further reduction of 10 to 15 percent is required to obtain stress ratios corresponding to multi-directional shaking, leading to overall correction factors on the order of 0.59 to 0.55 for most earthquake conditions. 


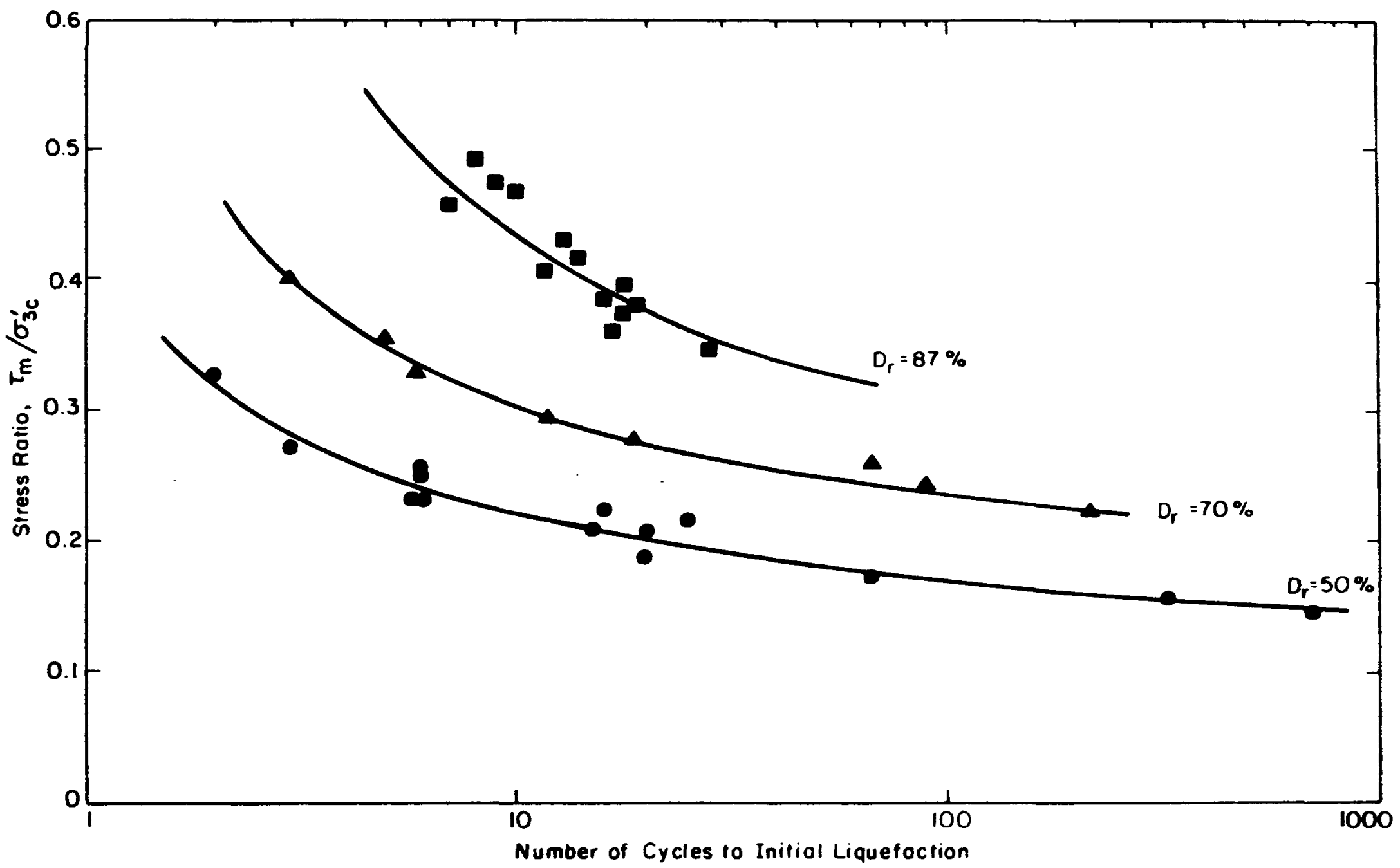

Fig. 6 I TRIAXIAL LIQUEFACTION TEST RESULTS FROM MULILIS (1975) 


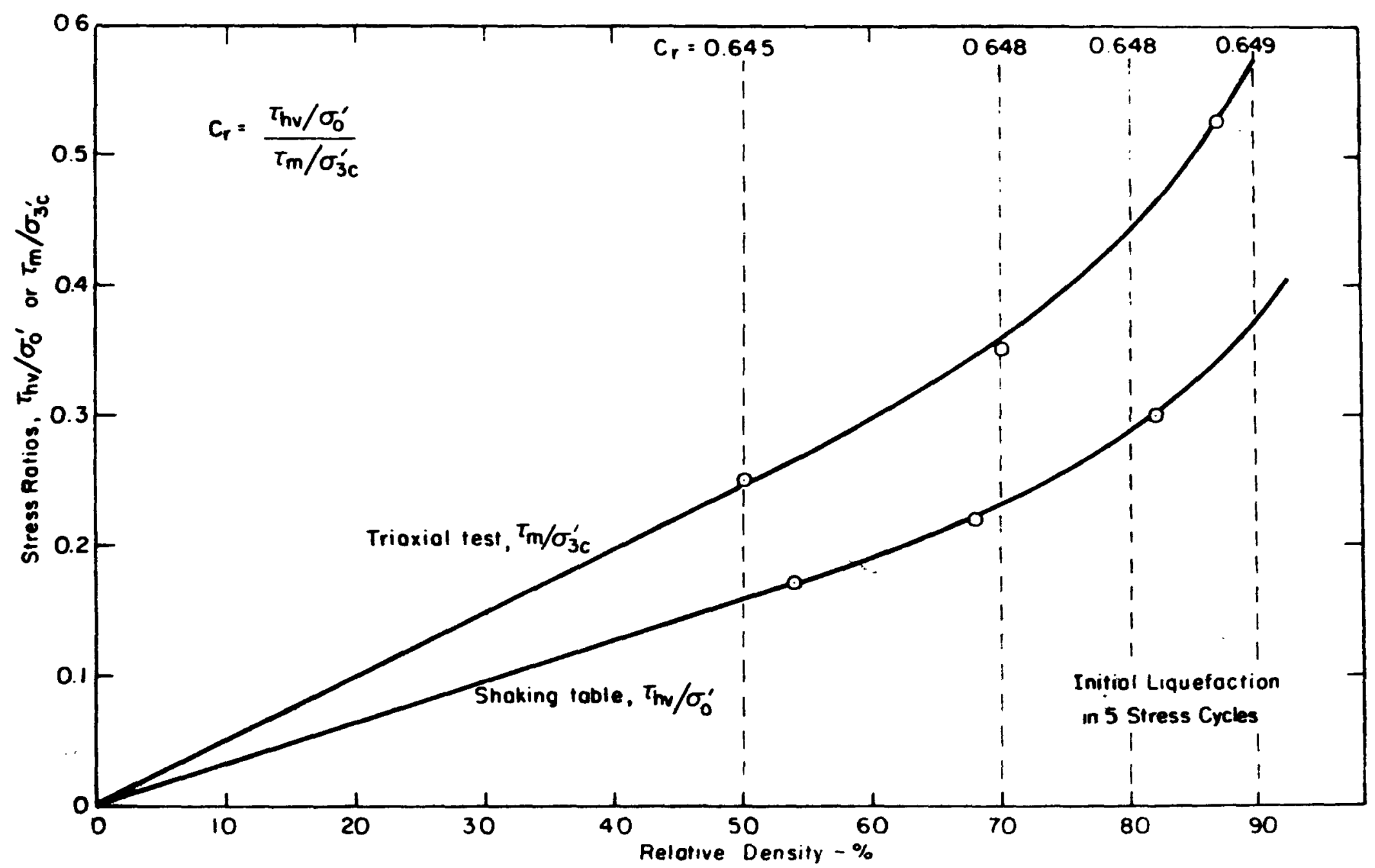

Fig. 6.2 COMPARISON OF SHAKING TABLE AND TRIAXIAL TEST RESULTS 


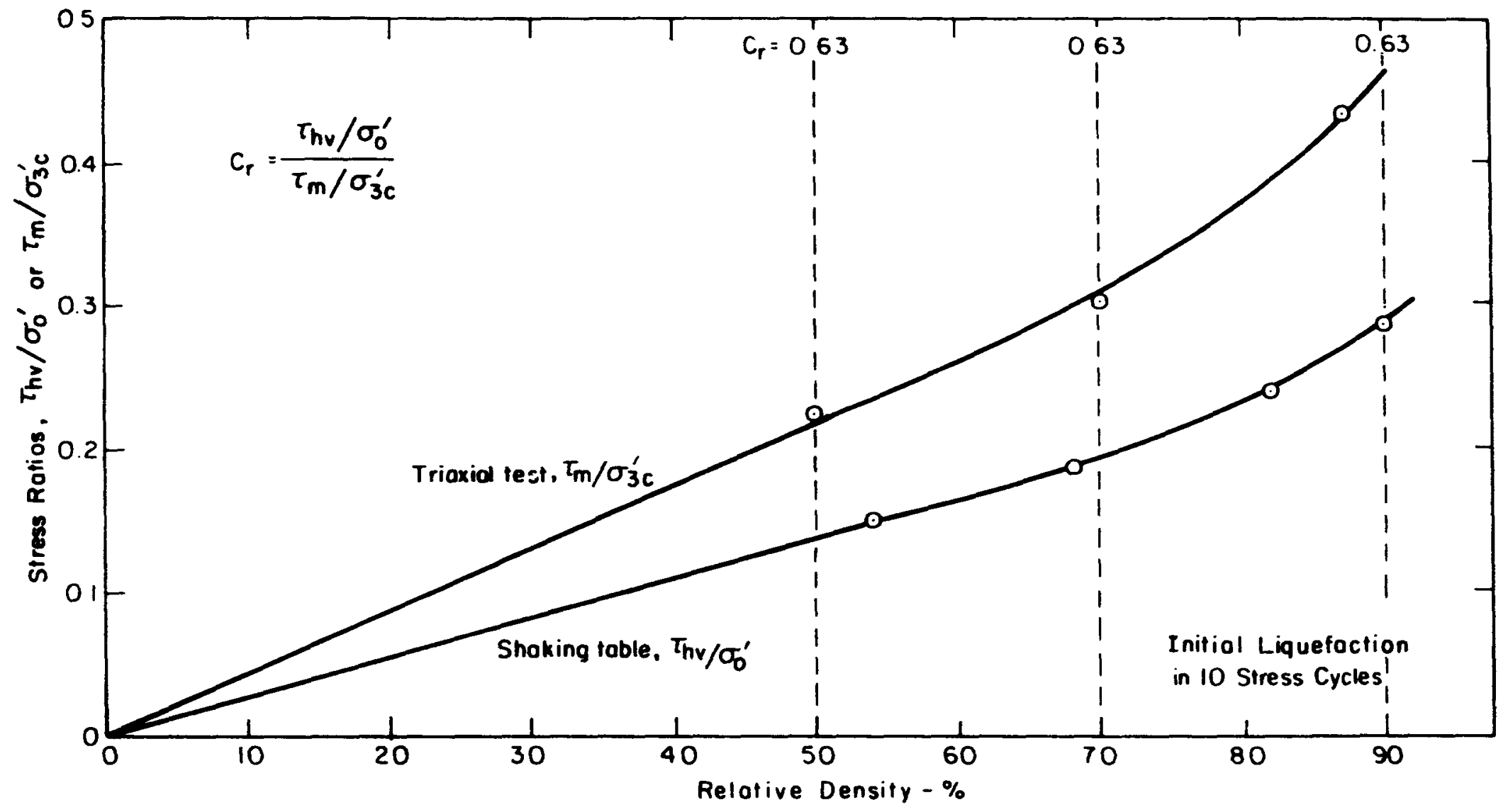

Fig. 6.3 COMPARISON OF SHAKING TABLE AND TRIAXIAL TEST RESULTS 


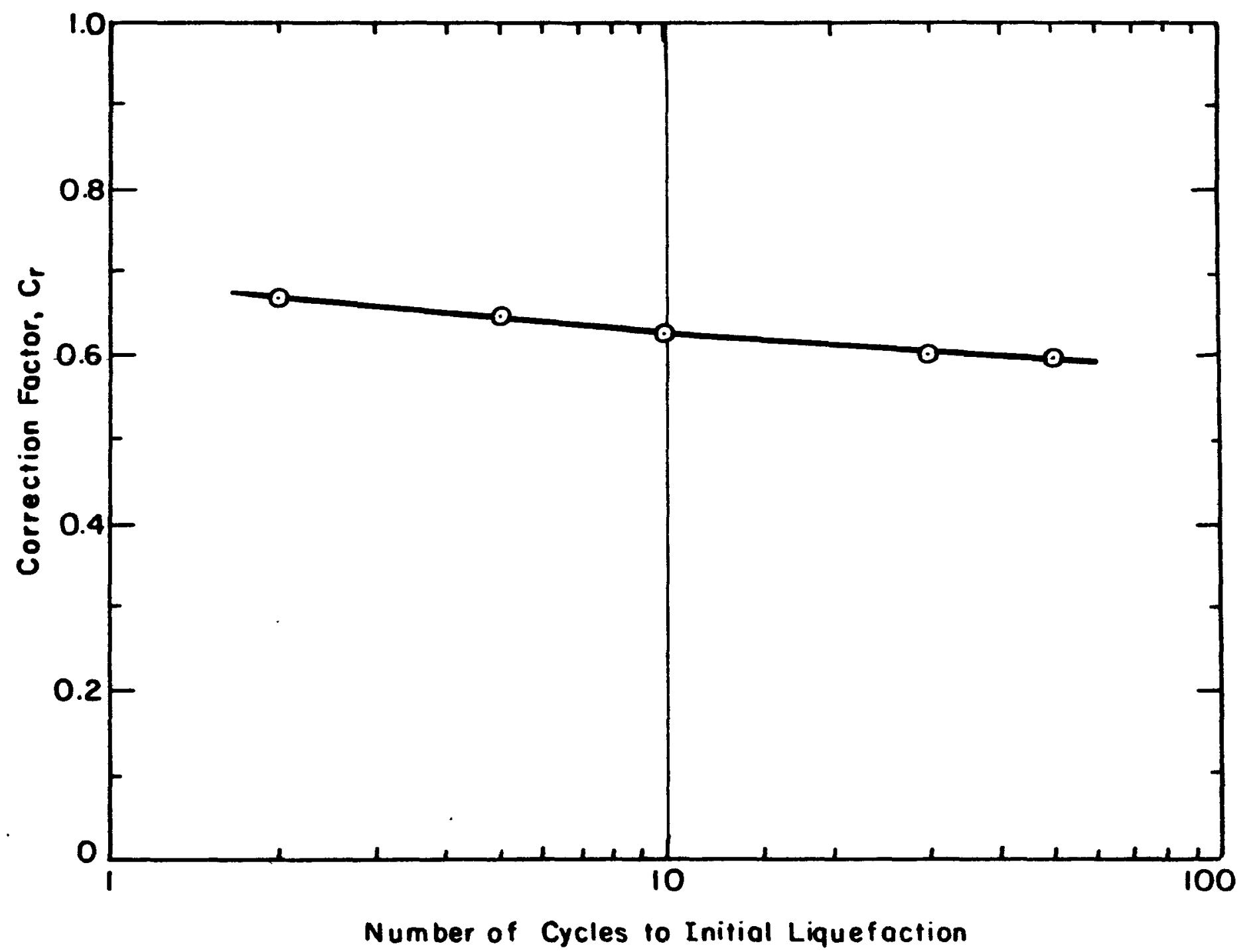

FIg. 6.4 CORRECTION FACTORS FOR TRIAXIAL TEST RESULTS 


\section{SUMMARY AND CONCLUSIONS}

The testing program described previously was carrled out to study the liquefaction characteristics of 'large specimens of clean, saturated medium sand in cyclic simple shear conditions. Measurements of pore pressure and shear strain development have been presented for sand specimens at relative densities of 54 , 68,82 , and 90 percent and the results interpreted to determine the values of stress ratio $\frac{\tau}{\sigma_{0}^{\prime}}$ causing liquefaction at the various relative densities.

The effects of system volume change were examined, and appropriate corrections made to the results. The corrected values are considered to be a very good approximation of the results that would be obtained from an ideal non-compliant testing system, and free of boundary effects.

The principal conclusions which may be drawn from this study are:

(a) Complete Iiquefaction of sand at relative densities greater than approximately 50 percent is a matter of def1nition of the maximum acceptable shear strain.

(b) Initial liquefaction, a condition where the dynamically Induced pore water pressure is equal to the initial vertical effective stress, may be induced even in dense deposits during large magnitude earthquakes. 
(c) The 11quefaction potential expressed in terms of the atress rat1o $\frac{\tau}{\sigma}$ varies ifnearly with relative density up to about $\mathrm{Dr}=80$ percent. At higher relative densities, the stress ratio necessary to produce initial liquefaction increases more rapidly with relative density.

(d) Test data obtained from properly conducted cyclic simple shear liquefaction tests in a Roscoe-type simple shear device closely approximate the results obtained from shaking table tests in terms of $\underset{0}{\tau}$ vs Dr.

(e) Correction factors can be established for cyclic triaxial liquefaction tests, to obtain from them $\frac{T}{0}$ values representative of the large-scale test or field results. To obtain values of $\frac{\tau}{0}$ representative of field conditions involving multi-directional shaking, the cyclic triaxial test data in terms of $\frac{\tau_{m}}{\sigma_{3 c}^{\prime}}$ should be multiplied by a correction factor of the order of 0.59 to 0.55 , depending on the number of stress cycles involved. To obtain values of $\frac{\tau}{\sigma_{0}^{\prime}}$ representative of one-directional cyclic simple shear conditions, the triaxial test data should be multiplied by a correction factor of the order of 0.66 to 0.61 depending on the number of stress cycles Involved.

The results obtained from this study have provided considerable insight into various aspects of liquefaction development; however, other problems related to this phenomenon, such as the effects of soll fabric and previous stress h1story on 
1iquefaction potential, require further study. Furthermore, corresponding advances in determining the relative density of potentially liquefiable deposits in situ are also required to further improve evaluations of the Iiquefaction potential of saturated sands as a result of earthquake shaking. 


\section{APPENDIX I}

\section{Compliance Measurements}

Special tests were carrled out to measure the total volume change of the saturated sand specimens as the initial effective pressure was released by increasing the pore water pressure. Tests were carried out at 54 and 82 percent relative density and for Initial effective pressures of $4.5,8$ and $13 \mathrm{psi}$, in the following way:

A sand specimen was prepared and saturated as for a normal test, described in Chapter III. At that point, the specimen was under back pressure, using the arrangement shown schematically in Fig. A.1.1. Once complete saturation was obtained, the effective pressure was adjusted to the required initial value. Then, additional air pressure was applied through the backpressure line to the top of the graduated water column connected to one of the spectmen chamber drains. Water flowed lnto the specimen as the pore pressure increased, causing the spectmen to rebound, and membrane penetration to decrease. At regular Intervals, the air pressure was held constant, and reading of the drop in height of water in the graduated column was taken. Thus the total volume change could be measured for pore pressure Increments approaching the initial effective pressure, simulating the pressure buildup in liquefaction tests. Measured volume change versus pressufe curves are shown in F1gs. A.1.1, A.1.2, A.1.3, and A.1.4. In these figures it may be seen that the final 


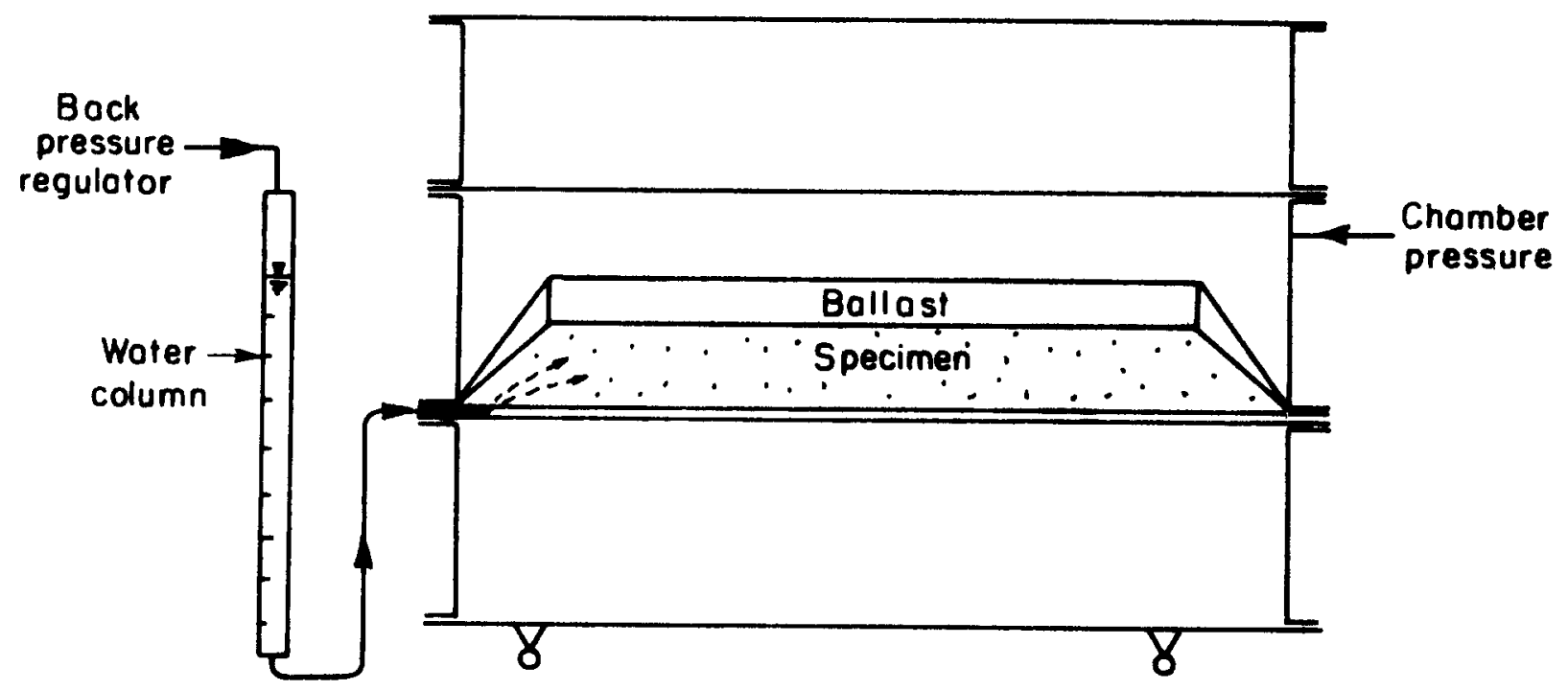

Fig. A-I.I BACK PRESSURE APPLICATION 


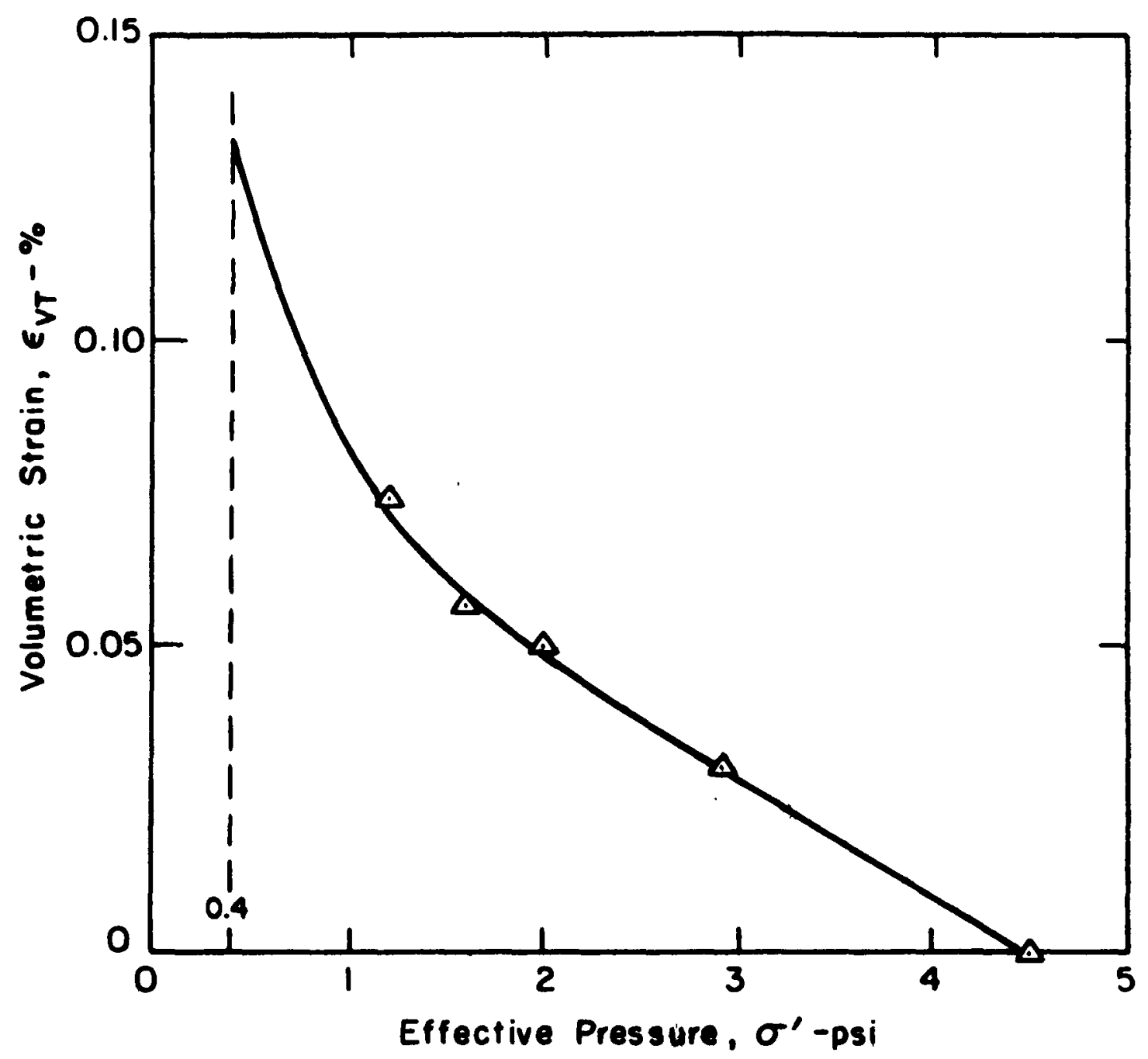

Fig. A-I.2 TOTAL VOLUMETRIC REBOUND OF $4^{\text {" }} \mathrm{HIGH}$ SPECIMEN FOR $\sigma_{0}^{\prime}=4.5 \mathrm{psi}, D_{r}=54 \%$ 


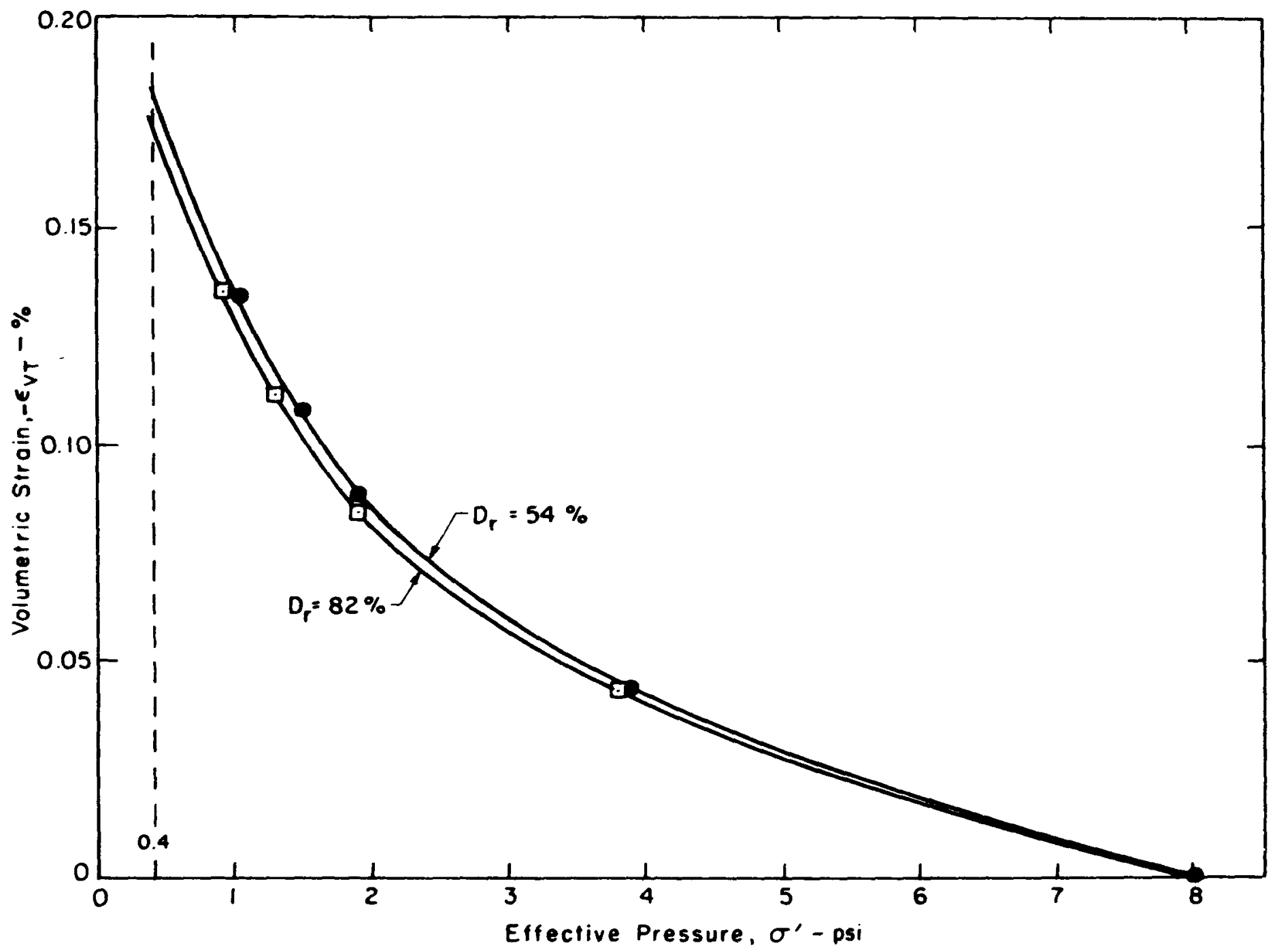

Fig. A-I.3 TOTAL VOLUMETRIC REBOUND OF $4 "$ HIGH SPECIMEN FOR $\sigma_{0}^{\prime}=8$ pSi 


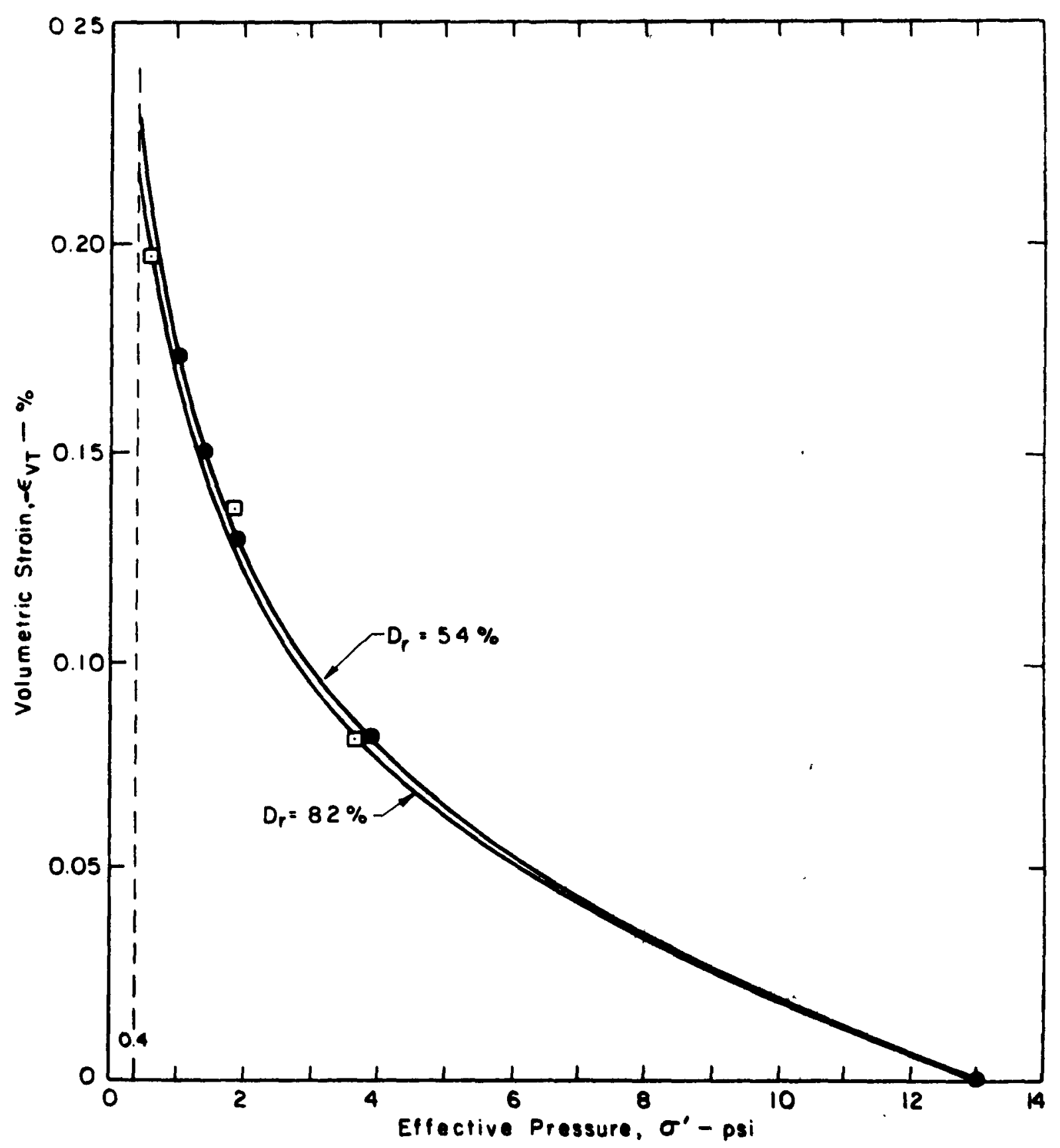

Fig. A-1.4 TOTAL VOLUMETRIC REBOUND OF 4 " HIGH SPECIMEN FOR $\sigma_{0}^{\prime}=13$ psi 
volumetric change on unloading could be determined by extrapolation to the small positive effective pressure value of 0.4 psi. This pressure was selected, rather than zero pressure, 88 1t was considered that gravity loads acting on the specimen, i.e. self-weight and the weight of the ballast, produced a small residual effective pressure value, on the order of $0.4 \mathrm{ps} 1$. The volume changes measured in these tests included both material rebound and membrane penetration effects; in order to separate the two effects, it was decided to obtain volume change data for another specimen height, as the differences in volume change for the same pressure conditions, and different heights, would be proportional to the difference in material rebound. Accordingly, another serles of tests was carried out using $0.125^{\prime \prime}$ high specimens, for which material rebound would be very low; the results of these tests are summarized in F1g.A.1.5. In this case it may be seen that the minimum residual effective pressure was considered to be on the order of $0.3 \mathrm{psi}$.

Rebound volume change data were therefore available for two specimen heights and for different initial effective pressures. It was then possible to separate system compliance from material rebound as follows: Plots of volume change versus specimen helght were prepared, and that part of the total volume change due to system compllance was measured by projecting to zero specimen height, thus eliminating all material rebound effects. This plot is shown in Fig. 4.2, Chapter IV. The values of system compliance and material rebound thus obtalned were then used to 


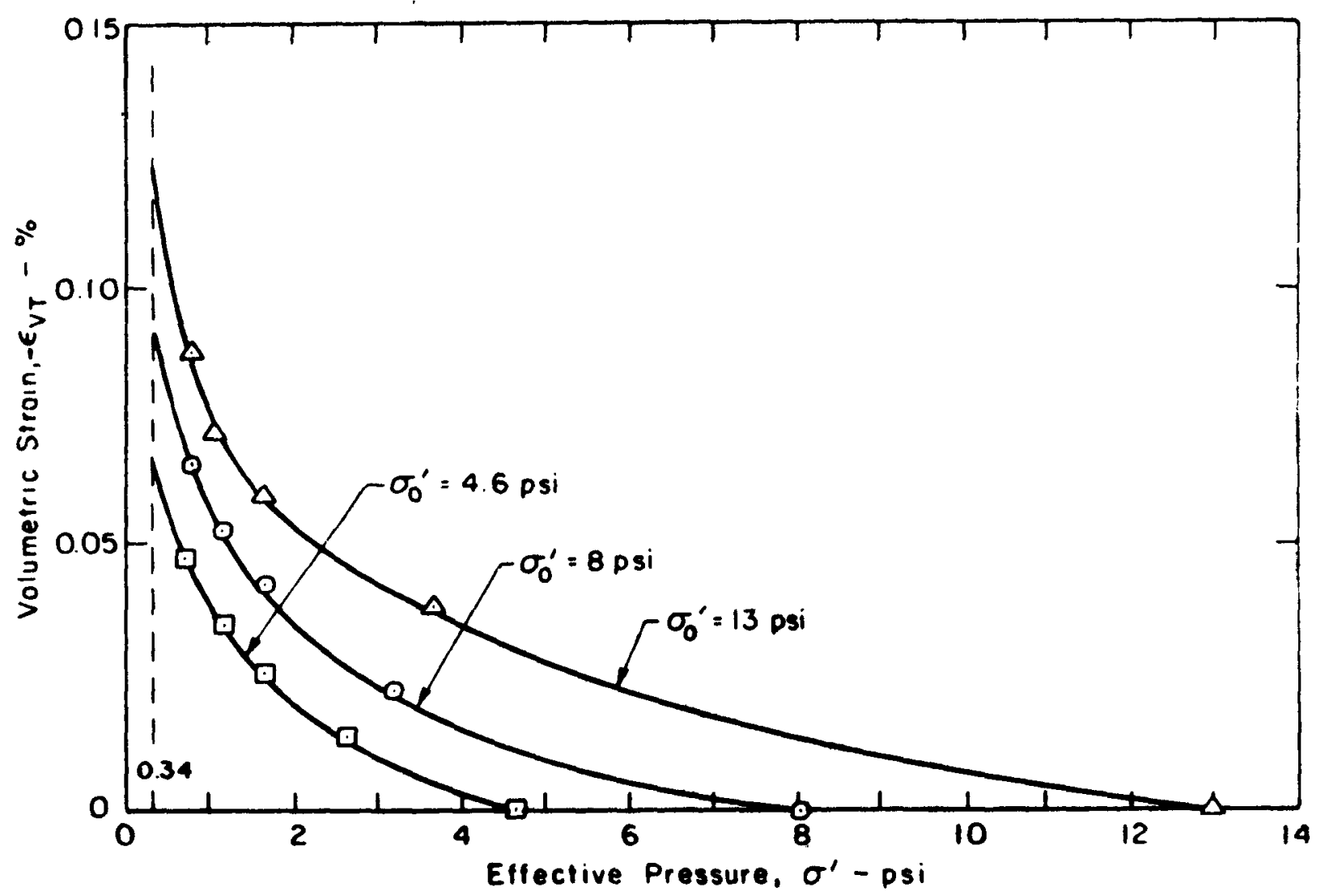

FIg. A-1.5 TOTAL VOLUMETRIC REBOUND FOR $1 / 8$ " HIGH SPECIMEN 
calculate the corrected values of stress rat 10 causing 11que-

faction in the shaking table tests, as described in Chapter IV. 


\section{APPENDIX II}

\section{Dynamic Pore Pressure Records}

This appendix contains complete dynamically induced pore pressure development curves for the tests presented in this report. Both maximum and minimum pressures recorded after 11quefaction are shown. There was a considerable scatter in the minimum pressure values observed when the specimen dilated; values have not been given for every cycle, but were chosen to Indicate the general tendency of pore pressure decrease due to dilation. It is considered that pore pressure measurements recorded for more than about 10 or 15 cycles after 11quefaction may not be representative of natural behavior, as the specimen was cons1derably distorted, especially in the case of tests at 54 percent relative density.

A complete discussion of pore pressure development is found in Chapters III and $V$ of this report. 


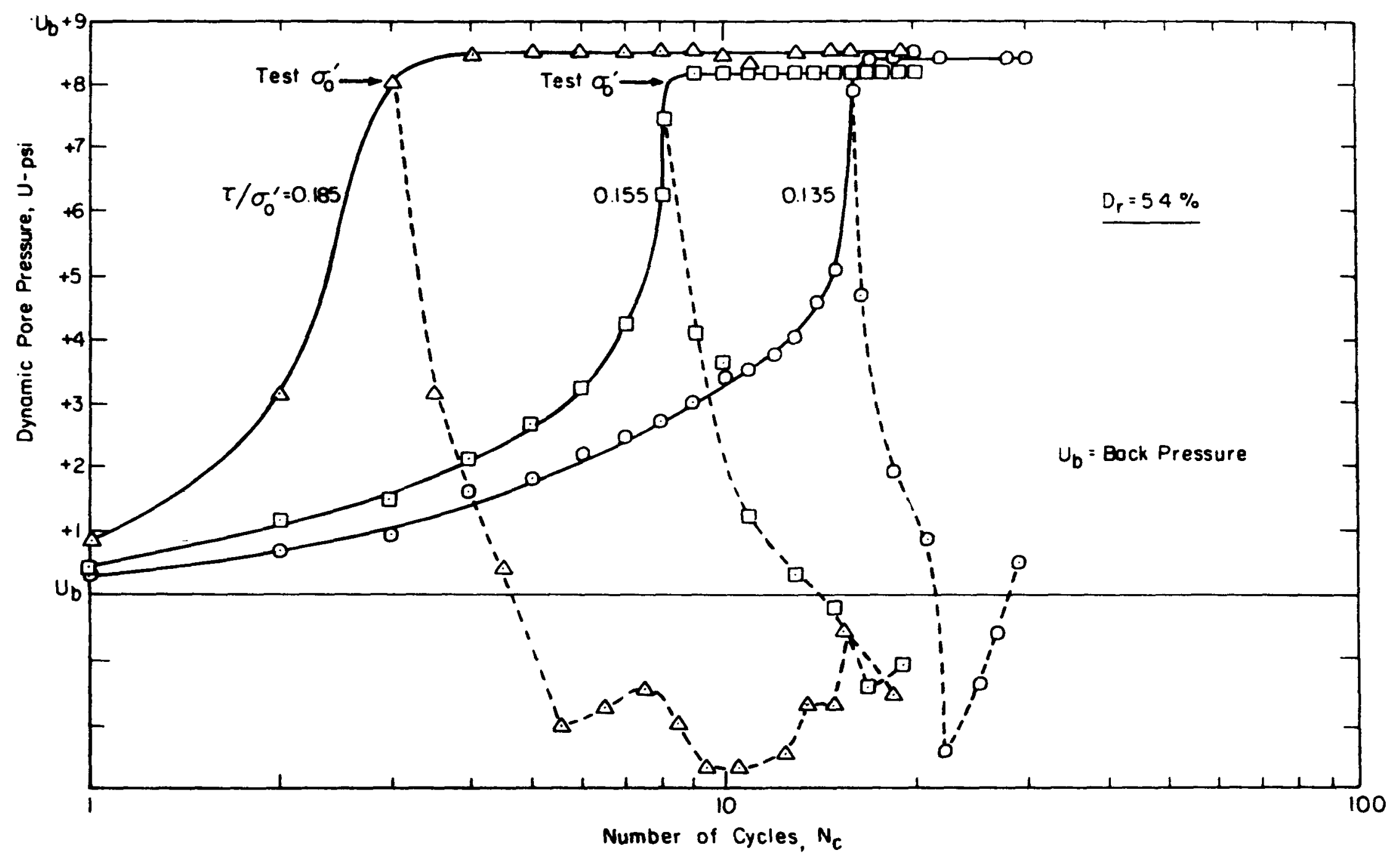

Fig. A-2.I DYNAMIC PORE PRESSURE DEVELOPMENT 


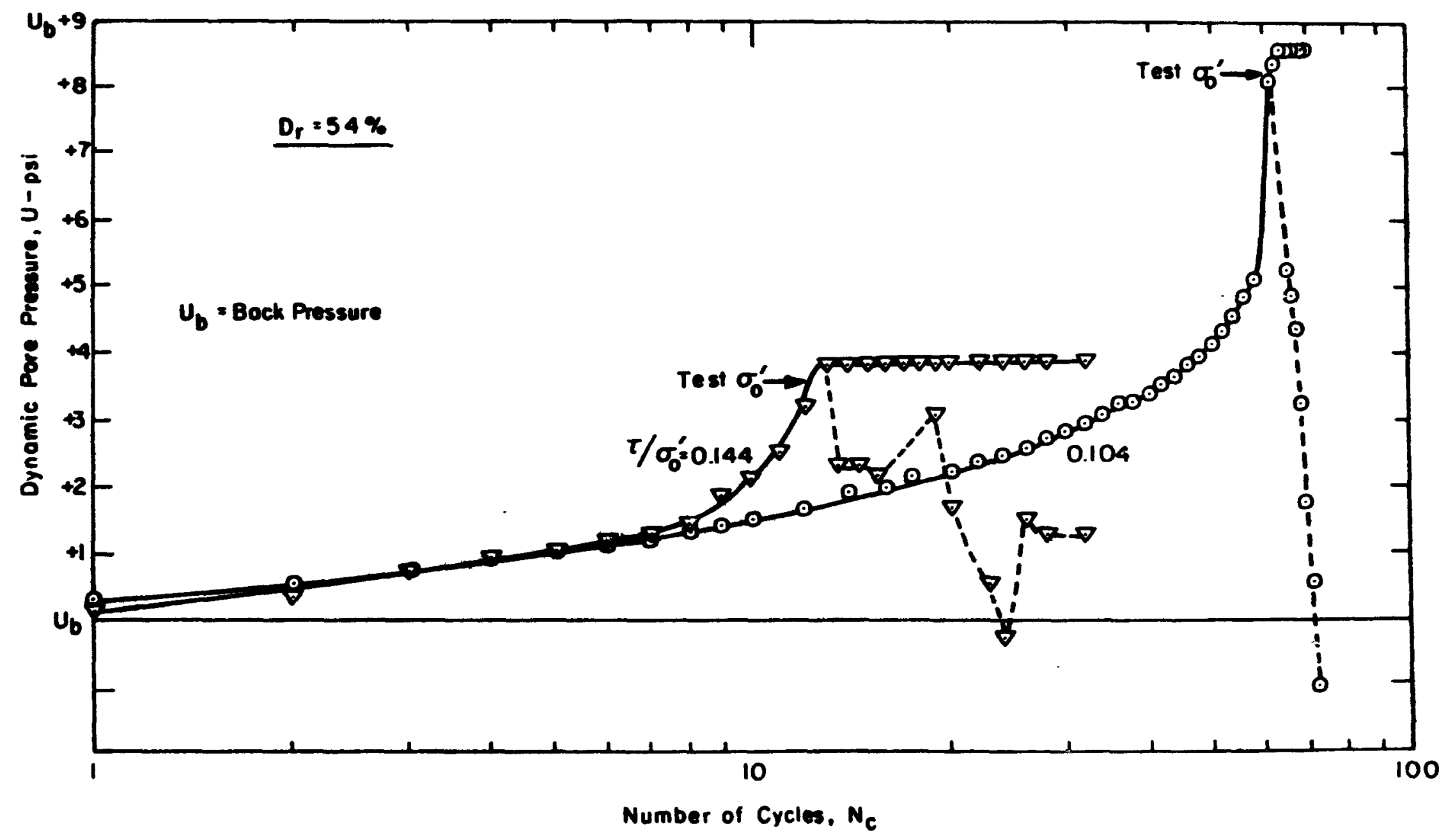

Fig. A-2.2 DYNAMIC PORE PRESSURE DEVELOPMENT 


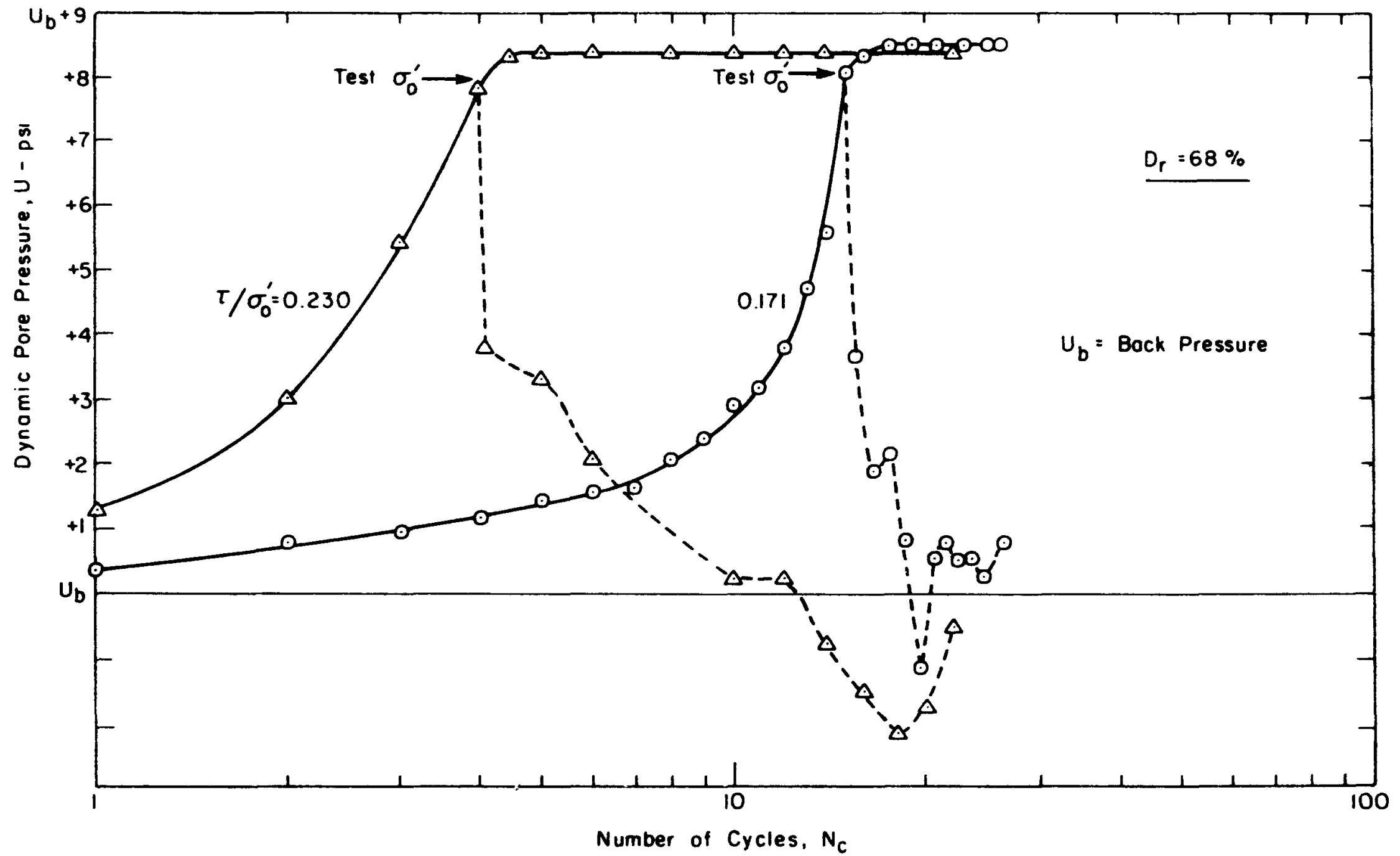

FI. A-2 3 DYNAMIC PORE PRESSURE DEVELOPMENT 


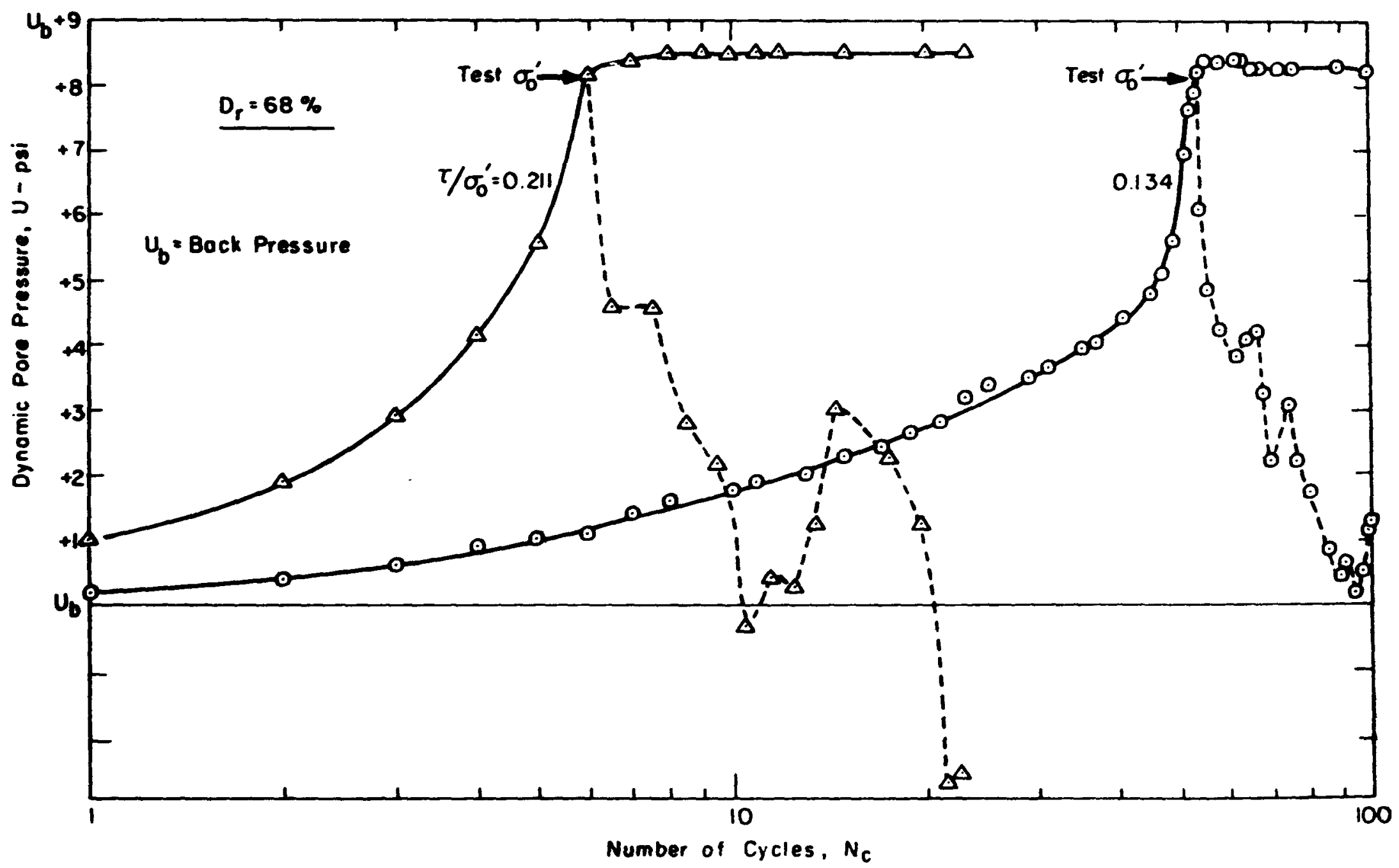

FIg.A-2.4 DYNAMIC PORE PRESSURE DEVELOPMENT

$=$ 


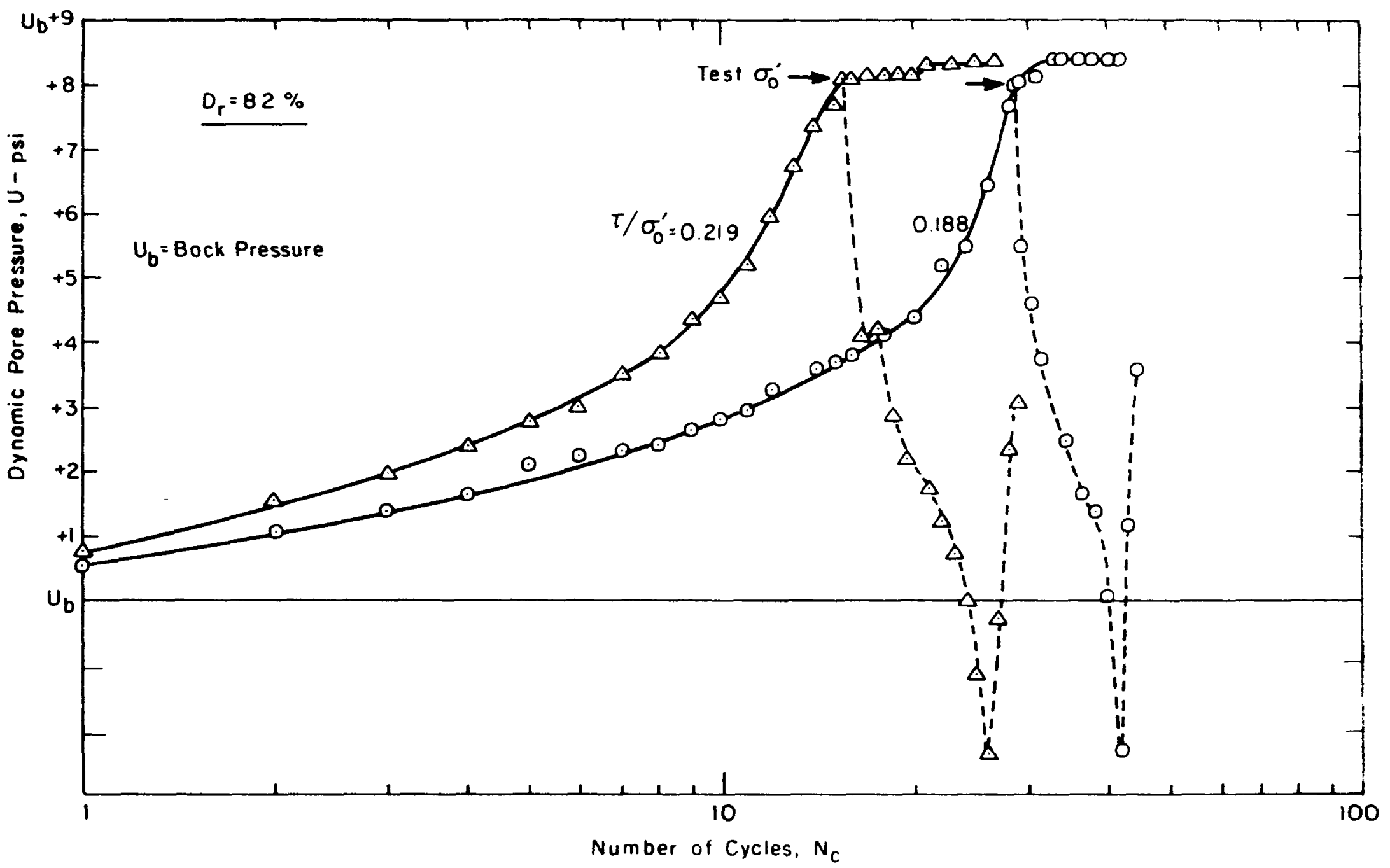

FIg A-2.5 DYNAMIC PORE PRESSURE DEVELOPMENT

三 


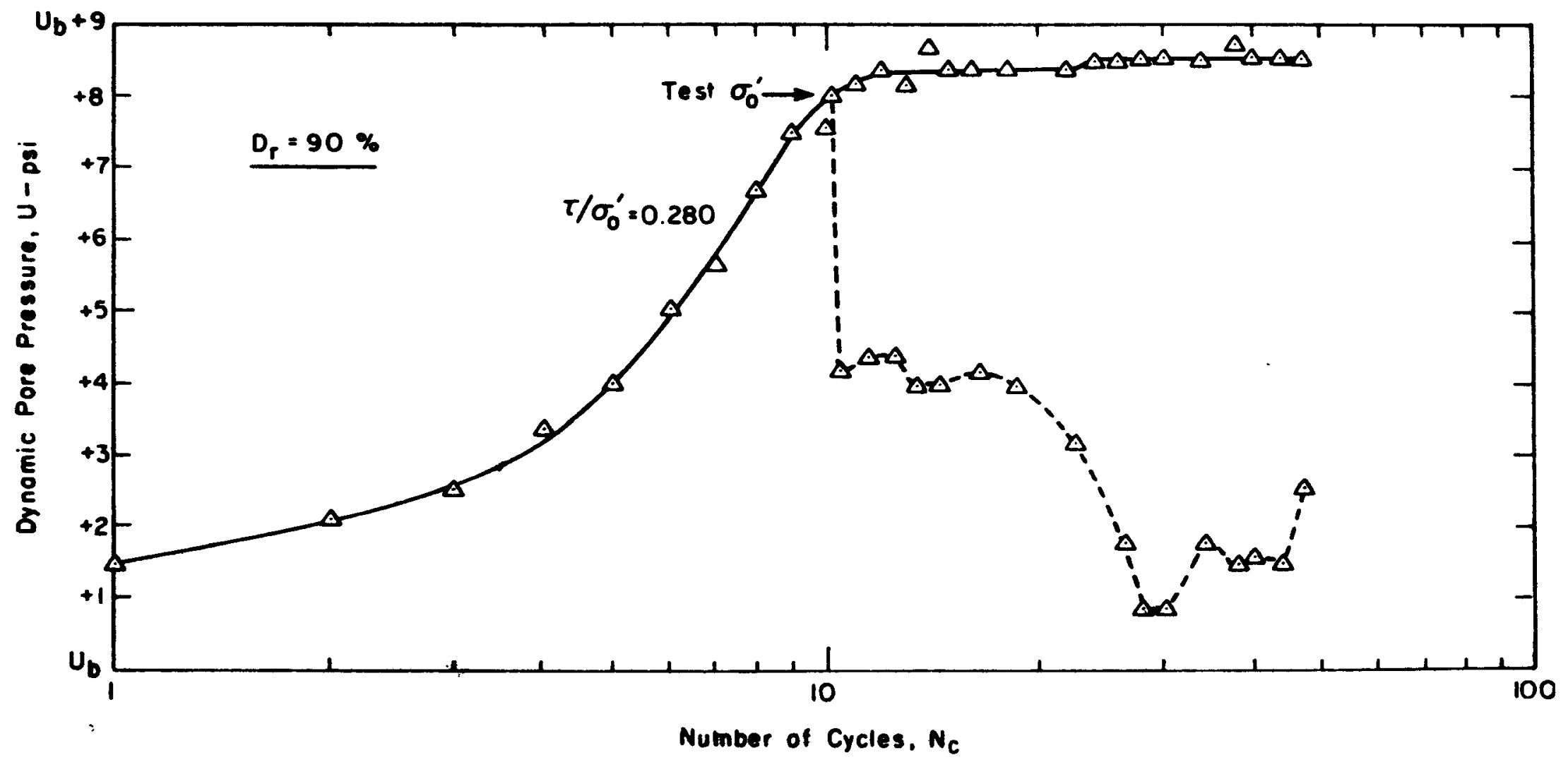

Fig. A-2.6 DYNAMIC PORE PRESSURE DEVELOPMENT 


\section{APPENDIX III}

\section{Effective Pressure and B-Value Measurements}

The system used for effective pressure and B-value measurements is shown schematically in Fig. A.3.1. The basic idea behind the design was to use the same transducer to measure both the total pressure and the pore water pressure, thereby avoiding discrepancies due to differences in transducer calibration. The single transducer could be isolated by means of two lowcompliance valves, $A$ and $B$, shown in the figure. In order to measure pore water pressure, valve $A$ was closed and valve $B$ was opened, connecting the transducer to a small-diameter tube fitted with a fine needle tip protected by a porous bronze plug set into the base of the specimen chamber. The pore pressure value was then read from the digital voltmeter connected to the transducer. The system was saturated with dealred water before each test, by opening both valves $A$ and $B$, and applying a small air pressure to the water in the reservoir, causing water to circulate through the system, and flushing out any bubbles in the 11ne.

In order to measure the chamber alr pressure, valve $B$ was closed and valve $\mathrm{A}$ was opened; then a pressure line was connected to a quick-release fitting leading through the chamber side, thus communicating the chamber pressure to the top of the water reservoir. From the measured chamber pressure and pore pressure values, the effective pressure at the bottom of the specimen was then calculated as shown in Fig. A.3.2; it will be noted that a 


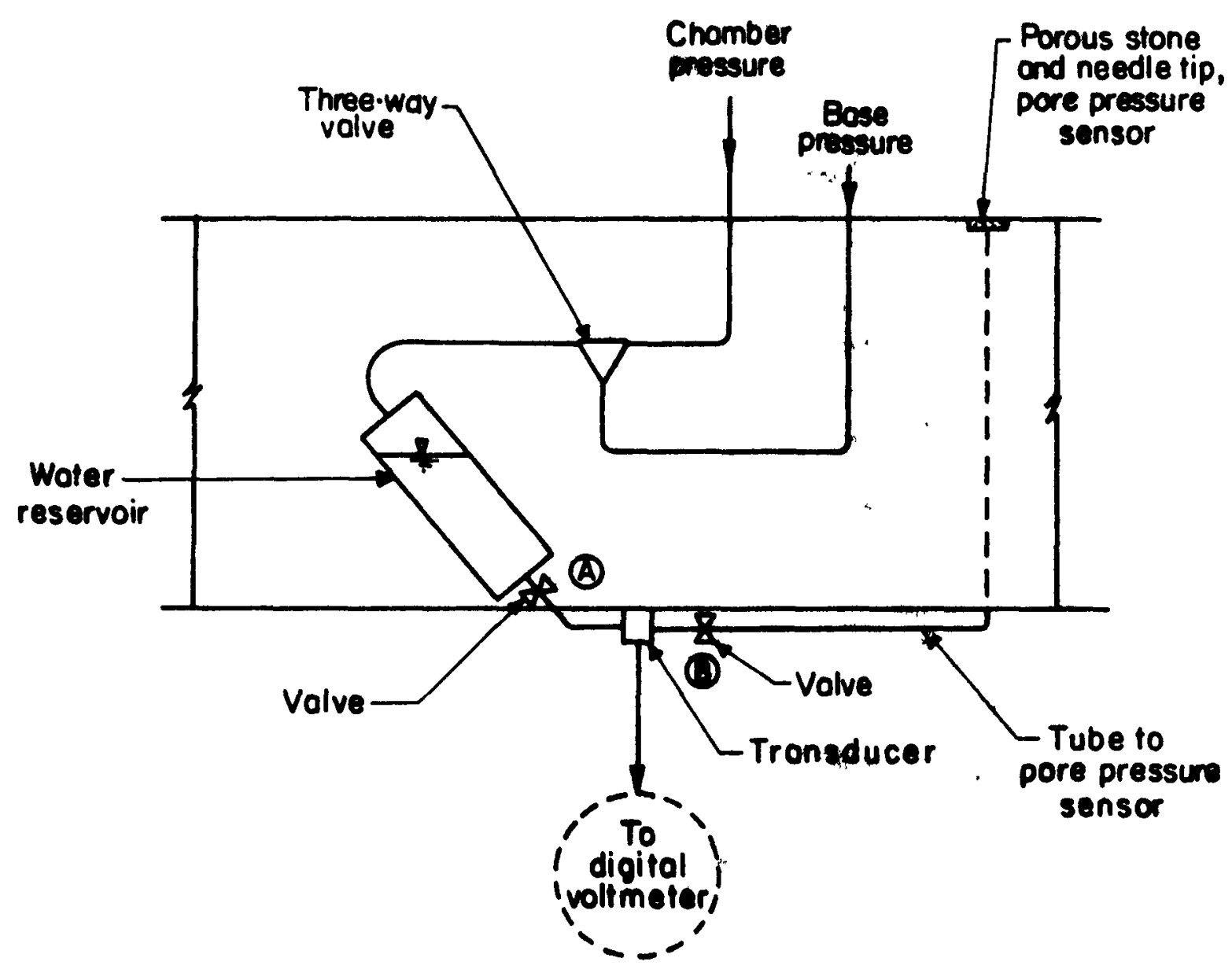

Fig. A-3.1 B-MEASUREMENT DEVICE 


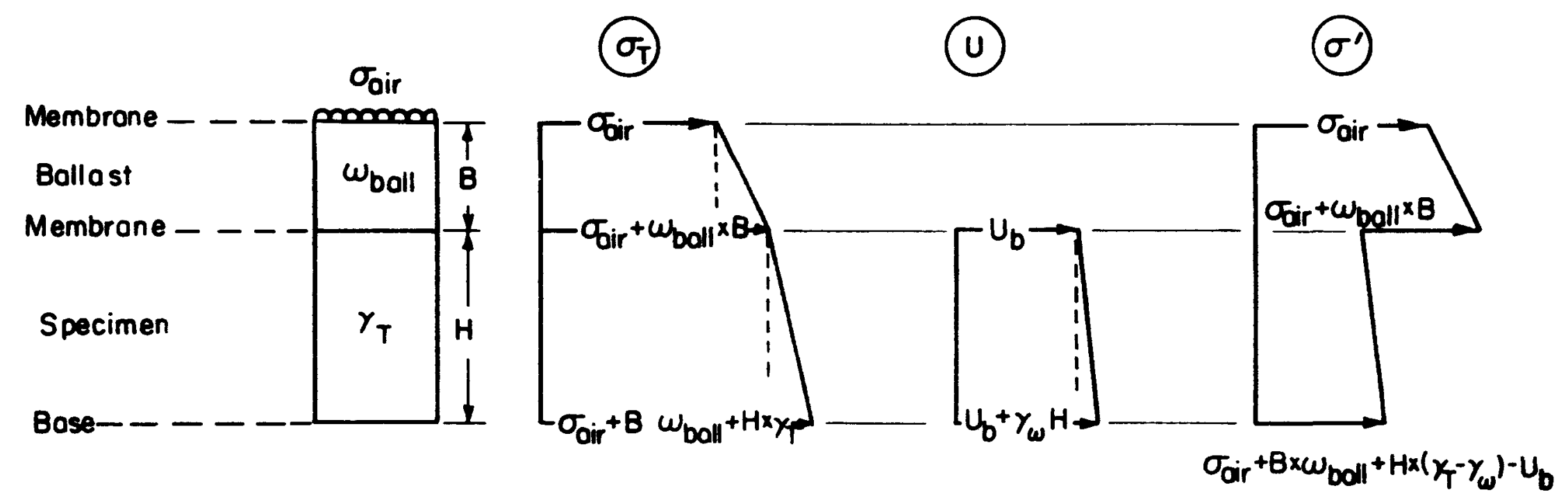

Effective pressure at bottom of specimen: $\sigma_{b}^{\prime}=\left(\sigma_{\text {air }}^{\top}-U^{\top}\right)+\omega_{\text {ball }} \times B+\gamma_{T} \times H+\gamma_{\omega} \Delta Y$

where:

$\begin{array}{ll}\sigma_{\text {oir }}^{T}=\text { Chamber pressure of transducer } & \gamma_{T}=\text { Total unit weight of sand } \\ U^{T}=\text { Pore water pressure of transducer } & \gamma_{\omega}=\text { Unit weight of water } \\ \omega_{\text {boll }}=\text { Unit weight of ballast } & \Delta Y=\text { Head difference of transd }\end{array}$

$\omega_{\text {boll }}=$ Unit weight of ballast

$\Delta Y=$ Head difference at tronsducer

Fig. A-3.2 EFFECTIVE PRESSURE CALCULATION 
small correction, $\gamma_{w} \Delta \mathrm{Y}$, on the order of $0.2 \mathrm{ps} 1$ was made, to account for the static head differences in the water IInes leading to the two sides of the transducer.

The measurement of Skempton's B was carried out with the same system as follows: Once the back pressure had been applied, the drainage valves were closed, and an intial pore pressure reading was taken with the digital voltmeter. The transducer was then set to measure the chamber pressure, an initial reading was taken, and the chamber pressure was increased by approximately 5 psi. Final readings were then taken of the chamber pressure and pore pressure with the digital voltmeter. Precise measurements of $\Delta U$ and $\Delta \sigma a 1 r$, and consequently of the B-value, could thus be obtained. Table A.3.I is a list of the measured B values. Finally, this device was used to set the correct value of the base pressire before each test; in practlce, the pressure under the 'floating' base had to be set slightly higher than the chamber pressure, as there was a slight difference in the pressurized areas due to the instruments projecting through the base plate, which reduced the area of the underside of the plate. A volume booster regulator connected to the chamber pressure was used to maintain the required pressure difference. Once the chamber was assembled and pressurized, pressure lines were connected from the chamber and base to the three-way valve of the measuring device, and the base pressure was set by connecting first the chamber pressure and then the base pressure to the transducer by changing the position of the three-way valve, F1g. A.3.1. Fig. A.3.3 Is a photograph of the measuring device, showing also the chamber and base pressure regulators. 
TABLE A.3.1

MEASURED B VALUES

\begin{tabular}{|c|c|c|c|}
\hline DATE & $D_{r}$ & $\mathrm{~N}_{c \ell}$ & B \\
\hline Dec. $\quad 5 / 73$ & $54 \%$ & 8 & 0.995 \\
\hline Dec. $7 / 73$ & $54 \%$ & 3.25 & 1.02 \\
\hline Dec. $10 / 73$ & $54 \%$ & 12.5 & 0.995 \\
\hline Dec. $12 / 73$ & $54 \%$ & 16 & 1.00 \\
\hline Jan. $15 / 74$ & $54 \%$ & 63 & 1.01 \\
\hline Jan. $17 / 74$ & $68 \%$ & 15 & 0.990 \\
\hline Jan. $23 / 74$ & $68 \%$ & 4 & 0.985 \\
\hline Jan. $25 / 74$ & $68 \%$ & 53 & 0.985 \\
\hline Feb. $\quad 7 / 74$ & $68 \%$ & 6 & 0.986 \\
\hline Feb. $15 / 74$ & $82 \%$ & 450 & 0.985 \\
\hline Feb. $22 / 74$ & $82 \%$ & 10 & 0.982 \\
\hline Mar. $\quad 9 / 74$ & $82 \%$ & 28.5 & 0.985 \\
\hline Mar. $12 / 74$ & $82 \%$ & 15.5 & 0.982 \\
\hline June $14 / 74$ & $90 \%$ & 10.5 & 0.96 \\
\hline
\end{tabular}




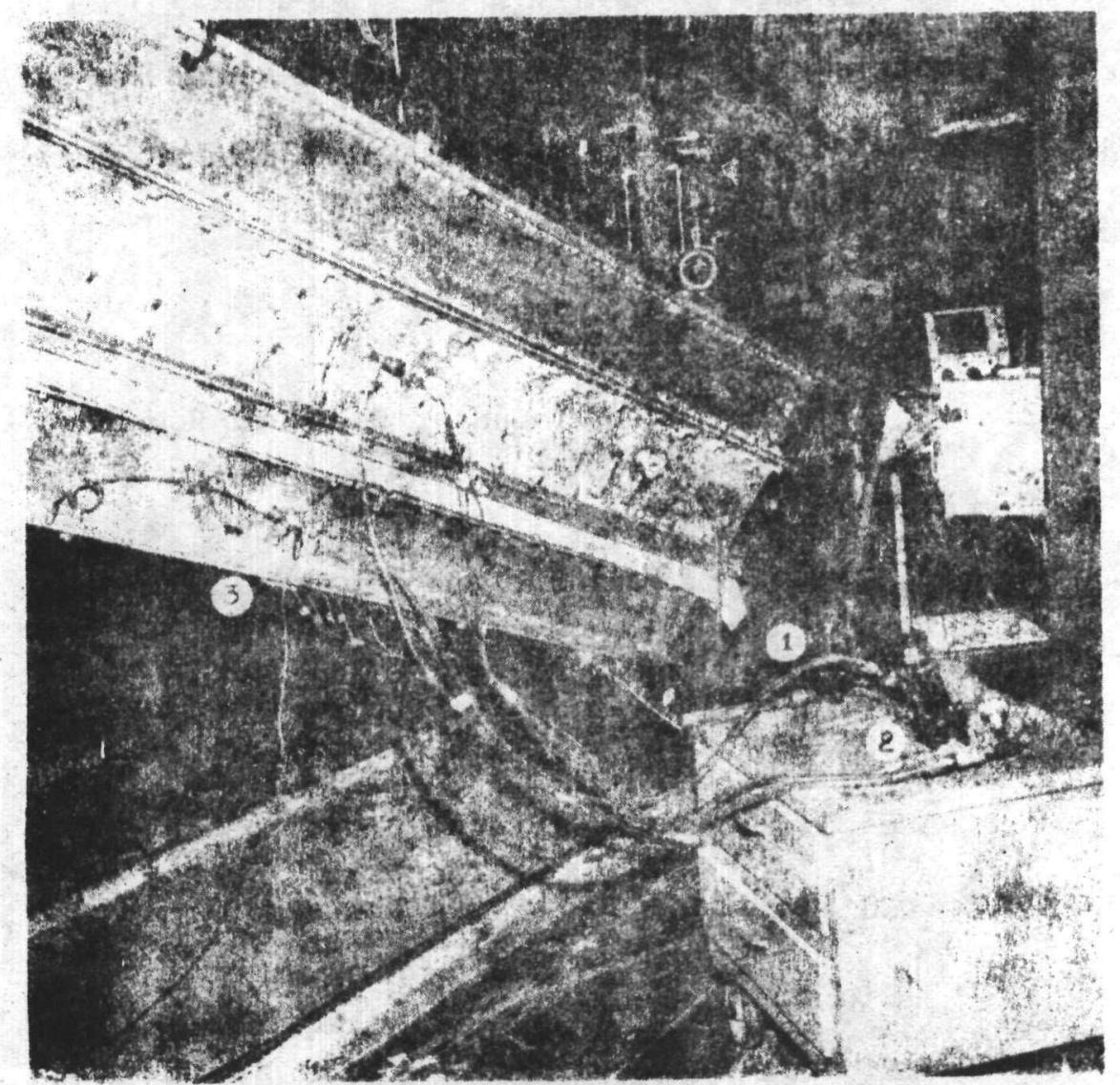

Fig. A-3.3 SUSPENDED SPECIMEN CHAMBER, SHOWING PRESSURE REGULATORS AND MEASURING DEVICE

I. Chomber pressure regulotor

2. Volume booster to bose

3. Pressure measurement device 


\section{APPENDIX IV}

\section{Instrument Characteristics}

of the shaking table instruments described in Chapter II, those that gave the most important results were the pore pressure transducers and the ballast LVDT'S. The sallent characteristics of these instruments are as follows:

\section{Base Pore Pressure Transducers}

-Manufacturer: CEC Instruments Division of Bell and Howell Corp., Pasadena, Calif.

-Type: 4 - 312 pressure transducer. Unbonded strain gauge type, temperature compensated. Four transducers of this type were set into the base of the chamber. Their diaphragms were protected by porous bronze plugs to prevent direct contact of the transducers with the sand. -Range: 0 - 50 psig -Compensated temperature range: $-65^{\circ} \mathrm{F}$ to $+250^{\circ} \mathrm{F}$. -Linear Vibration: At 158 peak sinusoldal vibration from 5 to $2000 \mathrm{~Hz}$, response does not exceed \pm 0.16 percent of the full range per 8 .

2. Burled Pore Pressure Transducers -Manufacturer: Entran Devices, New York, N.Y. -Type: EPA - 125 - 50 piezoresistive pressure transducer. These transducers were fitted with special tips to prevent contact of their diaphragms with the sand. The unit weight of transducer and tip was approximately that of the so1l. 
-Range: 50 psig

-Operating Temperature Range: $-40^{\circ} \mathrm{F}$ to $+250^{\circ} \mathrm{F}$

-Natural Frequency: $60 \mathrm{KHz}$

-Dimensions: diameter of diaphragm $=3.2 \mathrm{~mm}$

$$
\text { length }=4.6 \mathrm{~mm}
$$

3. Ballast Linear Variable Differentlal Transformer (LVDT).

-Manufacturer: Schaevitz Engineering, Pennsauken, N. J.

-Type: PCA - 117 - 1000, with spring-loaded probe. D.C. input and output.

-Range: \pm One inch (gauging range); mechanical stroke = 2. 37"

-Sensitivity: $0.33 \mathrm{mV} / 0.001 " /$ volt. 


\section{LIST OF REFERENCES}

Arango, I. and Seed, H. Bolton (1974) "Seismic Stability and Deformation of Clay Slopes," Journal of the Geotechnical lngineering Division, ASCE, Vol, 100, No. GT2, February.

Black, K. D. and Lee, K. L. (1973) "Saturating Laboratory Samples by Back Pressure," Journal of the Soll Mechanics and Foundations Division, ASCE, Vol. 99, No. SM1, January.

Casagrande, A. (1936) "Characteristics of Cohesionless Solls Affecting the Stability of Slopes and Earth Fills," Journal of the Boston Society of Civil Engineers, January.

Chan, C. K. (1975) "A Pneumatic Sinusoidal Loading System," Technical Note submitted to Journal of the Geotechnical Division, ASCE.

Duke, C. M. and Leeds, D. J. (1963) "Response of Solls, Foundations, and Earth Structures to the Chilean Earthquake of 1960," Bull., Seismological Society of America, Vol. 63, No. 2, February.

Florin, V. A. and Ivanov, P. L. (1961) "Liquefaction of Saturated Sandy Soils," Proc. Fifth International Conference on Soil Mechanics and Foundation Engineering, Paris, France.

Finn, W. D. Liam, Emery, J. J. and Gupta, Y. P. (1970) "A Shaking Table Study of the Liquefaction of Saturated Sands during Earthquake Engineering, Sofia, Bulgaria.

Finn, W. D. Liam, Pickering, D. J. and Bransby, P. L. (1971a) "Sand Liquefaction in Triaxial and Simple Shear Tests," Journal of the Soil Mechanics and Foundations Division, ASCE, Vol. 97, No. SM4, Apr11.

Finn, W. D. Liam, Emery, J. J. and Gupta, Y. P. (1971b) "So11 Liquefaction Studies Using a Shaking Table," Closed Loop, MTS Systems Corporation, Fall/Winter.

Finn, W. D. Llam (1972) "Liquefaction of Sands," Proc. International Conference on Microzonation, Seattle, Washington.

Ishibashi, I. and Sherif, M. A. (1974) "So11 Liquefaction by Torsional Simple Shear Device," Journal of the Geotechnical Engineering Division, ASCE, Vol. 100, No. GT8, August.

Ishihara, K. and Li, S. (1972) "Llquefaction of Saturated Sand in Triaxial Torsion Shear Test," Soils and Foundations, Vol. 12, No. 2, June. 
Kish1da, H. (1970) "Characterlstics of Liquefaction of Level Sandy Ground during the Tokachlok1 Earthquake," Sollo and Foundations, Vol. X, No. 2, June.

Kolbuszewski, J. J. (1948) "General Investigation of the Fundamental Factors Controlling Loose Packing of Sands," Proc., Second International Conference on Soll Mechanics and Foundation Engineer:ing, Rotterdam.

Kovacs, W. D., Seed, H. Bolton, and Chan, C. K. (1971) "Dynamic Moduli and Damping Ratios for a Soft Clay," Journal of the Soll Mechanics and Fourdations Division, ASCE, Vol. 97, No. SM1, January.

Lade, P. V. (1972) "The Stress-Strain and Strength Characteristics of Cohesionless Soils," Ph.D. Dissertatiun, University of California, Berkeley.

Lee, K. L. and Seed, H. Bolton (1967) "Cyclic Stresses Causing Liquefaction of Sand," Journal of the Soil Mechanics and Foundations Division, ASCE, Vol. 93, No. SM1, January.

Lee, K. L. and Fitton, J. A. (1968) "Factors Affecting the Cyclic Loading Strength of So11," Vibration Effects of Earthquakes on Solls and Foundations, ASTM STP 450, American Society for Testing and Materials, 1969.

Lee, K. L. and Chan, K. (1972) "Number of Equivalent Significant Cycles in Strong Motion Earthquakes," Proc. Internation Conference on Microzonation, Seattle, Washington.

Marsa1, R. J. (1961) "Behavior of a Sandy Uniform Soll During the Jaltipan Earthquake, Mexico," Proc. Fifth International Conference on Soll Mechanics and Foundation Engineering, Paris, France.

Martin, G. R., Finn, W. D. LIam, Seed, Bolton (1974) "Fundamentals of Liquefaction under Cyclic Loading," University of British Columbia, Dept. of Civil Engineering, Soll Mechanice Series No. 23.

Maslov, N. N. (1957) "Questions of Seismic Stability of Submerged Sandy Foundations and Structures," Proc. Fourth International Conference on Soll Mechanics and Foundation Engineering, London, England.

Mul1118, J. P. (1975) "The Effect of Sample Preparation on the Cyclic Stress-Strain Behavior of Sand," Ph.D. Dissertation, University of California, Berkeley.

Nunnally, S. W. (1966) "Developmett of a Liquefaction Index for Cohesionless Solls," Ph.D. Dissertation, Northwestern University. 
0-Hara, S. (1972) "The Results of Experiment on the Liquefaction of Saturated Sands with a Shaking Box: Comparison with Other Methods," Technology Reports of the Yamaguchi University, Vol. 1, No. 1, December.

Ohsaki, Y. (1970) "Effects of Sand Compaction on Liquefaction during the Tokachiok1 Earthquake," Soils and Foundations, Vol. X, No. 2, June.

Ortigosa, P. (1972) "Licuacion de Arenas Sometidas a Vibraciones Horizontales," Revista del Idiem Vol. II, No. 3, December.

Peacock, W. H. and Seed, H. Bolton (1968) "Sand Liquefaction under Cyclic Loading Simple Shear Conditions," Journal of the Soll Mechanics and Foundations Division, ASCE, Vol. 94, No. SM3, Proc. Paper 5957, May.

Pyke, R. M. (1973) "Settlement and Liquefaction of Sands under Multi-Directional Loading," Ph.D. Dissertation, University of California, Berkeley.

Pyke, R. M., Chan, C. K. and Seed, H. Bolton (1974) "Settlement and Liquefaction of Sands under Multi-Directional Shaking," Earthquake Engineering Research Center Report No. EERC 74-2, University of California, Berkeley, February.

Roscoe, K. H. (1953) "An Apparatus for the Application of Simple Shear to Soll Samples," Proc. Third International Conference on Soil Mechanics and Foundation Engineering, Vol. 1.

Seed, H. Bolton and Lee, K. L. (1966) "Liquefaction of Saturated Sands during Cyclic Loading," Journal of the Soll Mechanics and Foundations Division, ASCE, Vol. 92, No. SM6, November.

Seed, H. Bolton and Idriss, I. M. (1967) "Analysis of Soll Liquefaction: Nilgata Earthquake," Journal of the Soll Mechanics and Foundations Division, ASCE, Vol. 93, No. SM3, May.

Seed, H. Bolton (1968) "Landslides during Earthquakes due to Soll Liquefaction," Journal of the Soil Mechanics and Foundations Division, ASCE, Vol. 94, No. SM5, September.

Seed, H. Bolton and Idriss, I. M. (1970) "A Simplified Procedure for Evaluating Soil Liquefaction Potential," Report No. EERC 70-10, University of California, Earthquake Engineering Research Center, Berkeley, California, November.

Seed, H. Bolton and Peacock, W. H. (1971) "Test Procedures for Measuring Soil Liquefaction Characteristics," Journal of the So11 Mechanics and Foundations Division, ASCE, Vol. 97, No. SM8, August. 
Shannon and Wilson, Inc. and Agbablan-Jacobsen Associates (1971) "So1l Behavior under Earthquake Loading Conditions: Interim Report No. 1," for Union Carbide Corp., Nuclear Divisfon, OakRidge National Laboratory, Oak RIdge, Tetnessee.

Shannon and Wilson, Inc. and Agbabian-Jacobsen Assoclates (1972) "Soil Behavior under Earthquake Loading Conditions: Interim Report No. 2," for Union Carblde Corp., Nuclear Division, OakRidge National Laboratory, Oak Ridge, Tennessee.

Silver, M. L. and Seed, H. Bolton (1969) "The Behavior of Sands under Seismic Loading Conditions," Report Ho. EERC 69-16, University of California, Earthquake Engineering Research Center, Berkeley, California, December.

Tanimoto, K. (1967) "Liquefaction of a Sand Layer Subjected to Shock and Vibratory Loads," Proc. Third Asian Regional Conference on Soll Mechanics and Foundation Engineering, Haifa, Vol. 1.

Yoshimi, Y. (1967) "An Experimental Study of Liquefaction of Saturated Sands," Soils and Foundations, Vol. VII, No. 2, June.

Yoshimi, Y. and Oh-Oka, H. (1973) "A Ring Torsion Apparatus for Simple Shear Tests," Proc. Eighth International Conference on Soil Mechanics and Foundation Engineering, Vol. 1.2, Moscow, USSR.

Walker, B. P. and Whitaker, T. (1967) "An Apparatus for Forming Uniform Beds of Sand for Model Foundation Tests," Géotechnique, Vo1. 17.

Whitman, R. V. (1970) "Summary of Results from Shaking Table Tests at University of Chile using a Medium Sand," Progress Report No. 9, Effect of Local Soil Conditions upon Earthquake Damage, Research Report R70-25, Soils Pub. No. 258, MIT. 